\title{
Room for Play: \\ An Evaluation of the Lost [Healing] Spaces \\ in Pediatric Healthcare Facilities.
}

\author{
by \\ Matthew Fung
}

\begin{abstract}
A thesis submitted to the Faculty of Graduate and Postdoctoral Affairs in partial fulfillment of the requirements for the degree of
\end{abstract}

Master of Architecture

in

Azrieli School of Architecture and Urbanism

\section{Carleton University \\ Ottawa, Ontario}

(C) 2021

Matthew Fung 


\section{ROOM FOR O An Evaluation of the Lost [Healing] Spaces in Pediatric Healthcare Facilities}




\section{A BSTRACT}

The essence of space within pediatric healthcare has been governed through a catalyst of distinct criteria. Although these criteria are functional for medical and research practice requirements associated with hygiene and health, they should also reflect healing therapeutics and a sense of serenity. During our turbulent times, the COVID-19 pandemic has evolved the way healthcare is procured and practiced.

The built environment provides a place for people to live, work, and partake in their day-today activities. However, the built environment of the spaces for pediatric healthcare lacks the "room for play" in their built fabric, to such a degree as lost spaces. These "rooms for play" are synonymous for spaces for self-reflection, places for thinking, relaxing, grieving, celebration, and not lost child's play. It inspires confidence, encourages playfulness, evokes feelings of belonging and offers hope for healing. These multifunctional spaces have the potential to supplement the designated functions of the built healthcare environment of which they are a part. This thesis evaluates the possibility to integrate the spaces of healthcare with rooms for play that are conducive to an integral human perceptual response enhancing our overall sense of well-being and restorative healing. Case studies and literary research will support a design proposal for The Hospital for Sick Children, Toronto,

Ontario. 


\section{ACKNOWLEDGEMENTS}

It has been quite the journey from where I started and how I ended here. My love and appreciation towards my wife, Merene and my children Justin and Gemma for supporting me these past eight months. It has been a tumultuous while living a COVID-19 lifestyle. Your patience and understanding continued to inspire me to complete this chapter in my life. To all my friends, family, and supporters, thank you for providing me encouraging words of advice.

To my thesis team, our weekly virtual conference calls was motivating during our turbulent times. I wish you all the best of luck in your future endeavors. Lastly, to my advisor, Dr. Federica Goffi, your advice was imperative throughout the entire process. Your guidance and support were essential to molding this writing and myself - as an individual. I look forward to meeting you and the team in person to celebrate this accomplishment when this pandemic over!

To the Doctors, Nurses and Frontline workers who selflessly expose themselves everyday caring for the COVID-19 infected, no words can express your devotion and dedication... Thank You! 


\section{TABLE OF CONTENTS}

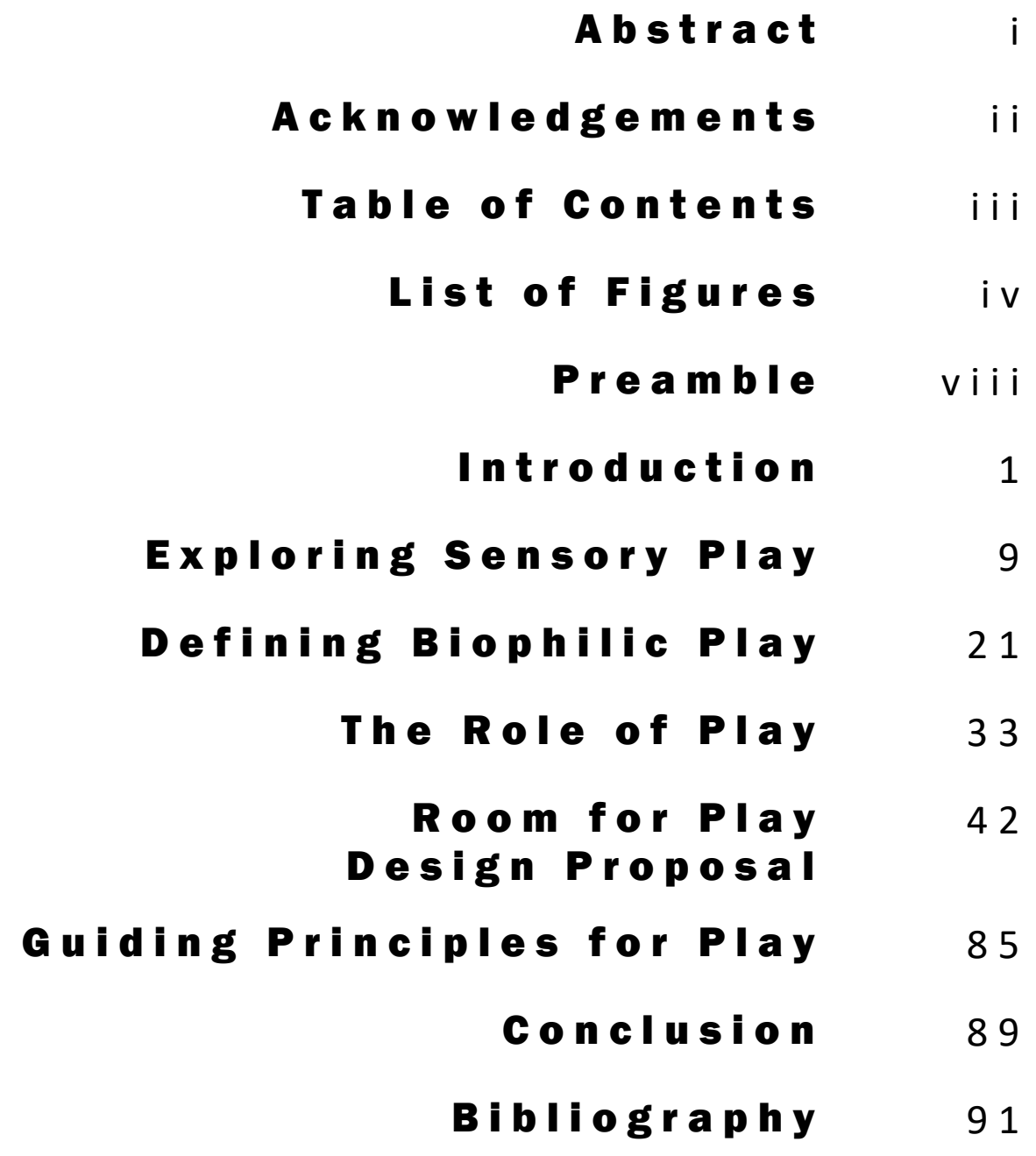




\section{LIST OF FIGURES}

Figure 1 The City of Toronto - as imagined and drawn by a 3-year-old. By vii Author's son

Figure 2 Can You Tell Me How to Get to Sesame Street? Strong Museum of Play, Rochester, NY. By Author

Figure 3 Exterior of Children's Museum of Indianapolis, IN. By Indy's Child Figure 4 Children Dress Up and Theatre. By Canadian Museum of History

Figure 5 Ann \& Robert H Lurie Children's Hospital of Chicago lobby area. By ZGF Architects Inc.

Figure 6 Sandcastle MRI Machine, designed by Arc the Diez. By Team T Photography

Figure 7 The Therme Vals Spa baths at night. By Hotel Therme Vals

Figure 8 Inside the Oculus by Sanitago Calatrava. New York. By Author

Figure 9 Children's ward, Royal Victoria Hospital, 1894. By Annmarie Adams.

Figure 10 Children on the rooftops at the Children's Memorial Hospital. By Annmarie Adams.

Figure 11 Children outside. The Hospital for Sick Children in Thistletown. (C)Toronto Star Newspapers Ltd.

Figure 12 Paimio Sanatorium, Roof Terrace (C) Fabrice Fouillet

Figure 13 Eye of the Oculus, Jewel Changi Airport, Singapore. By John Seaton Callahan / Getty Images.

Figure 14 A busy board can help to reduce agitation and mentally engage your loved one. By Becky Upham

Figure 15 Multisensory Room at SickKids. A calming and relaxing environment for multisensorial engagements and activities.

(C) The Hospital for Sick Children

Figure 16 Location of Major Hospitals in Toronto, ON. By Author

Figure 17 Location of Major Green Spaces in Toronto, ON. By Author 
Figure 20 Site Plan ref. MMM Geomatics Ontario Limited. Sept 9, 2015. By

Figure 21 Future Proposal Hospital Expansion by Sickkids.ca.

(c) The Hospital for Sick Children (SickKids)

Figure 22 Victoria Hospital for Sick Children. c1910 (C) 2018 John Chuckman

Figure 23

Figure 24 Hospital for Sick Children, c1960 @ John Chuckman

Figure 25 The Atrium. Nov 24,2020. By Author.

Figure 26 University Ave. Looking East. Nov 24,2020. By Author.

Elizabeth Street Main Entrance into the Atrium. Nov 24,2020.

By Author.

Figure 27 Elizabeth Street and Elm Avenue Looking North-West. Nov 24,2020. By Author.

Figure 28 Elizabeth St. \& Gerrard Ave. Looking South-West. By Author.

Figure 29 The Atrium Floor Plan ref. from Zeidler Architecture Inc. Floor Plan Recreated by Author

Figure 30

Patient Pink Room Ward 7C. c2017. (C) Parkin Architect

Figure 31

Patient Green Room Ward 7C. c2017. (C) Parkin Architect

Figure 32

Existing Floor Plan. By Author

Figure 33

Existing Enlarged Floor Plan. By Author

Figure 34

Existing Patient Rooms 3D Floor Plan Rendering. By Author

Figure 35

Existing Patient Rooms. 3D Isometric Rendering. By Author

Figure 36

Figure 37

Proposed dwelling room, Daytime Rendering. By Author

Proposed dwelling room, Evening Rendering. By Author

Figure 38

Proposed dwelling room. Interactive digital wall. By Author

Figure 39

Concept I, Floor Plan. By Author

Figure 40

Concept I, Enlarged Floor Plan. By Author

Figure 41

Concept I, Dwelling Rooms 3D Floor Plan Rendering. By Author

Figure 42

Concept I, Dwelling Room. 3D Isometric Rendering. By Author 
Figure 43

Figure 44

Figure 45

Figure 46

Figure 47

Figure 48

Figure 49

Figure 50

Figure 51

Figure 52

Figure 53

Figure 54

Figure 55

Figure 56

Figure 57

Figure 58

Figure 59

Figure 60

Figure 61

Figure 62

Figure 63

Figure 64

Figure 65

Figure 66

Figure 67

Figure 68

Figure 69

Figure 70

Figure 71
Final Concept Floor Plan. By Author

Final Concept Enlarged Floor Plan. By Author

Final Concept, Dwelling Rooms 3D Floor Plan Rendering. By Author

Final Concept, Dwelling Room. 3D Isometric Rendering. By Author

Existing 8-foot-wide corridor. Coloured walls relate to different wards. Image by Author

Intermediate care ward 7C corridor. c2017. (C) Parkin Architect

Corridor Elevation, wayfinding Concept. By Author

Existing reserved enclosed play area. By Author

Climbscapes Floor Plan. Exploration and Risk Taking By Author

Image 1, Climbscapes. Exploration and risk taking By Author

Image 2, Climbscapes. Exploration and risk taking By Author

Image 3, Climbscapes. Exploration and risk taking By Author

Existing outdoor green space. Nov 24, 2020. By Author.

Existing Samsung Space. (C) The Hospital for Sick Children (SickKids)

Elm Street. South Elevation. Nov 24, 2020. By Author.

Existing rooftop condition. Nov 24, 2020. By Author.

Private Courtyard, accessible from fifth floor. By Author

Private Courtyard, accessible from sixth floor. By Author

Private Courtyard, upper floors. Superimposed sun-path diagram.

By Author

Proposed Rooftop. By Author

Proposed South Elevation. By Author

Proposed South Elevation, coloured rendering. By Author

Exterior Isometric Rendering. By Author

Exterior Isometric Rendering. By Author

Courtyard, West to East Building Section. By Author

Courtyard, South to North Building Section. By Author

Entering Interior Courtyard, $5^{\text {th }}$ Floor. By Author

Interior Courtyard, Performance Stage. By Author

Interior Courtyard, Performance Stage. By Author 
Figure 72

Figure 73

Figure 74

Figure 75

Figure 76

Figure 77

Figure 78

Figure 79

Figure 80

Figure 81

Figure 82

Figure 83

Figure 84

Figure 85

Figure 86

Figure 87

Figure 88

Figure 89
Interior Courtyard, Performance Stage. By Author Entering Interior Courtyard, $5^{\text {th }}$ Floor. By Author Interior Courtyard. By Author

Interior Courtyard, Performance Stage. By Author Interior Courtyard. By Author

Entering Interior Courtyard, $6^{\text {th }}$ Floor. By Author

Entering Interior Courtyard, $6^{\text {th }}$ Floor. By Author

Interior Courtyard, upper terrace. By Author

Interior Courtyard, upper terrace. By Author

Interior Courtyard, view from patient room balcony. By Author Interior Courtyard, view from patient room balcony. By Author Interior Courtyard, view from patient room balcony. By Author Looking up 12pm lightwell. By Author Looking up 8am lightwell. By Author

Looking up 4pm lightwell. By Author

Exterior Terrace curtain wall. By Author

Exterior Terrace. By Author

Children's Hospital and College Street, c1910. Observe how the word "Sick" has been removed. (C) John Chuckman 
All pediatric hospitals are a self-sustaining homogenous community - a small metropolis. The grandeur scale of the architecture can be intimidating and bewildering to any person, even more so, to a young mind. We are at our most vulnerable when we are sick, by conceding ourselves into the healthcare system we are forfeiting our autonomy and our sense of belonging and identity; we are merely a number on an indestructible identification wristband. We are instructed where to go, what to do, and where to stand -2 meters apart. For the past year, the SARS-CoV-2 (COVID-19) has put the medical and research communities on high alert while increasing mental stress on doctors, clinicians, patients, and their caregivers. As the planet was caught off guard, the pandemic revealed defects within the hospital design and infrastructure. This thesis focuses on some of the seminal issues of pediatric hospital design asking the question of how architectural design can influence the healing, recovery, and well-being - both physically and mentally - to the community who reside and work within the hospital. Design proposals, in real world sustainable applications, will reveal how the lost spaces for rooms for play can foster therapeutic qualities between architecture and occupant at the Hospital of Sick Children, Toronto, ON. 


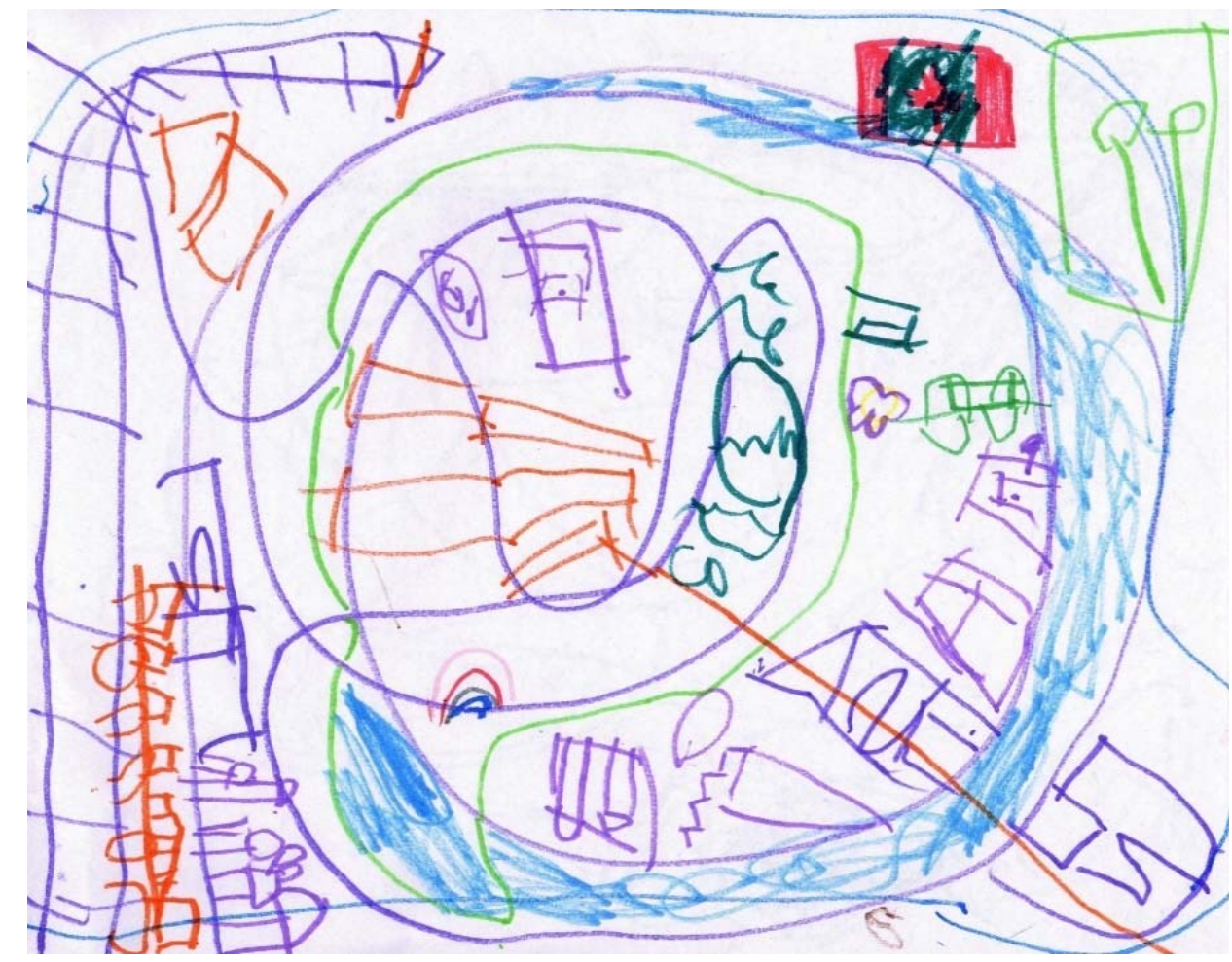

Figure 1. The City of Toronto - as imagined and drawn by a 3-year-old. By Author's son

A new effort has to be made to reconnect human beings to the buildings and places

they inhabit by giving more than enough Spielraum (literally, "room for play"). ${ }^{1}$

- Marco Frascari (1945-2013)

${ }^{1}$ Frascari, Marco. 2012. "De Beata Architectura, Places for Thinking." In The Cultural Role of Architecture, by Paul Emmons, John Hendrix and Jane Lomholt, 143-155. Milton Park,Abingdon: Routledge. P.146. 


\section{NTRODUCTION}

The hospital is the primary location for the delivery of healthcare, to research,

prevent and study diseases, to educate medical clinicians and physicians, advancing research and applying innovative technology - all to improve human health. Public health care can be considered as a whole, as a service to the community; it includes medical necessities for healing both physically and mentally. However, the healing characteristics of the health care environment have lacked the design attention they deserve shortly after the mid-20 th century. Time and again, the design processes are impacted or marginalized by current political gains, cultural, and socioeconomical developments. Technological development and the emergence of new evidence-based research have shown that hospital design contributes to the healing process. ${ }^{1}$ The built environment is particularly important in pediatric hospitals since children are in need of learning and interacting with the world around them, which requires specific activities for appropriate development and healing processes. Therefore, hospitals' design should offer a safe healthcare environment while bringing activities such as

${ }^{1}$ Mohamed Yusoff Abbas, and Roslinda Ghazali. Healing Environment of Pediatric Wards. P.950. 
playground areas, academics, and social spaces, among others, to the inside, since child convalescence are often confined within hospitals and their rooms. This thesis intends to demonstrate the importance of "room for play" in places of healing therapeutics lost within pediatric hospitals through sensory adaptation, biophilic design and through the act of play.

According to the World Health Organization Constitution, "health is a state of complete physical, mental and social well-being and not merely the absence of disease or infirmity. ${ }^{2}$ Healing is defined as a holistic, transformative process of repair and recovery in mind, body, and spirit resulting in positive change, finding meaning, and movement towards self-realization of wholeness, regardless of the presence or absence of disease. ${ }^{3}$ The concept of a healing environment gained prominence in the late 1980 s as it became a crucial factor in the designing and planning of medical facilities. Healthcare professionals considered medical institutions to be healing environments despite the lack of understanding of the term "healing environment." ${ }^{4}$ Despite the significance of the built environment in enhancing patients' general well-being, the built environment of many modern hospitals only

\footnotetext{
${ }^{2}$ World Health Organization. 2021. Constitution. Accessed March 15, 2021.

${ }^{3}$ US National Organization. 2015. November. Accessed December 4, 2020.

${ }^{4}$ Huelat, Barbara J. 2003. Healing Environments: Design for the Body, Mind and Spirit. P.29.
} 
contributes a modest role to the process of therapeutic healing due in part to the design principles utilized in the postmodern period (1950s and 60s). These architectural shortcomings have led to hospitals being unable to fulfill the psychological, emotional, and social needs of the patients, caregivers, families, and the healthcare community.

The discipline of architecture deals with the relationship between space and time and provides that relationship with a human scale. ${ }^{5}$ Design can create spaces based on desired experiences often based on previous memories and imagination of what may be possible. The Eyes of the Skin: Architecture and the Senses by Finnish architect, philosopher, and professor Juhani Pallasmaa, investigates the multisensory nature of bodily encounters with space and time, the tangible, and the intangible, which have long been acknowledged in contemporary design. Adding to this, rooms for play have an essential role in affecting emotions and well-being and are synonymous with spaces for self-reflection, places for thinking, relaxing, grieving, celebration, and offers hope for healing. However, pediatric hospitals tend to disregard the significance of rooms for play, often overlooked by the

\footnotetext{
${ }^{5}$ Pallasmaa, Juhani. 2012. In The Eyes of the Skin: Architecture and the Senses. P.19.
} 
medical treatment's operations and functions coupled with administrative susceptibilities.

The contemporary architecture concerns often exclude the embodied experiences of the body and the senses, causing an imbalance in our sensory system. ${ }^{6}$ Architecture plays a vital role in how people interact with their environments and how this in turn affects the general well-being. Swiss Architect, Peter Zumthor noted:

"Architecture has its own realm. It has a special physical relationship with life. I do not think of it primarily as either a message or a symbol, but as an envelope and background for life, which goes on, in and around it, a sensitive container for the rhythm of footsteps on the floor, for the concentration of work, for the silence of sleep." 7

The human body can self-heal whilst in a positive healing environment, facilitated by the body's ability to "tap into internal pharmacies" by responding to the positive

\footnotetext{
6 Ibid, P.22.

${ }^{7}$ Zumthor, Peter. 2006. Thinking Architecture. P.30
} 


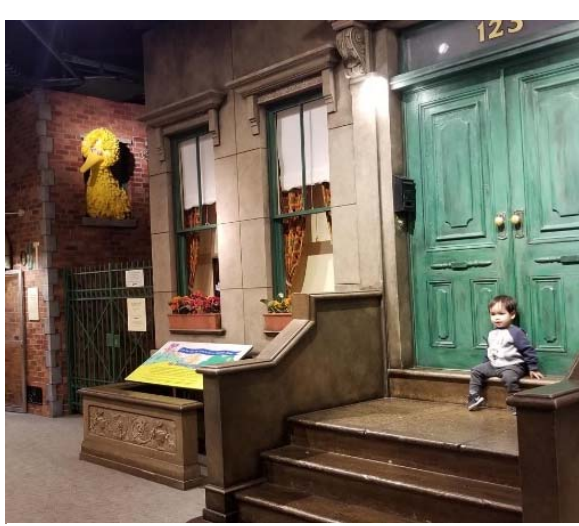

Figure 2. Can You Tell Me How to Get to Sesame Street? Strong Museum of Play, Rochester, NY. By Author

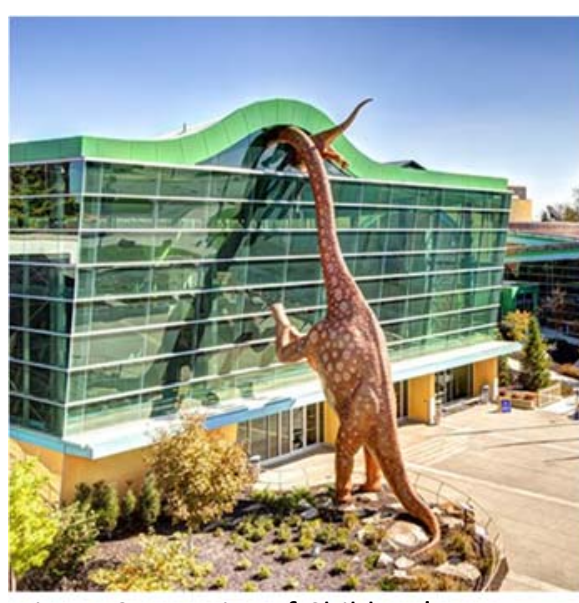

Figure 3. Exterior of Children's Museum of Indianapolis, IN. By Indy's Child environment. The human body achieves self-healing by releasing chemicals from the brain, such as serotonin, that helps regulate mood; endorphins, the body's natural pain reliever; dopamine, the 'happy' hormone; and oxytocin, promotes trust and empathy in relationships, which can enhance immune responses and reduce pain. ${ }^{8}$ However, many medical institutions have turned to efficient and flexible oriented design rather than the healing dynamics in their overall architecture.

Ornamentation assimilated from Disney-like inspiration attempts to create a playful

environment, but the hegemony of visual aesthetics overpowers and separates the other senses and often leaves our memories and imaginations dormant (Figure 1, 2). For architecture to be inclusive of a healing environment the tensions between an assumed ocularcentrism and types of nonvisual sensations should not be underexplored or underdeveloped in architectural thinking, design practice and especially in the design of a healing environment for children. Such spaces should maintain tranquility to ignite our

\footnotetext{
${ }^{8}$ Raypole, Crystal. 2019. How to Hack Your Hormones for a Better Mood. Healthline. September 30.
} 
imagination and emotions. ${ }^{9}$ According to Debra and Miller, great places are an outcome of decisive actions and deliberate plans of imaginative and structured thinking coupled with the ability of the designer to visualize "what is and what might be." 10

Designing great places is essential in the efforts to manage many of the challenges of contemporary society. Creating spaces that do not resonate with our environment or expectation can result in negative outcomes and short comings. For instance, young children require play spaces since they are in an exploratory stage of their lives, where they need physical activity and social interaction through play to grow and develop. This points to the importance of designing healing spaces as part of the built environment to enhance sensory input among children. The involved architecture that entails safety considerations and ergonomics, artwork, color, play areas, daylight, fresh air, and nature has been shown to contribute to the healing process and help pediatric patients manage pain and aggression. ${ }^{11}$ However, the ergonomic requirements for children have been a concern for architects since

\footnotetext{
${ }^{9}$ Pallasmaa, Juhani. 2012. In The Eyes of the Skin: Architecture and the Senses. P.22.

${ }^{10}$ Cushing, Debra Flanders, and Evonne Miller. 2020. Creating Great Places: Evidence-Based Urban Design for Health and Wellbeing. P.46.

${ }^{11}$ Abbas, Mohamed Yusoff, and Roslinda Ghazali. 2010. "Healing environment of pediatric wards." Procedia Social and Behavioral Science. P.951.
} 
they are not like those of adults. This is attributed to the fact that children are in a

continuous state of development perceptually, physically, socially, and cognitively. ${ }^{12} \mathrm{An}$

optimal healing framework should be focused through a child's perspective and how they

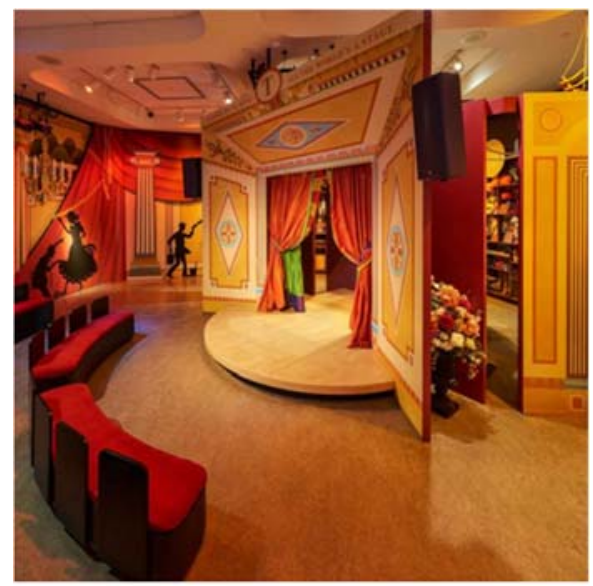

Figure 4. Children Dress Up and Theatre. By Canadian Museum of History interact with rooms for play within healthcare environments.

However, it is important to note that children's free play is, by nature, complex as it may exhibit multiple types, forms, and stages. ${ }^{13}$ Adapted from Disney theme parks or children play centers, the forms of play can be described based on the social, locomotor skills, and object dimensions. Play inspires confidence, encourages joyfulness, evokes feelings of belonging and restorative healing. Play can be classified as constructive play, functional play, games with rules, competitive play, symbolic, and dramatic/fantasy plays (figure 4).$^{14}$ In this regard, the most dominant types of play are constructive, functional, nonplay, and symbolic. Pediatric institutions and architects can borrow these principles in designing the built environment to the holistic healing of children.

\footnotetext{
12 Lueder, Rani. 2003. "Are Just Little Children Adults? ." ErgoSolutions Magazine. P.34

${ }^{13}$ Hewes, Jane. 2014. "Seeking Balance in Motion: The Role of Spontaneous Free Play in Promoting Social and Emotional Health in Early Childhood Care and Education." Children. P.285.

${ }^{14}$ Sawyers, Janet K. 1994. "The Preschool Playground: Development Skills Through Outdoor Play." Journal of Physical Education, Recreation \& Dance. P.33.
} 
The architectural design proposal of this thesis is a remodeling aimed at adding spaces of room for play based on assessments and observations of the existing conditions within the Slaight Family Atrium (circa 1993) expansion by Zeidler Architecture Inc. at the Hospital for Sick Children (SickKids Hospital), Toronto, Ontario. As the hospital foresees expansion within the next decade, the proposal will entail a speculative response to the redesign of existing patient rooms (the dwelling), the common corridors (the streets), and a proposal to introduce a shared private communal courtyard space for patients and the hospital community-a room for play.

The SARS-CoV-2 (COVID-19) pandemic hindered my on-site field studies and research while limiting my ability to document to the fullest degree. At this moment in time the Hospital for Sick Children is under pandemic protocols while only next of kin and hospital staff are allowed entry. The following documentation is based on scholarly literature, the (few) emails from current and former hospital staff and my previous recollected memories while staying there for a few days in the winter of 2016. 


\section{EXPLORING SENSORY PLAY}

"Don't put that in your mouth!" - Every Parent

The conception of architectural sensorial play entails tectonic configurations of textures, materials, spartial experiences, structures that are used to craft our dispositions, imagery and use of a building. Therefore, architectural designs play a significant role in impacting our mood and reaction to the built environment. We often desire a physical and mental connection to the world. This connection creates our response and relationship within the built environment and architecture. Conversely, in Western culture, vision has been the dominant way of teaching, conceiving, and critiquing architecture for a long time, which has resulted in the loss of multisensory modality in architecture. ${ }^{15}$ In this regard, Pallasmaa noted that,

"an architectural work is not experienced as a series of isolated retinal pictures, but in its full and integrated material, embodied and spiritual essence. It offers pleasurable shapes and surfaces molded for the touch of the eye and the other senses, but it also

\footnotetext{
${ }^{15}$ Pallasmaa, Juhani. 2012. In The Eyes of the Skin: Architecture and the Senses. P.11
} 
incorporates and integrates physical and mental structures, giving our existential experience

a strengthened coherence and significance."16

Similarly, architect and architectural theorist, Marco Frascari (1945-2013) states,

"humans instinctively long for physical and mental connections to a cosmopoiesis.

The human sensorial systems through which these processes take place establish the

human relationship and response to architecture."17

In both cases, multisensorial environments within the contemporary architectural framework are often obscured by ocularcentric components. The responsive stimuli through the eye tends to neglect the non-visual senses of hearing, smell, touch and even taste. In order to incorporate synaesthetic design in contemporary architecture that promotes our health and well-being, it is the role of the architect to reconnect human beings to the building and places they inhabit by offering what Frascari calls Spielraum (literally a "room

\footnotetext{
16 Ibid, 13.

${ }^{17}$ Frascari, Marco. 2012. "De Beata Architectura, Places for Thinking." In The Cultural Role of Architecture, by
} Paul Emmons, John Hendrix and Jane Lomholt. P.146 
for play"). ${ }^{18}$ The long-term implication of such an assumption would be that the meaning of

a given building supersedes architecture and directs human consciousness to conform to the sense of self and the immediate world.

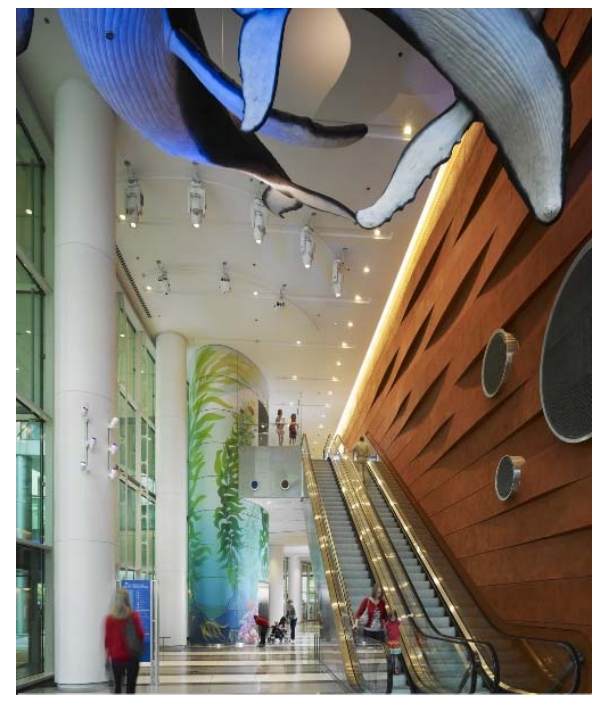

Figure 5. Ann \& Robert H Lurie Children's Hospital of Chicago lobby area. By. ZGF Architects Inc.

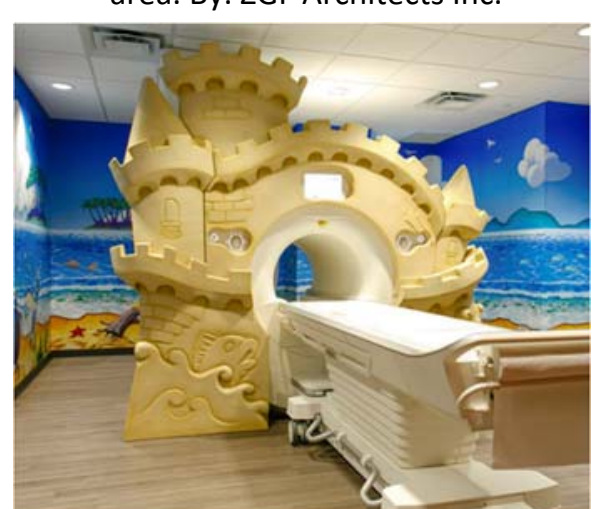

Figure 6. Sandcastle MRI Machine, designed by Arc the Diez. By Team T Photography
Emerging in the 1950-60's, the postmodern hospital returned to the belief that the

child patient and the family were the primary focus. ${ }^{19}$ These designs were often modern

buildings, implementing the latest medical technological advancements, spatially organized,

and efficiently planned, and accompanied by visual distractions: colourful popular culture

motifs, ornaments, and historical imagery. These design strategies were meant to provide

reassurance, comfort, and entertainment to child patients and their caregivers. ${ }^{20}$ The guiding

design principles by one of the world's leading experts in pediatric hospitals Bruce Komiske,

suggest incorporating regional, non-health related themes such as villages, ocean life,

firetrucks or even a real zoo within hospital environments (Figures 5, 6). In contrast,

architectural historians and professors, Annmarie Adams and David Theodore imply "a

${ }^{18} \mathrm{Ibid}$. P.146.

${ }^{19}$ Adams, Annmarie, and David Theodore. 2006. "The Architecture of Children's Hospitals in Toronto and Montreal, 1875-2010." In Children's Health Issues in Historical Perspective. P.463.

${ }^{20}$ Ibid. P.463. 
complete denial of their function as hospitals." ${ }^{21}$ Although playful and whimsical in nature, there has been no evidential consensus whether these themed environments influence the wellbeing or have restorative healing qualities. Adams and Theodore argue the rational of these motives can distract and redirect the search for real architectural solutions to healthcare design rather than providing environments specifically supportive to children's experiences. ${ }^{22}$ In this regard, visual familiarities and suggestive motifs are only a temporal diversion and not necessarily an approach to restorative healing. Conversely, there is a discord in perception of how adults view the world compared to a child's imaginative view, often approaching reality without preconceptions. The familiarity or mimicry of everyday activities at a reduced scale - to suit the ergonomic requirements of a child - evokes play, exploration, and cognitive development which are associated with healing. For example, our adult perceptions see the kitchen as a space for daily meal preparation, whereas the child imitates mom and dad without any forethought on the physical activity and procedural techniques of food preparation. It is through these activities that children stimulate their

\footnotetext{
${ }^{21}$ Annmarie Adam, et al. "Designing for "Little Convalescents": Children's Hospitals in Toronto and Montreal, 1875-2006." (CBMH/BCHM Volume 9, 2002), P.236.

22 Ibid. P.236.
} 
active imaginations and creativity, which contributes to reduce emotional stress and anxiousness. Pallasmaa states, "buildings have turned into image products detached from existential depth and sincerity." ${ }^{23}$ As other various philosophers have assessed that the dominance of vision over the other senses is integral to our atmospheric perception, would these principles also be applicable to rooms for play within pediatric hospital environments for the child-player (more than the child as a user)? The design conceptions by architects seemingly subjugate to the preconception that adults and children perceive spaces in analogous ways, yet a child's mind is to always be in play, learning and developing cognitively. Swiss psychologist and advocate on the education of children, Jean Piaget (18961980) theorized that children's brains do not function to that of adults and that "our brain and mental functioning develops through a series of universal stages." ${ }^{24}$ The child's cognitive development evolves during each stage which is largely influenced by their sensorial perceptions with the surroundings around them. The significance of the built environment should define a harmonious connection between the built tectonic

\footnotetext{
${ }^{23}$ Pallasmaa, Juhani. 2012. In The Eyes of the Skin: Architecture and the Senses. P.33

24 Johnson, Andrew P. 2014. "Cognitive Development: Piaget and Vygotsky." In Education Psychology: Theories of Learning and Human Development. P.2.
} 
configurations and the ergonomic requirements for both the children and adults as each contribute to the holistic healing.

The experience of architecture is palpable since we physically interact with surfaces. Tactile senses play a significant role in the human understanding and experience of the world, which reiterates the significance of the suppressed sense modalities. As Pallasmaa describes, "the door handle is the handshake of a building." ${ }^{25}$ The sensation of a door handle fabricated out a natural wood to that of stainless steel to the touch of the hand or stepping on grass to that of a cold stone floor with bare feet predicates adulations with past events and memories. Material connection has positive physiological responses to natural materials. In a participated study by Ikei, Song and Miyazaki, they observed how the body and mind reacted to the tactile simulation of four different materials: white oak, marble, tile, and stainless steel. Based on their scientific analysis they discovered that the oak material induces physiological relaxation, decreased blood pressure, heart rate and stress levels. ${ }^{26}$ In a similar manner, the Therme Vals Spa by Peter Zumthor and the correlation of different

\footnotetext{
${ }^{25}$ Pallasmaa, Juhani. 2012. In The Eyes of the Skin: Architecture and the Senses. P.62

${ }^{26}$ Ikei, Harumi, Chorong Song, and Yoshifumi Miuazaki. 2017. "Physiological Effects of Touching Wood." International Journal of Environmental Research and Public Health. P.19
} 
temperatures of both water, touchable surfaces, and the diverse spaces creates a tranquil and therapeutic atmosphere (Figure 7). The acuity of temperature and texture characteristics of a material is intrinsic to the total multisensory experience within healthcare design, especially when children are often exploring their surroundings with their

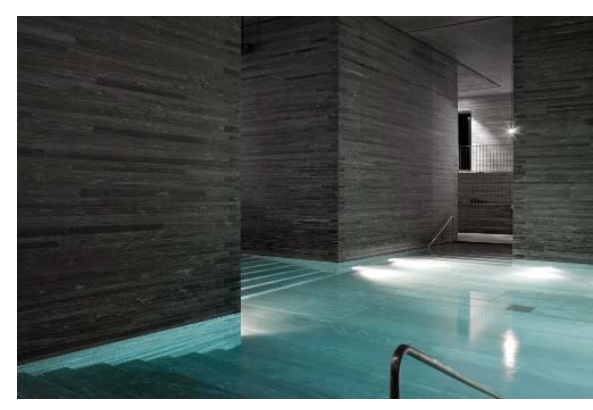

Figure 7. The Therme Vals Spa baths at night. By Hotel Therme Vals

hands.

The auditory sounds of healthcare institutions are distinctive. Often patient wards are convoluted with the sounds of chatter, paging systems, and the constant beeps from an electrocardiogram (ECG). These ambient noises have a direct impact to the well-being of patients and staff. Emotional fatigue, sleep deprivation, elevated blood pressure, and burnouts are among the symptoms caused by inadequate acoustical environments. ${ }^{27}$ Sound control is important within healthcare environments and can be mitigated by installing highperformance sound absorbing acoustical materials such as acoustical ceiling tiles. Although crucial in silencing external noise for a person's solitude, the healthcare environment needs to be comprehended through the acoustic percept which is often characterized as an

\footnotetext{
27 Joseph, Anjali, and Roger Ulrich. 2007. "Sound Control for Imporved Outcomes in Healthcare Settings." The Center for Health Design. P.3
} 
"unconscious background experience." ${ }^{28}$ In as much as sight provides a visual image to an individual, the acoustic unconscious background experience creates a sense of solidarity and connection that conjures additional images from imagination, memories, and dreams. For instance, the auditory cue of laughter is a perpetual tool that accentuates positivity, evokes happiness, boosts immunity, lowers stress hormones, decreases pain, relaxes muscle, which are a relative optimism for healing. ${ }^{29}$ According to Dr. Lee. S. Berk, "laughter helps to increase the count of natural-killer cells and raises the antibody levels in the body." 30

Notwithstanding the medical evidence, laughter is contagious especially among the young. Hearing laughter creates intrigue and exploration for the child and often encourages the able-bodied to leave their domicile and go in search of where the excitement is - where there is laughter, there must be play.

The olfactory sense within the hospital environment is ubiquitous and indicative of a sterile environment. Superficially odorless environments for patients are regulated for those

\footnotetext{
28 Pallasmaa, Juhani. 2012. In The Eyes of the Skin: Architecture and the Senses. P.54.

${ }^{29}$ Vijayalakshmi, J, S Kamala, and Chandrakala Maran. 2018. "Laugh Your Way to a Quality Life with Laughter Yoga." International Education and Research Journal. P.1

${ }^{30}$ Berk, Dr. Lee S., interview by Janelle Ringer. 2019. Laughter: A fool-proof prescription (April 1)
} 
who experience chronic hyperosmia, a "heightened and hypersensitive sense of smell." ${ }^{31}$ In the advent of COVID-19, many healthcare institutions realized that re-circulating indoor air was not conducive of prohibiting viral spread. Improving air quality and circulation would provide an effective response to the sick building syndrome (SBS). Providing patient rooms with operable windows would permit natural air circulation, which can be used to affect positive behavioral change while increasing thermal comfort. The notion of fresh air in a hermetically sealed building evokes olfactory aspects of the outdoor environment which is significant for calming and restorative healing. In a study by Song et al. she demonstrated the psychological benefits of walking through forest areas and found that "walking through forest areas decreased the negative moods of depression-dejection, tension-anxiety, angerhostility, fatigue, and confusion and improved the participants' positive mood of vigor compared with walking through city areas." ${ }^{32}$ The qualitative characteristic of fresh air in supporting the healing process of pediatric patients can improve the overall satisfaction of

${ }^{31}$ Healthline. 2021. Hyperosmia. Accessed March 20, 2021. https://www.healthline.com/human-bodymaps/depressor-septi-nasi

32 Song, Chorong, Harumi Ikei, Bum-Jin Park, Juyoung Lee, Takahide Kagawa, and Yoshifumi Miyazaki. 2018. "Psychological Benefits of Walking through Forest Areas." International Journal of Environmental Research and Public Health. P.4 
the patient room. In as much as we yearn for life outdoors within a hospital setting, outdoor environments are crucial in facilitating the optimized process of cognition.

Among all the senses, taste is the most ambiguous in architectural practice.

Pallasmaa perceives past the ambiguity and states, "vision becomes transferred to taste as

well; certain colours and delicate details evoke oral sensations." ${ }^{\prime 33}$ In this regard, Pallasmaa is relating to the subliminal taste stimuli to that of the materialistic qualities of a polished

stone surface. To a greater degree, these material manifestations are closely attributed

linked to our past memories. Infants and toddlers intuitively explore their surroundings by

putting everyday objects in their mouths. This act of tasting is a self-taught reflex of

discovering and cognitive development, or as Paiget describes the Sensorimotor stage. ${ }^{34}$ It is

a phenomenon every human has been through, establishing a cache of rules to educate the next generation before something distasteful is orally consumed. Notably the sense of smell is closely accompanied with the sense of taste, experiencing a "loss of smell can greatly

\footnotetext{
33 Pallasmaa, Juhani. 2012. In The Eyes of the Skin: Architecture and the Senses. P.63

34 Johnson, Andrew P. 2014. "Cognitive Development: Piaget and Vygotsky." In Education Psychology: Theories of Learning and Human Development. P.3.
} 
impact your sense of taste." 35 Taste is evocative and autonomous, Pallasmaa's oral

sensitivity to polished stone may not be in similar taste to that of the wet smell of cedar

shingles. The natural qualities of cedar evoke connections with forests but in the same

manner the extractives of cedar remind us of foods that infuse the flavour of cedar that we

have consumed in the past.

The Montessori method, founded by physician and child educator Maria Montessori

(1870-1952), recognizes that the senses are how we perceive, experience, and interpret the

world. Her pedagogy intentionally creates situations through stimulated activities which

children learn to develop through multisensory play. She states,

"The training and sharpening of the senses has the obvious advantage of enlarging

the field of perception and of offering an over more solid foundation for intellectual

growth. The intellect builds up its store of practical ideas through contact with, and

exploration of its environment." 36

\footnotetext{
${ }^{35}$ Healthline. 2020. Can a Loss of Taste and Smell Be a Symptom of COVID-19? October 12. Accessed March 5, 2021. https://www.healthline.com/health/coronavirus-loss-of-taste-loss-of-smell\#bottom-line.

${ }^{36}$ Montessori, Maria. 1948. The Discovery of the Child. P.101.
} 
Restorative healing is achieved through an optimal healing environment, which is defined as "one where the social, psychological, physical, and behavioral components of healthcare support and stimulate the body's innate capacity to heal itself." 37 Architectural concepts do not advocate for human beings to live in a world that is obscured with ubiquitous designs or visual distractions but reinforces an articulation of the experience including underlining elements of self, sense, and reality. The design does not need to be obvious in its rational nor does it need to mimic other typologies to ignite the child's mental dimensions of emotions, imagination, and memory.

\footnotetext{
${ }^{37}$ Ghazali, Roslinda, and Mohamed Yusoff Abbas. 2010. "Paediatric Community: Healing Environment Conducive Enough?" P.43.
} 


\section{DEFINING BIOPHILIC PLAY}

"I want to stay outside and play!" - Every Child

Biophilic design is an emerging concept in the built environment introducing natural ecological elements into building design. This research dates to the early 1980 's, when biologist Edward O. Wilson theorized the philosophy of biophilia, exploring the biological

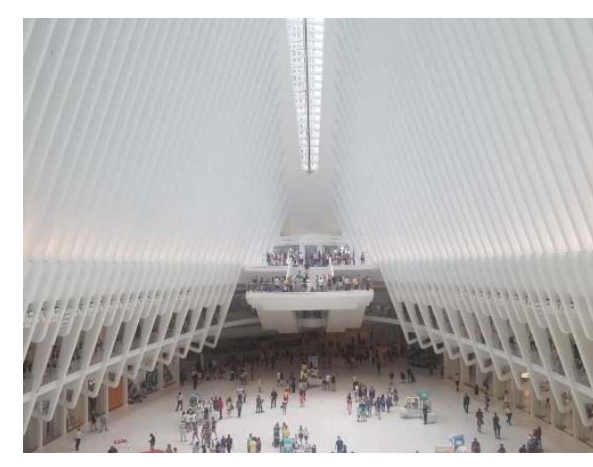

Figure 8. Inside the Oculus by Sanitago Calatrava. New York. By Author affinity of humanity's attraction for the natural world. ${ }^{38}$ Applications of biophilic design have been associated to architectural history for a long time. Antoni Gaudi's central columns of the nave of the Basilica of the Sagrada Família in Barcelona, representing the transition between the trunk and branches of a tree are evocative of a large forest area; Frank Llyod Wright integrated a residence in its site fostering the coexistence within the natural elements of a scenic waterfall; and Santiago Calatrava's skeletal framework of zoomorphic

\footnotetext{
${ }^{38}$ Schwab, Katharine. 2019. What is biophilic design, and can it really make you happier and healthier? April 11.
} Accessed March 13, 2021. 
forms, are notably inspired from natural elements (Figure 8). However, what is important to

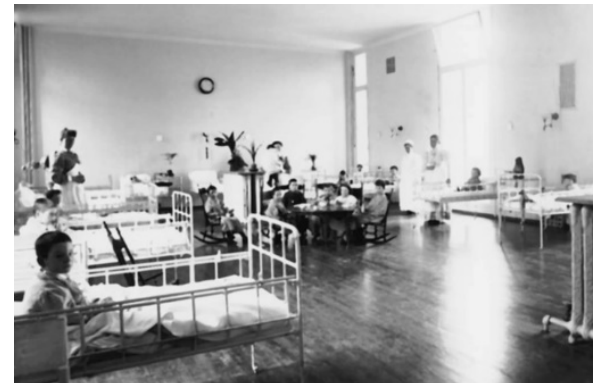

Figure 9. Children's ward, Royal Victoria Hospital, 1894. By Annmarie Adams.

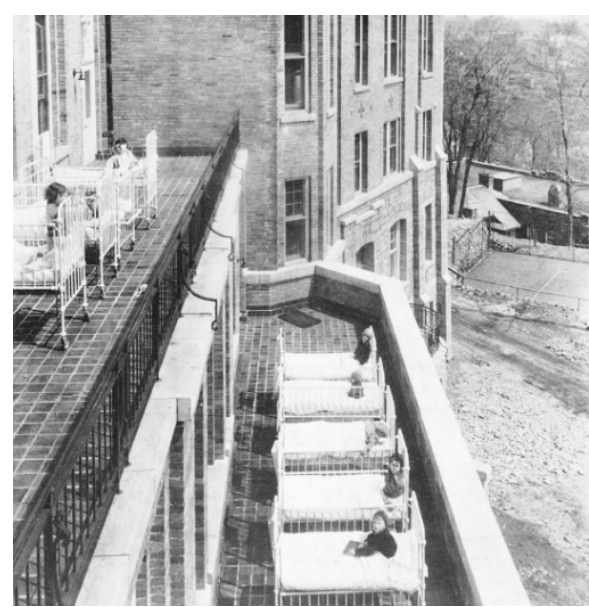

Figure 10. Children on the rooftops at the Children's Memorial Hospital. By Annmarie Adams. P.63. impact on physical and mental health as well as overall well-being.

In 1883 , a methodology was introduced in pediatric hospitals called the pavilion plan. Inspired by the ideas of Florence Nightingale (1820-1910), a founder of modern nursing, the children patient wards were conceived as open concept, with thirty to forty beds arranged against the outer walls in close proximity to large, operable windows (Figure 9). This concept would allow the circulation of fresh air in the wards decreasing the risk of contagious spread. ${ }^{39}$ Furthermore, Montreal's Children's Memorial Hospital recognized the importance of outdoor spaces as a disctintive design feature serving as outdoor wards for patients. It was evident during a Commencement Day in 1912 where photos showed nurses parading children in their beds dressed for both winter and summer weather outside the grounds of corridor rooftops (Figure 10). ${ }^{40}$

During this era, the leading cause of death in Canada was turberculosis (TB) and the common treatment to counter this highly infectious disease was fresh air and rest

\footnotetext{
${ }^{39}$ Adams, Annmarie. 2008. Medicine by Design The Architect and the Modern Hospital, 1893-1943. P.10.

${ }^{40}$ Ibid, 62
} 
(Figure 11). This was caused by, dark, stagnant spaces where unventilated air accumulated.

In the late $19^{\text {th }}$ century, as Gwendolyn Wright stated, particulate-laden infections, such as

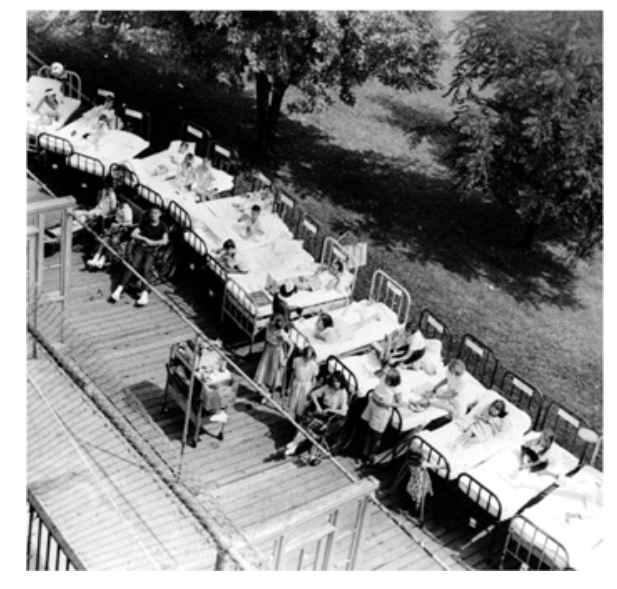

Figure 11. Children outside. The Hospital for Sick Children in Thistletown. CToronto Star Newspapers Ltd.
TB, pneumonia, and typhoid, within crowded impoverished tenament buildings were three to five times more prevalent. ${ }^{41}$ As Jeanne Kisacky wrote, it was known that "if windowless rooms did not directly breed disease, they bred the conditions that led to disease." 42 Kisacky, further states that, with the development of germ theory, advancements in modern medical theory and practices altered and natural sunlight and fresh air became crucial for health regeneration within the healthcare environment; "the hospital building itself was a form of therapy." ${ }^{43}$ In the same article, Kisacky acknowledges that American architect Talbot

F.Hamlin (1889-1956) stated, "the quality of the surroundings of the sick person may be as important in the cure as the specific therapeutic measures themselves." 44

${ }^{41}$ Wright, Gwendolyn. 1983. Building the Dream, A Social History of Housing in America. P.120

${ }^{42}$ Kisacky, Jeanne, "When Fresh Air Went Out of Fashion at Hospitals," Smithsonian Magazine, June 14, 2017,

43 Ibid.

${ }^{44}$ Kisacky, Jeanne. 2017. Rise of the Modern Hospital: An Architectural History of Health and Healing, 18701940. P.355 
The holistic design of the Paimio Sanatorium is an architectural example that encapsulates the ideology of a building aimed for therapeutic healing. A young Finnish architect Alvar Aalto (1898-1976) along with his wife Aino Aalto (1894-1949), won a design competition for a hospital specializing in the treatment of tuberculosis as the disease was the

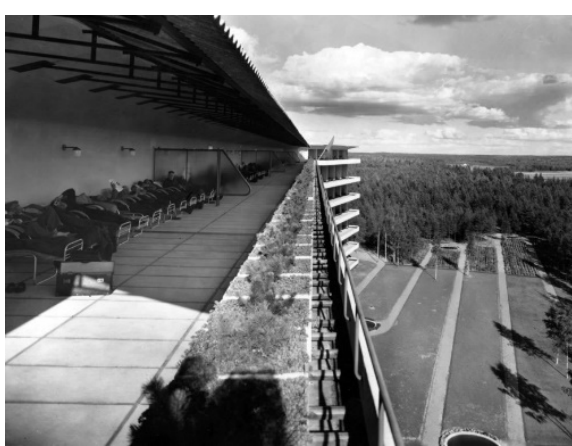

Figure 12. Paimio Sanatorium, Roof Terrace (C) Fabrice Fouillet leading cause of death in Finland in the early $20^{\text {th }}$ century. Located in Southwestern Finland,

in a secluded area of moraine hills and surrounded by thick woods, the architectural design is

a composition of elements that encourages rest and healing. Recognizing that the patient

was the primary design focus, the design approach was to provide an environment that

would enrich everyday use for a recovering patient. For example, private roof terraces

(Figure 12) and the tandem patient rooms had views oriented towards the forests and

gardens secluded from the street traffic. The Aaltos developed the ribbon windows to have

a two-fold scope, as Alvar states, “Morning sun on the patients' beds; afternoon sun on the

front part of the room, in front of the window...with permanent ventilation through glass

panes with vertical openings. Exposure to the sun can be adjusted using external blinds."45

The Aaltos understood that treatments for TB included natural daylight and fresh air. The

${ }^{45}$ Aalto, Alvar. 1932. "Sanatorium Paimio, Finland." The Master Builde. P.80 
only usage of mechanical ventilation was found in the kitchen whereas the entirety of the hospital benefitted from natural ventilation, since fresh air is important towards the healing process. ${ }^{46}$ Along with the architecture, the Aaltos designed furniture and common fixtures that contributed towards the holistic solution aimed at improving patient health and wellbeing in a therapeutic environment, or as Alvar revered the building as a "medical instrument." 47

Aalto's design solutions for the Paimio Sanatorium was the world's first example of modern healthcare architecture, which also influenced upcoming Finnish Hospital designs. Notwithstanding the key benefits and the awareness of controllable risk, why were these healing conceptions, introduced by the Aaltos, absent from postmodern industrial hospital designs? More importantly, why have outdoor spaces for physical and mental healing and regeneration been neglected within pediatric hospitals?

\footnotetext{
${ }^{46}$ Aalto, Alvar. 1995. Alvar Aalto Volume / 1922-1962. Basel, Switzerland: Birkhauser Verlag GmbH. P.31

${ }^{47}$ Archeyes. 2020. Paimio Sanatorium / Alvar Aalto. May 15. Accessed May 16, 2021.

https://archeyes.com/paimio-sanatorium-alvar-aalto/
} 
Kisacky affirms that in the first few decades of the $20^{\text {th }}$ century, medical advances,

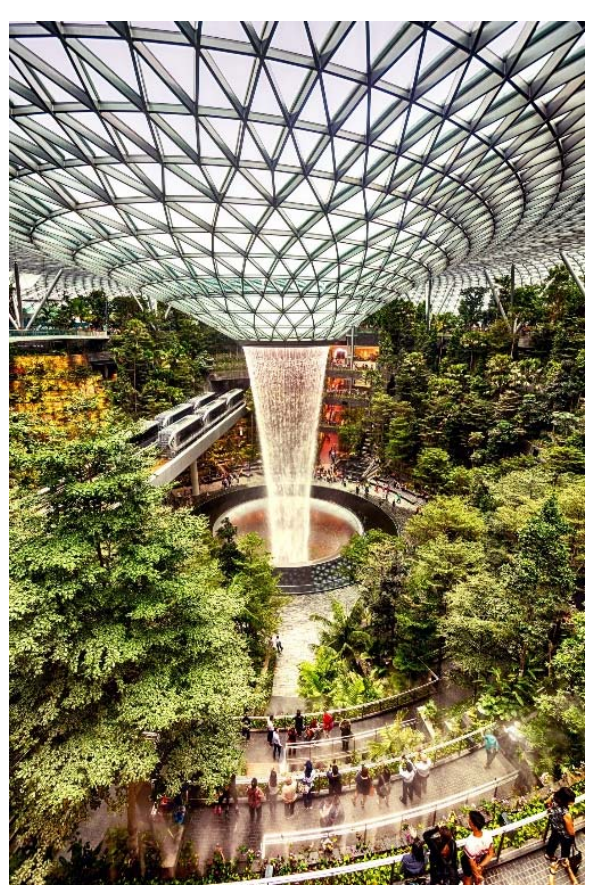

Figure 13. Eye of the Oculus, Jewel Changi Airport, Singapore. By John Seaton Callahan / Getty Images. building technology innovations, urban growth, and philanthropic contributions transformed

hospitals. The interest for healthy environments were soon overshadowed by rising construction costs and efficient workflow. ${ }^{48}$ The emphasis on efficiency was binding in the modern design and layout of the hospital, replacing light and air, devoid of healthiness. By the 1950 's, doctors and medical practitioners believed that "total environmental control" of the patient's health could be maintained regardless of the built environment. ${ }^{49}$ "Windows were no longer necessary to healthy hospitals" as central air ventilation and electric lighting regulated interior spaces. ${ }^{50}$ The introduction of concepts such as those of efficiency and flexibility made doctors and designers overlook the values of the "therapeutic" hospital design, which became merely a tool to facilitate medicine. The advent of the worldwide COVID-19 pandemic is bound to alter the medical profession as well as building science professional's approach to the conception of healing environments. The circulation of this infectious airborne pathogen within existing mechanized ventilation systems of a

\footnotetext{
${ }^{48}$ Kisacky, Jeanne. 2017. When Fresh Air Went Out of Fashion at Hospitals. June 14. Accessed March 15, 2021.

${ }^{49}$ Ibid.

50 Ibid.
} 
hermetically sealed building is detrimental to controlling outbreaks. Providing natural ventilation and direct access to nature within a built environment can help remedy these concerns.

Bettina Bolten and Giuseppe Barbiero indicate that biophilic design was developed to improve the relationship between nature and human beings by introducing vegetation in artificial spaces, enhancing physical well-being and creativity. Disregarding nature harms the quality of human lives. ${ }^{51}$ According to the 2001 National Human Activity Pattern Survey, $86.9 \%$ of our daily lives are spent indoors. ${ }^{52}$ Inevitably, this percentile has grown exponentially during COVID-19 as the populace was relegated to work from home. Biophilic design seeks to address building performance and ensure the maximization of human experiences within the built environment. As architects seek to integrate nature into their designs, this concept can have a significant benefit to our livelihoods. Biophilic design will

\footnotetext{
${ }^{51}$ Bolten, Bettina, and Giuseppe Barbiero. 2020. "Biophilic Design: How to Enhance Physical and Psychological Health and Wellbeing in our Built Environments."

52 Klepeis, Neil E., et. al. 2001. "The National Human Activity Pattern Survey (NHAPS)." J Expo Anal Environ Epidemiol. P.239
} 
continue to be a popular concept considering that people are more aware about climate change and are continuously looking for strategies to enhance their artificial spaces.

The development of evidence-based research has created awareness of the power of biophilic design in supporting improved patient's healthcare outcomes. ${ }^{53}$ As Jie Yin et al. state, exposure to natural elements within an indoor environment supports individual's recovery from anxiety, stress, and associated reactions such as blood pressure, skin conductance level, and heart rate. ${ }^{54}$ Moreover, as we find ourselves confined to our residences during the pandemic, our health risks are worsened. Uncertainties of available vaccinations, personal freedoms, deprivation from social gatherings, large and growing financial deficits, job losses, and conflicting messages from leading authorities are among the major stressors that contribute to the emotional and mental distress and increased psychiatric illness. ${ }^{55}$ A 2019 study completed by researchers from Aauhus University in

${ }^{53}$ DuBose, Jennifer, Lorissa MacAllister, Khatereh Hadi, and Bonnie Sakallaris. 2018. "Exploring the Concept of Healing Spaces." The Center for Health Design. P.46.

${ }^{54}$ Yin, Jie, Jing Yuan, Nastaran Arfaei, Paul J. Catalano, Joseph G. Allen, and John D. Spengler. 2020. "Effects of biophilic indoor environment on stress and anxiety recovery: A between-subjects experiment in virtual reality." Environment International 136, December. P.1.

55 Pfefferbaum, Betty. 2020. "Mental Health and the Covid-19 Pandemic." The New England Journal of Medicine. August 6. Accessed February 12, 2021. 
Denmark concluded that children under the age of 10 were $55 \%$ less likely to develop mental health problems later in life if they grew up in close proximity to green spaces. ${ }^{56} \mathrm{~A}$ growing body of research has studied nature's ability to heal, informing how the concept should be introduced to healthcare facilities around the world. Individuals heal because nature has therapeutic benefits as it helps enhance emotional well-being, reducing stress and responding well to treatment. A recent article by Park and Hyo reveals that children are enamored with all living things. Interacting and playing with nature results in the stimulation of their imagination and creative associations. At an early age, children form a comprehensive relationship necessary for coexisting with nature. ${ }^{57} \mathrm{~A}$ high percentage of the children spend time indoors, as technology and media capture their attention.

Consequently, there is a reduction of outdoor activities and exercises experienced in nature. The disregard to outdoor play has impacted negatively to attention deficit hyperactivity

\footnotetext{
${ }^{56}$ Schwab, Katharine. 2019. Kids surrounded by greenery may grow up to be happier adults. March 01. Accessed March 13, 2021.

${ }^{57}$ Park, Sung Jun, and Hyo Chang Lee. 2019. "Spatial Design of Childcare Facilities Based on Biophilic Design Patterns." Sustainability. P.2.
} 
disorder (ADHD) symptoms. ${ }^{58}$ In order to circumvent this concern, it is necessary to create opportunities to interact with natural environments.

Damian Carrington proved that outdoor playgrounds or areas that were converted from gravel yards to mini forests, affected the immune systems of children positively within a month of the transformation having taken place. The improvement was attributed to the development of various microbes in the guts and the skin of the children due to their environment. ${ }^{59}$ By exposing the children to biodiverse natural environments, the beneficial changes in places where forest soil and plants were not available boosted the immune system.

The inherent basis of this body of research shows the benefits of nature on human health. The importance of design and technology integration is essential to the efficiency of the built structure, which is why smart buildings are appealing to individuals. Edge and Hayles highlight the need to look for ways to improve people's psychological and economic

\footnotetext{
58 Ibid. P2

${ }^{59}$ Carrington, Damian. 2020. Greener play areas boost children's immune systems, research finds. October 14. Accessed December 6, 2020.
} 
welfare, and biophilic design to provide holistic environmental strategies. ${ }^{60}$ Biophilic

strategies attempt to bond architecture with nature to introduce natural sunlight, fresh air systems and green spaces. We intuitively want to be affiliated with nature; however, many indoor designs have been associated to what is known as Sick Building Syndrome (SBS). This phenomenon is attributed to poor indoor air quality, the lack of adequate fresh-air intake/air filtration, electromagnetic radiations, poor lighting, and acoustics. The combination of offgassing contaminants from building materials, mold growth, volatile organic compounds, and other light industrial chemicals are also contributors to SBS. Joshi Sumedha explains that occupants often experience a range of common ailments causing discomfort that include irritation of the eyes (dry or watering eyes); congested or runny nose; dry and sore throat; dry skin irritation; nonspecific hypersensitivity reactions such as headaches, lethargy, and poor concentration. ${ }^{61}$ Nature, when incorporated into the built environment, has also been shown to improve air quality by removing harmful toxins often found in buildings. The

${ }^{60}$ Edge, Steve, and Carolyn Hayles. 2017. "Examining the economic, psychological and physiological benefits of retrofitting holistic sustainable and biophilic design strategies, for the indoor environment." February 10. P.557.

61 Joshi, Sumedha M. 2008. "The sick building syndrome." The National Center for Biotechnology Information. P.61. 
vegetation will protect the building from direct sunlight and control the temperature of

inside the spaces. ${ }^{62}$

The innovative approach of biophilic design ensures that indoor and outdoor spaces are developed to appeal to the human senses by providing a natural experience. ${ }^{63}$ Enhancing an individuals' experience by enhancing human stimuli using nature ensures that the design will appeal to the senses since the micro-climate is altered to create a healthy environment. The benefits of nature on human health enhances physical and mental well-being. The commonality of biophilic design is an uprising trend that architects and designers are embracing the incorporation of many natural elements to mimic nature within the building environment.

\footnotetext{
${ }^{62}$ Bolten, Bettina, and Giuseppe Barbiero. 2020. "Biophilic Design: How to Enhance Physical and Psychological Health and Wellbeing in our Built Environments." Visions for Sustainability, November.

${ }^{63}$ Park, Sung Jun, and Hyo Chang Lee. 2019. "Spatial Design of Childcare Facilities Based on Biophilic Design Patterns." Sustainability. P.3.
} 


\section{THE ROLE OF PLAY}

"Come play with me!" - Every Child

Play is an important part of a child's life as it contributes not only to their growth, both physically and psychologically but also to their wellbeing, as a function of human development. Although the term play is not susceptible to a singular definition, it is commonly understood as an experience of pleasure evoking sensations of satisfaction, joy, happiness, and fun. Psychologist Scott G. Eberle writes that,

"Play would not be playful if it were not fun. And because pleasure offers its own reward and because play entails pleasure, play perpetuates itself. We would not play if play were not, at least in some measure, fun." 64

\footnotetext{
${ }^{64}$ Eberle, Scott G. "The Elements of Play, Toward a Philosophy and a Definition of Play." (American Journal of Play. Winter 2014). P.224.
} 
It can be argued that play arouses a mix of physical, social, and emotional rewards at all stages of life. As we continue to mature and develop, we learn more about ourselves and gain experiences that add to the complexity of play. Games, toys, and multisensorial activity boards (busy boards or latch boards) are integrated as part of Sick Kids routine for patients with ADHD and other cognitive disabilities. Such items are often relied upon to foster a cordial clinician-patient relationship as well as to facilitate proper communication. The busy board is a multi-faceted itemized board that encourages visual reasoning, logic and utilizes problem-solving skills to complete specific tasks through interactive play.

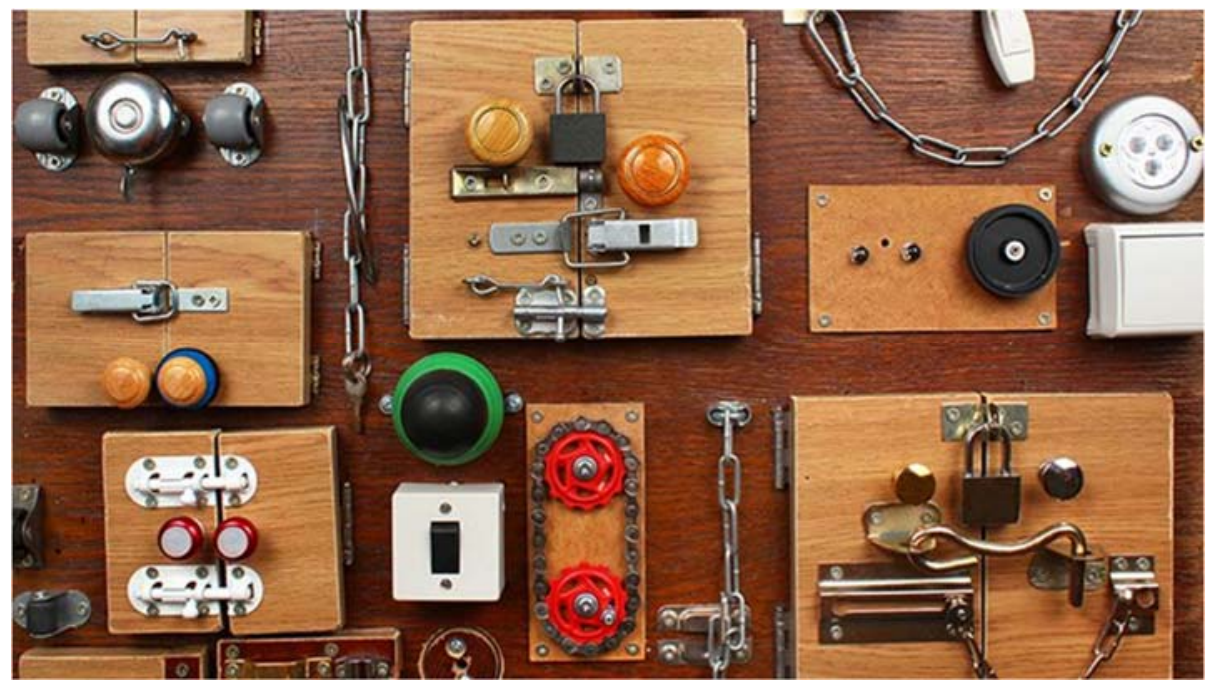

Figure 14. A busy board can help to reduce agitation and mentally engage your loved one. By Becky Upham 
The boards contain familiar everyday objects such as switches, bells, locks, zippers, and other stimulants that engage the patients' senses on multiple levels (Figure 14). The sense of touch is engaged through a tactile method, aiming to improve the child's fine motor skills. Additionally, these devices entice exploration and investigation; they help the brain create stronger connections to sensory information; finger dexterity; hand-eye coordination; observation; forming a hypothesis; analytical thought; experimenting; and making conclusions that are beneficial to the well-being and maturation of a child. ${ }^{65}$

Equally important, the Snoezelen or the controlled multisensory environment was developed in the Netherlands in the 1970s. It shares the same principles of the busy board. It is a therapy space for people with autism or individuals suffering from dementia, Alzheimer's and other cognitive impairments. The soothing and stimulating environment provides multisensory conditions specific to the needs of the patient through leisure experiences such as lighting, sounds, tastes, smells, and tactile sensations which arouse pleasure, reduce anxiety, stress, and pain. As a result, the Snoezelen space improves on the

65 Upham, Becky. 2020. Everydayhealth.com. June 8. Accessed November 22, 2020. 
patient's communication and functioning ability. ${ }^{66}$ Presently, there is a room reserved for multisensory stimulation and activities located in the Black Wing (c. 1950) at SickKids Hospital (Figure 15). Although, there has been little scientific conclusive results that the

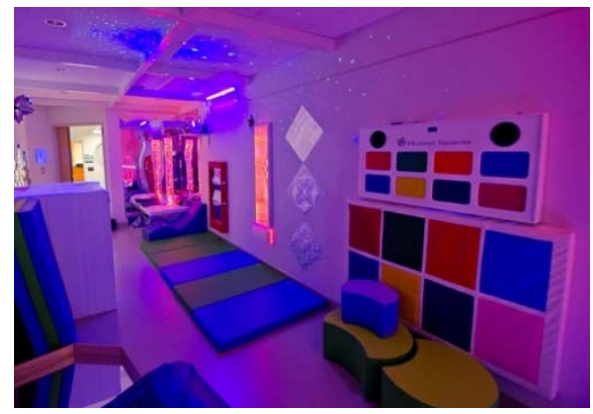

Figure 15. Multisensory Room at SickKids. A calming and relaxing environment for multisensorial engagements and activities.

(c) The Hospital for Sick Children multisensory spaces restore developmental cognitive diseases, they are however a place of

therapeutic modality that evokes play and self-discovery.

We intuitively know that children play together at an early age. Their curiosity about the environment that surrounds them, and the interest in the activities of other children are self-evident. Associative play has an impact in their social development. Child development sociologist, Midred B. Parten Newhall (1902-1970) categorized developmental play into six stages:

Unoccupied play: the child is observing the world around them, not necessarily with people in it.

\footnotetext{
${ }^{66}$ Burns, lan, Helen Cox, and Helen Plant. 2000. "Leisure or therapeutics? Snoezelen andthe care of older persons with dementia." International Journal of Nursing Practice. P.119.
} 
Solitary play: the child playing independently absent of any interaction.

Onlooker play: the child observing others nearby and not playing with them.

Parallel play: the child plays or does the same activity as others around them at the same time.

Associative play: the child plays side-by-side with others around them.

Cooperative play: the child actively plays with others while interacting with them and the activity. ${ }^{67}$

Newhall's research focused on children between the ages 2 and 5 years old. It is important to keep in mind that children develop at their own pace and solo activities are normal. Studies have proven that associative play has beneficial long term gains building resiliency to overcome setback and potential hardships.

67 Parten Newhall, Midred B. 1933. "Social Play Amoung Preschool Children." Journal of Abnormal Psychology. P.136. 
In the article, "Kids in the atrium: Comparing Architectural Intentions and Children's Experiences in a Pediatric Hospital Lobby," written by Annmarie Adams, et al., the authors noted that most children find the hospitalization stressful but "little is known about how hospital architecture may ameliorate or exacerbate this distress." 68 This fact demonstrates the importance of children play areas or room for play not only indoors but also outdoors. However, places within hospitals are often developed without the room for play concept in mind. In the mid 1970s, social scientists suggested that the "windowless, maze-like hallways, medicalized interior landscapes and unusual "smellscapes" could generate the feeling of "placelessness'" that could contribute to the distress experienced by young children during hospitalization in pediatric hospitals and general hospitals. ${ }^{69}$ This point of view has revolutionized architectural designs in pediatric hospitals to de-emphasize the connotations associated with institutionalized medicine and focus instead on a "sense of enchantment."70 The shift in focus has resulted in pediatric hospitals incorporating features that are thought

\footnotetext{
${ }^{68}$ Adams, Annmarie, David Theodore, Ellie Goldenberg, Coralea McLaren, and Patricia McKeever. 2010. "Kids in the atrium: Comparing architectural intentions and children's experiences in a pediatric hospital lobby." P.658

69 lbid. P.658

${ }^{70}$ lbid, P.658.
} 
to promote non-threatening therapeutic typologies, for example with the use of natural light, bright colors, indoor foliage, juvenile artwork, water fountains, television and film characters, fastfoods and store franchises with easily recognizable aromas. ${ }^{71}$ These themebased provisions are optimized to please the eye detached from the rest of the senses, therefore detaching itself to a place. Play often involves interaction and engaging activities that ignites the indiviuals imagination and emotions. In the book, Homo Ludens by Johan Huizinga (1872-1945) mentions that, "play only becomes possible, thinkable, and understandable when an influx of mind breaks down the absolute determinism of the cosmos." 72 Indeed the typologies of natural light, colours and natural environments have been proven to stimulate restorative healing, however the narrative of familiar symbolisms can have negative connotations towards an individual's accomplishments. The act of play involves free will and irrationality, "it begins in anticipation, in an imagination, predictive,

\footnotetext{
${ }^{71} \mathrm{lbid}$, P.658.

${ }^{72}$ Huizinga, Johan. 1938. Homo Ludens. P.3.
} 
pleasurable tension"73 and cannot be predetermined by previously existing causes - absolute determinism - otherwise it would not be play.

${ }^{73}$ Eberle, Scott G. "The Elements of Play, Toward a Philosophy and a Definition of Play." (American Journal of Play. Winter 2014). P.222. 


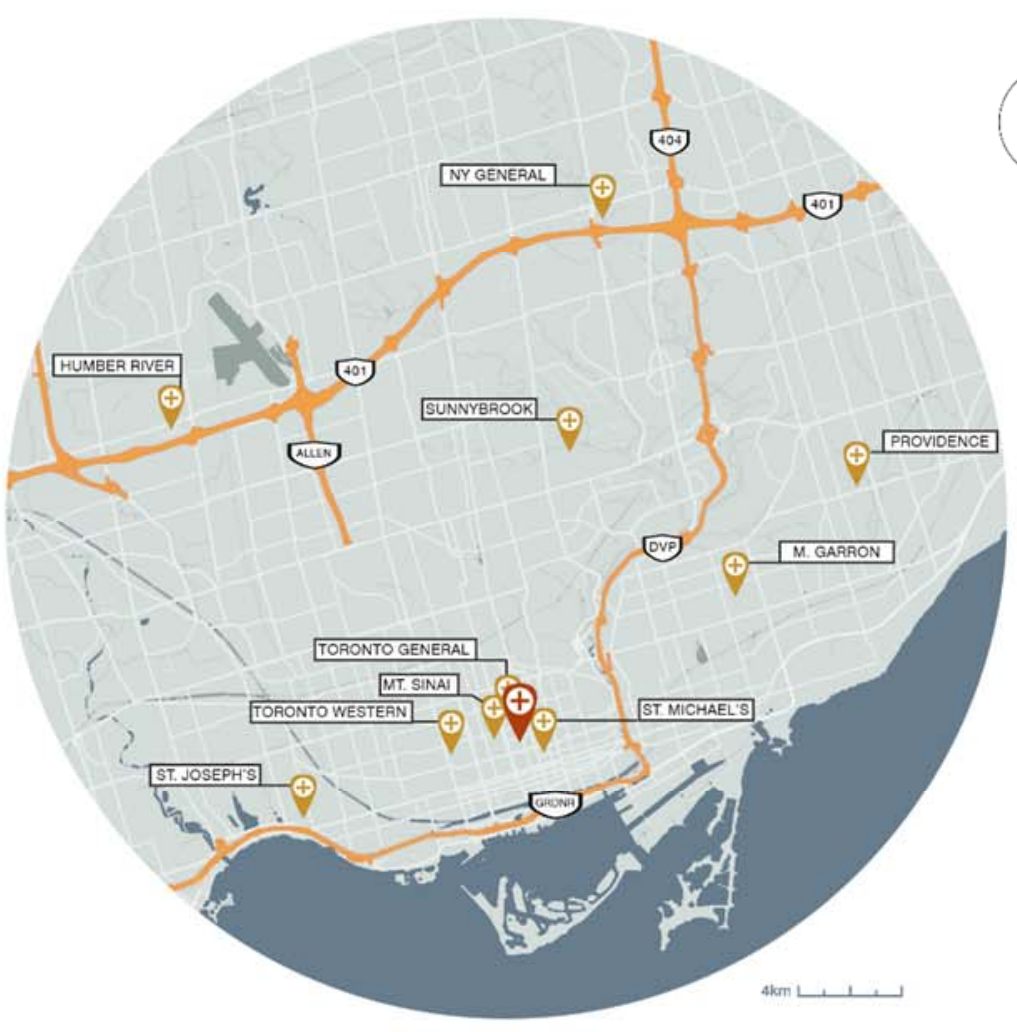

Figure 16. Location of Major Hospitals in Toronto, ON. By Author

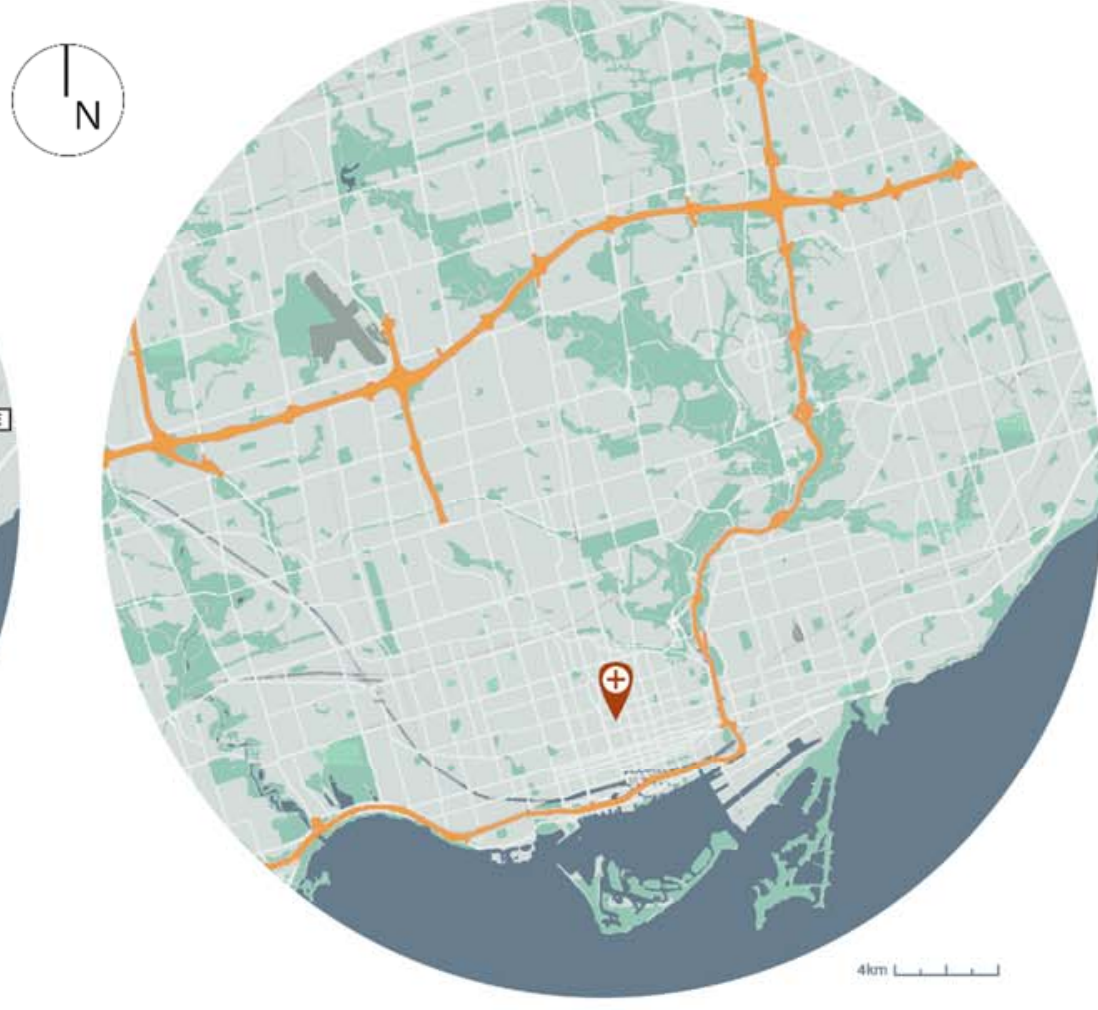

Figure 17. Location of Major Green Spaces in Toronto, ON. By Author 


\section{ROOM FOR PLAY \\ -DESIGN PROPOSAL.}

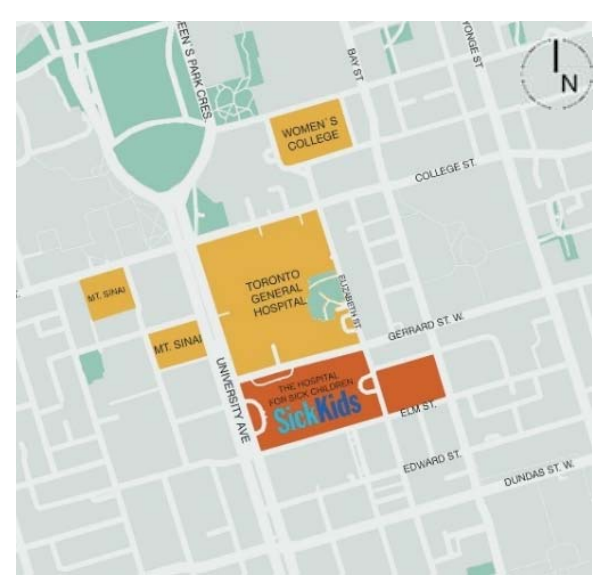

Figure 18. Key Plan (N.T.S.). By Author

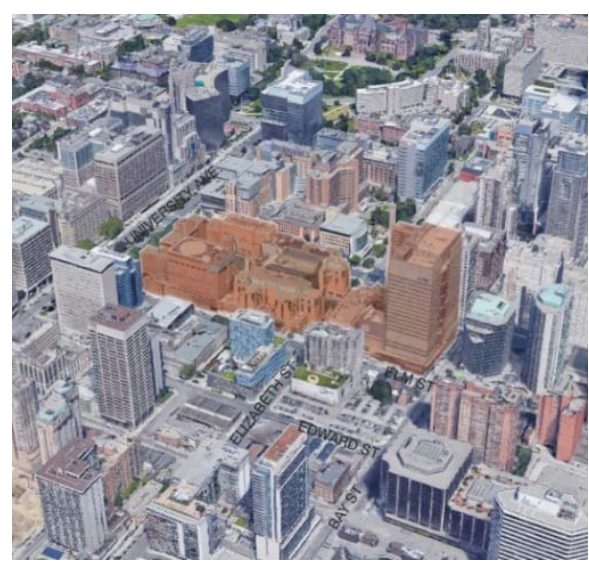

Figure 19. Referenced Isometric. Looking at South Elevation. Referenced from (C) Google Maps. By Author

\section{Site Location and Context}

The Hospital for Sick Children is located at 555 University Avenue, Toronto, Ontario and occupies a block bounded by Gerrard Street West to Elm Street, and University Avenue to Elizabeth Street (Figure 18). The building is connected to downtown Toronto's Discovery District along University Avenue which consists of acclaimed hospitals and biotechnology research institutions. The site lies within the Bay Street Corridor neighbourhood area, which consists of a variety of mid-rise and high-rise institutional buildings, predominantly dating from the mid- $20^{\text {th }}$ century onwards.

Founded in 1875, the Victoria Hospital for Sick Children (67 College St. Toronto, ON.), designed by Canadian Architects Frank Darling (1850-1923) and Samuel George Curry (18541942) was a state-of-the-art healthcare facility closely modeled after other pioneering medical sciences institutions and served as a training-ground for clinical practice 


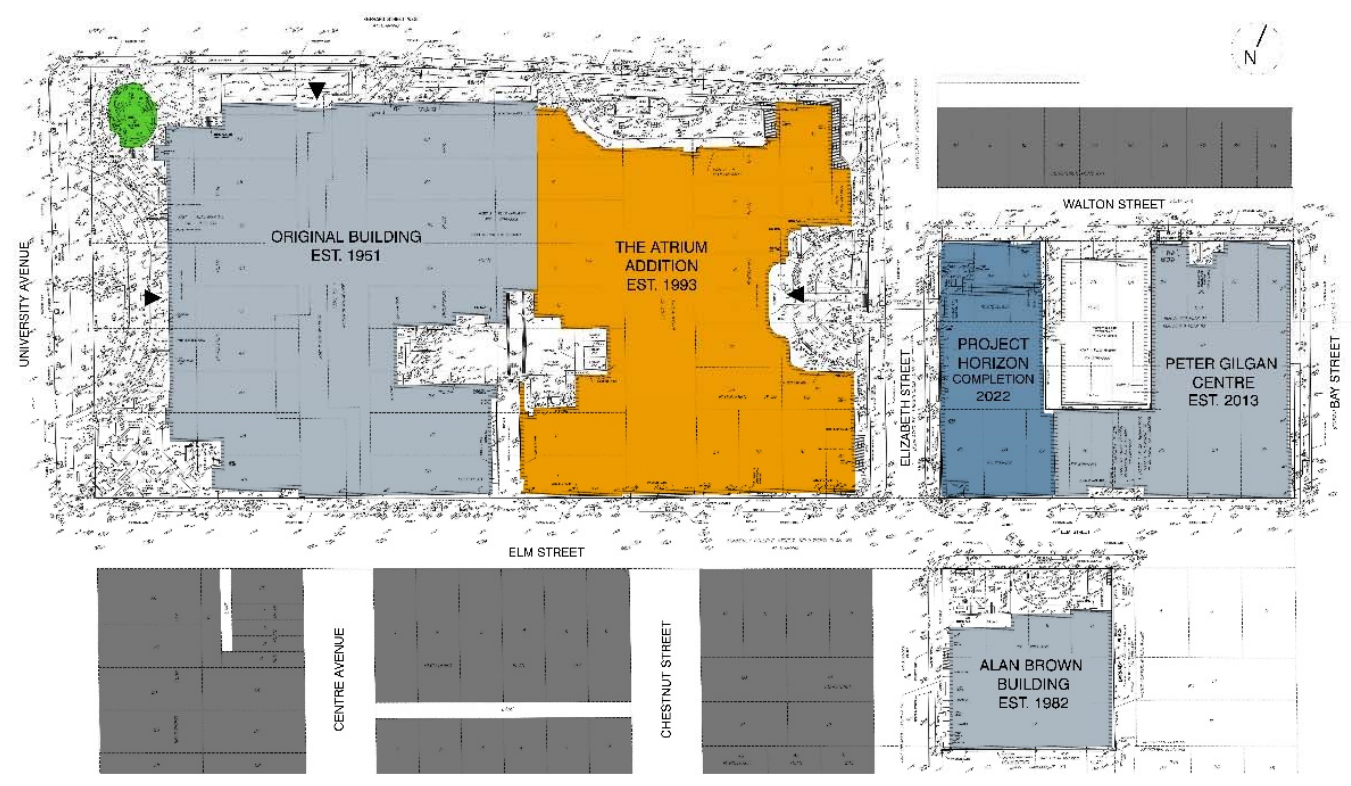

Figure 20. Site Plan ref. (C MMM Geomatics Ontario Limited. Sept 9, 2015. By Author

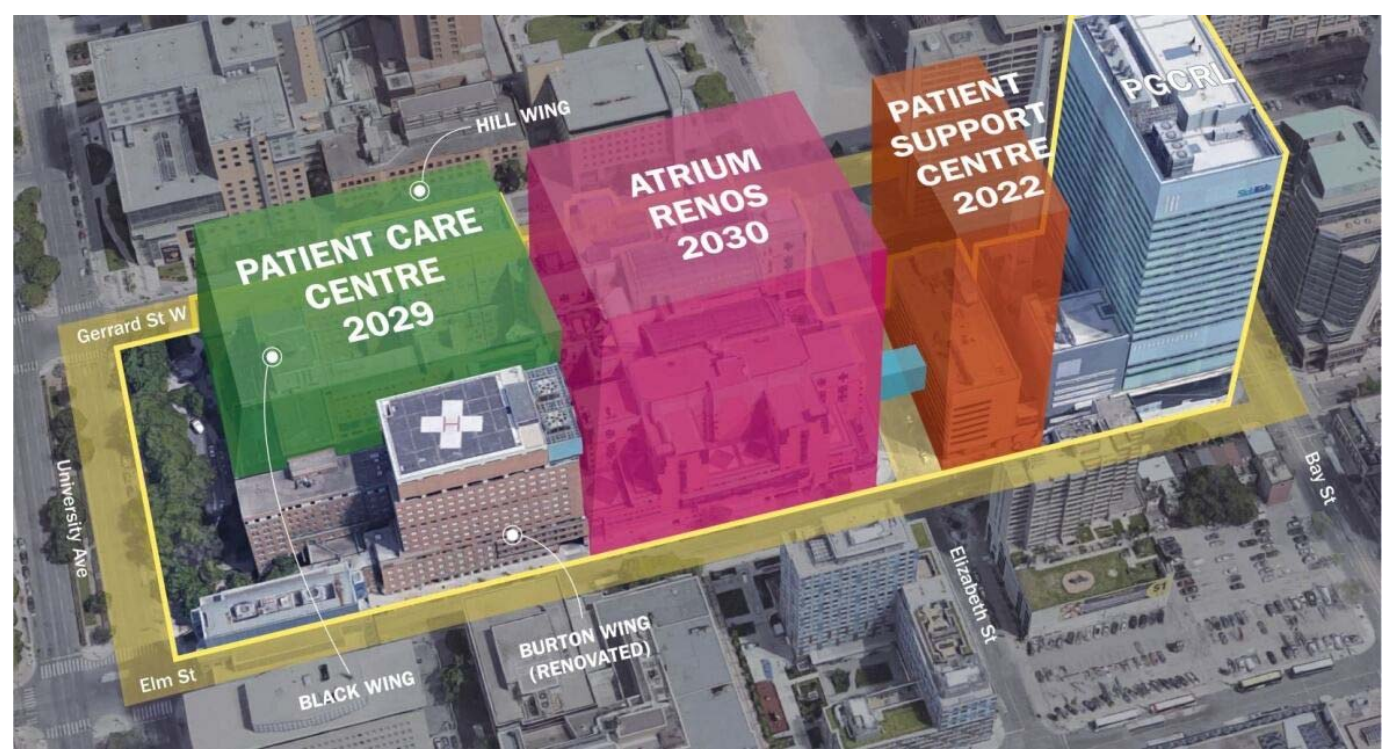

Figure 21. Future Proposal Hospital Expansion by Sickkids.ca. (c) The Hospital for Sick Children (SickKids) 


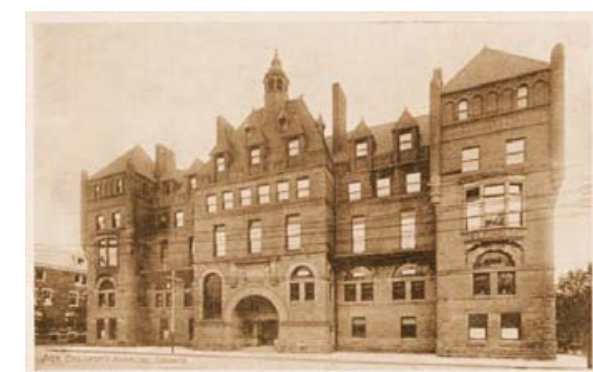

Figure 22. Victoria Hospital for Sick Children. c1910 (C) John Chuckman
(Figure 22). ${ }^{74}$ They conceptualized a domestic ideology that would provide the child patients a homelike environment. By the 1940s, space within the hospital became limited and the property lacked room for expansion. As a result, the hospital was forced to keep beds in hallways to meet the demand. ${ }^{75}$ After the turn of the century, as technological inventions and economic changes intensified, the hospital design began to change. The introduction of the elevator and land valuation had a significant impact on major development in healthcare construction. Where the footprint of the pavilion plan required large land areas and higher property rates, the financial bequest resulted in vertical construction. These vertical hospitals and health campuses increased the capacity of the patient units. ${ }^{76}$

A new hospital proposal was preordained in the late 1920s but was hampered by the Great Depression followed by the Second World War. On January 15,1951 , the inaugural Hospital for Sick Children was opened to the public. In its current location, this postwar architecture was designed by hospital specialists and consultants Govan, Ferguson, Lindsay,

\footnotetext{
74 Annmarie Adams, et al. "The Architecture of Children's Hospitals in Toronto and Montreal, 1875-2010." P.444 75 Wencer, David. 2011. Historicist: Your New Hospital for Sick Children. January 22. Accessed March 13, 2021.

76 Özgen, Elif. "An Evaluation on the change of healing perception at healthcare facilities the royal children's
} 
Kaminker, Maw, Langley and Keenleyside. ${ }^{77}$ This was a common style of architecture for many hospitals in the mid-20 $20^{\text {th }}$ century, emphasizing the minimalist or neutral elevations housing unadorned, boxy forms, and an abundance of repetitive horizontal window strips. ${ }^{78}$ Architectural modernism was perceived as a progressive language appropriate for institutions for scientific research and healthcare. As a result, this altered the experience of hospital users, clinicians, and patients. ${ }^{79}$ Conversely, the hospital environments "lost a distinct architectural and urban identity." 80 The various architectural characteristics were indistinguishable between the neighbouringing hospitals for adults and the surrounding office buildings (Figure 23). The response necessity in healthcare was merely triggered by pecuniary constraints and fast constructions without adequate research on the impact of spatial configurations towards the holistic process of patient healing.

\footnotetext{
77 Annmarie Adams, et al. "The Architecture of Children's Hospitals in Toronto and Montreal, 1875-2010." P.456.

${ }^{78}$ Annmarie Adams and David Theodore. "Designing for the Little Convalescents", P. 225. ${ }^{79}$ Annmarie Adams, et al. "The Architecture of Children's Hospitals in Toronto and Montreal, 1875-2010." P.460.

${ }^{79}$ Annmarie Adams, et al. "The Architecture of Children's Hospitals in Toronto and Montreal, 1875-2010." P.460.

80 Ibid. P.463.
} 


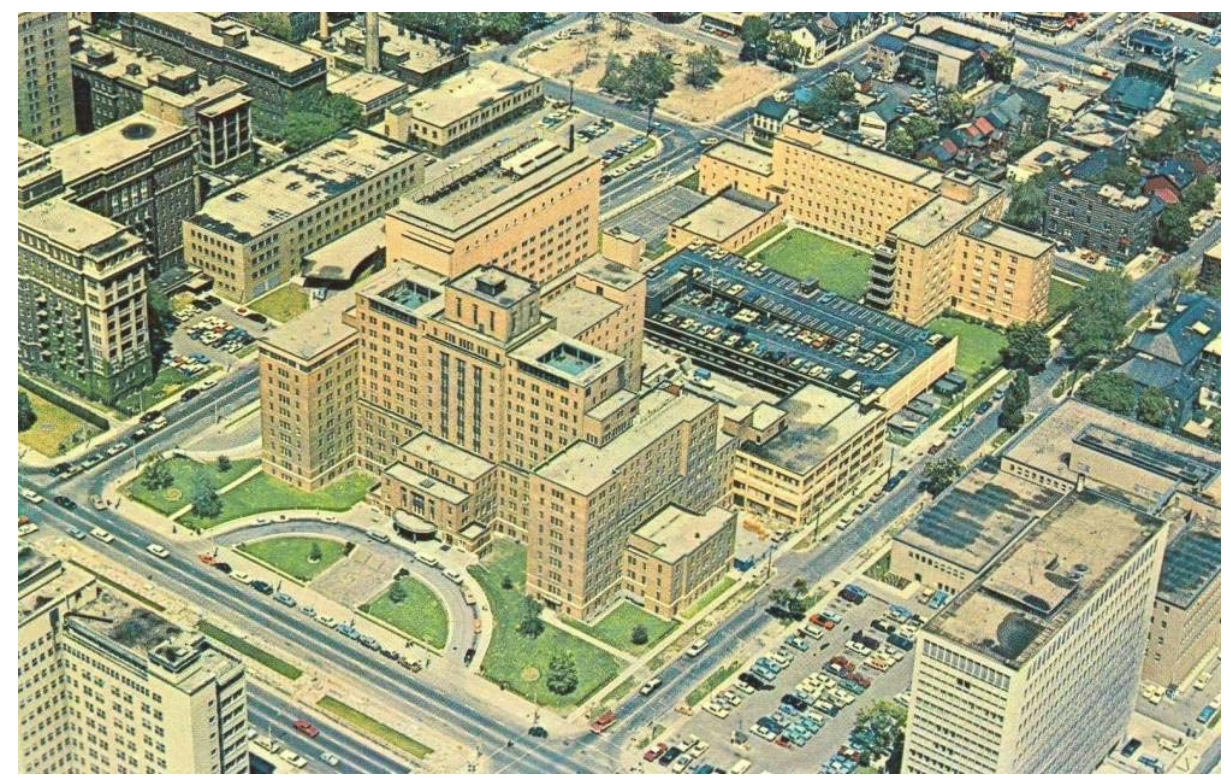

Figure 23. Hospital for Sick Children, c1960 (C) John Chuckman

In the following decades, the hospital continued to increase in size accommodating more patients and integrating new medical innovations. In 1993, Zeidler Roberts Partnership Architects recognized that the emotional needs of a sick child were the fundamental ideology towards an architectural environment of a well-functioning pediatric hospital. The SickKids Slaight Family Atrium, also known as the Atrium, is internationally recognized for its redefinition of paediatric healthcare architecture. ${ }^{81}$ Devoid of any resemblance from the

${ }^{81}$ Zeidler Architects Inc. 2021. SickKids Slaight Family Atrium. January. Accessed March 14, 2021. 


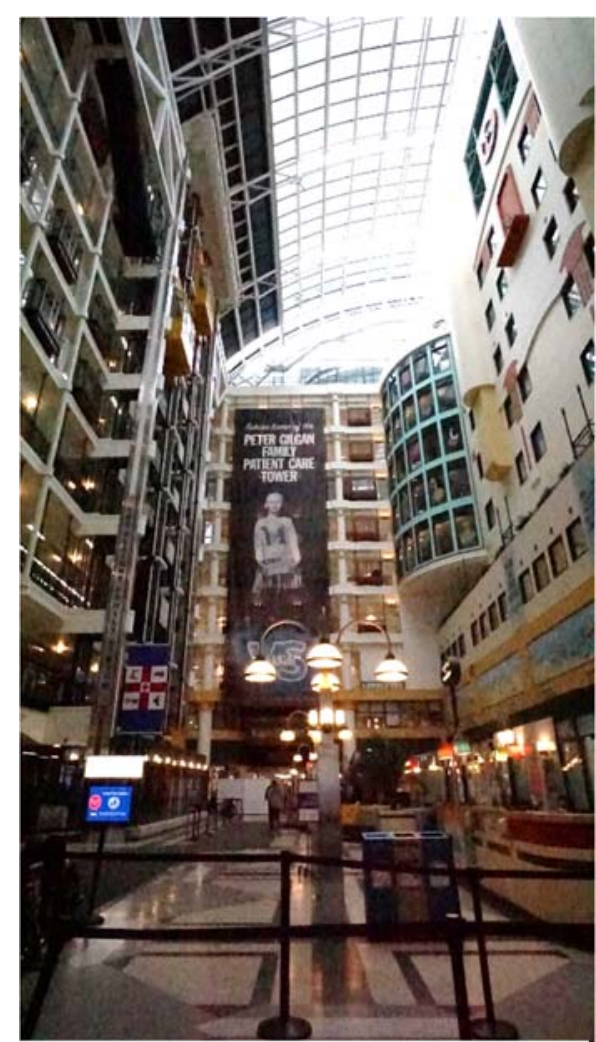

Figure 24. The Atrium. Nov 24,2020. By Author. postmodern style predecessor, the Atrium is a 9-storey, glass-roofed open public gathering space. Natural sunlight descends into the public lobby illuminating the shops and restaurants on the ground floor. 572-beds, patient rooms are located on floors five through to eight (Figure 24). The octothorp floor plan situates all the patient rooms on one of its eight arms allowing for natural light in each individual private patient room.

There are some notable mixed-use environments allotted for patients and their families within the hospital and they include; the family centre and library located on the Main Floor, Black Wing; Marnie's Lounge located on the $4^{\text {th }}$ Floor, Black Wing; Marnie's Studio \& Child Life TV located on the $4^{\text {th }}$ Floor, Black Wing; Samsung Space located on the $9^{\text {th }}$ Floor, the Atrium; Ronald McDonald House Charities Toronto Family Room located on the $4^{\text {th }}$ Floor, the Atrium; the Multisensory Room located on the $4^{\text {th }}$ Floor, Black Wing; and the WAV PlayPark located on the Main Floor of the Atrium. ${ }^{82}$

\footnotetext{
82 The Hospital for Sick Children. 2021. Family Spaces. March. Accessed March 18, 2021.
} 


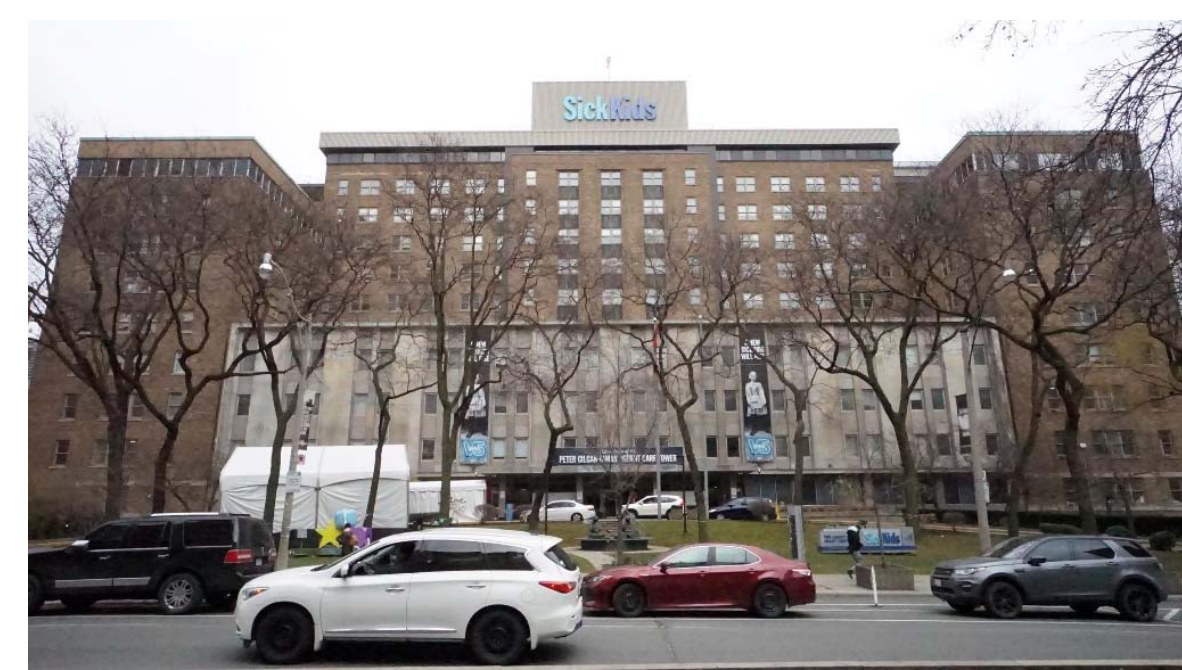

Figure 25. University Ave. Looking East. Nov 24,2020. By Author.

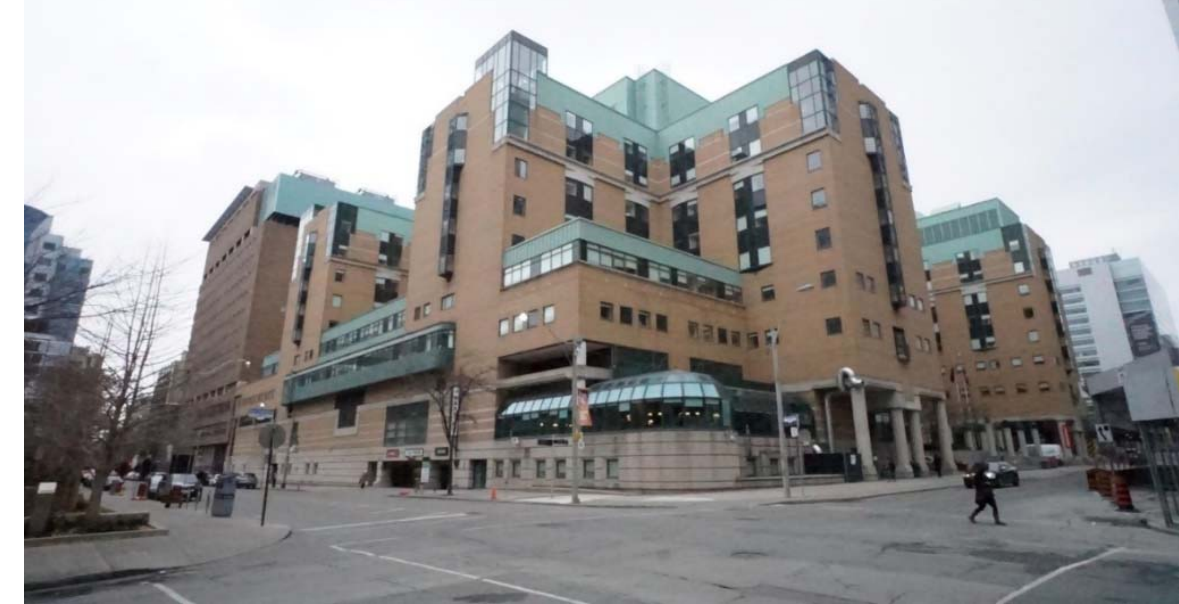

Figure 27. Elizabeth Street and Elm Avenue Looking North-West. Nov 24,2020. By Author.

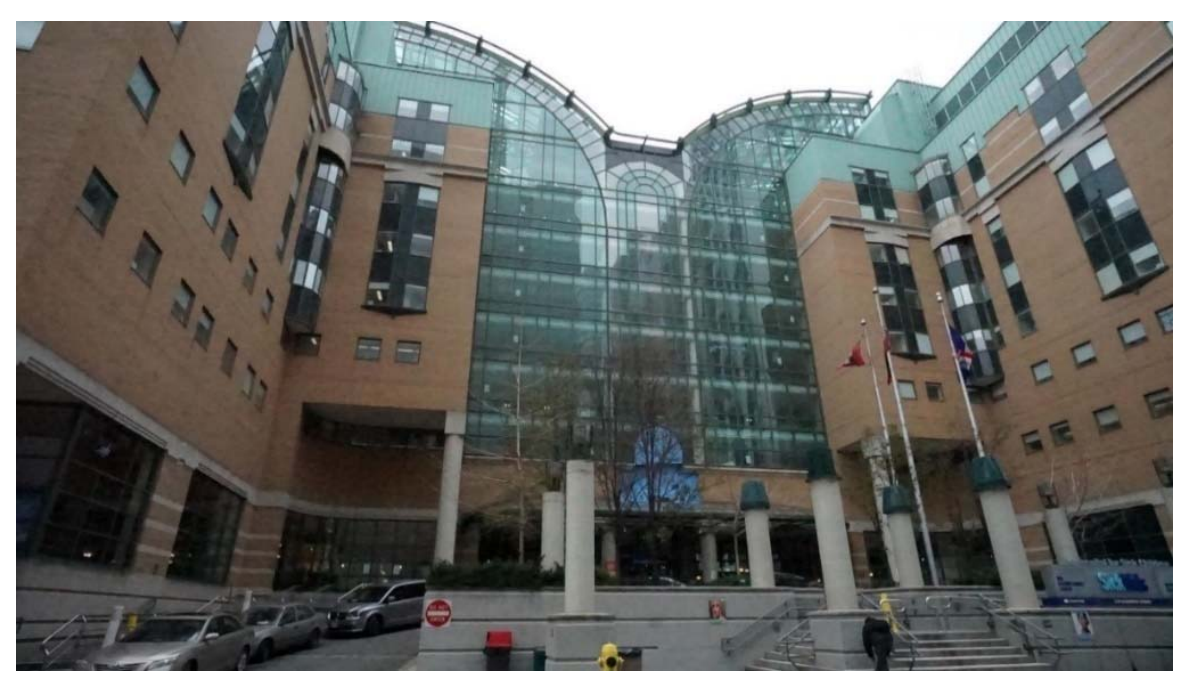

Figure 26. Elizabeth Street Main Entrance into the Atrium. Nov 24,2020. By Author.

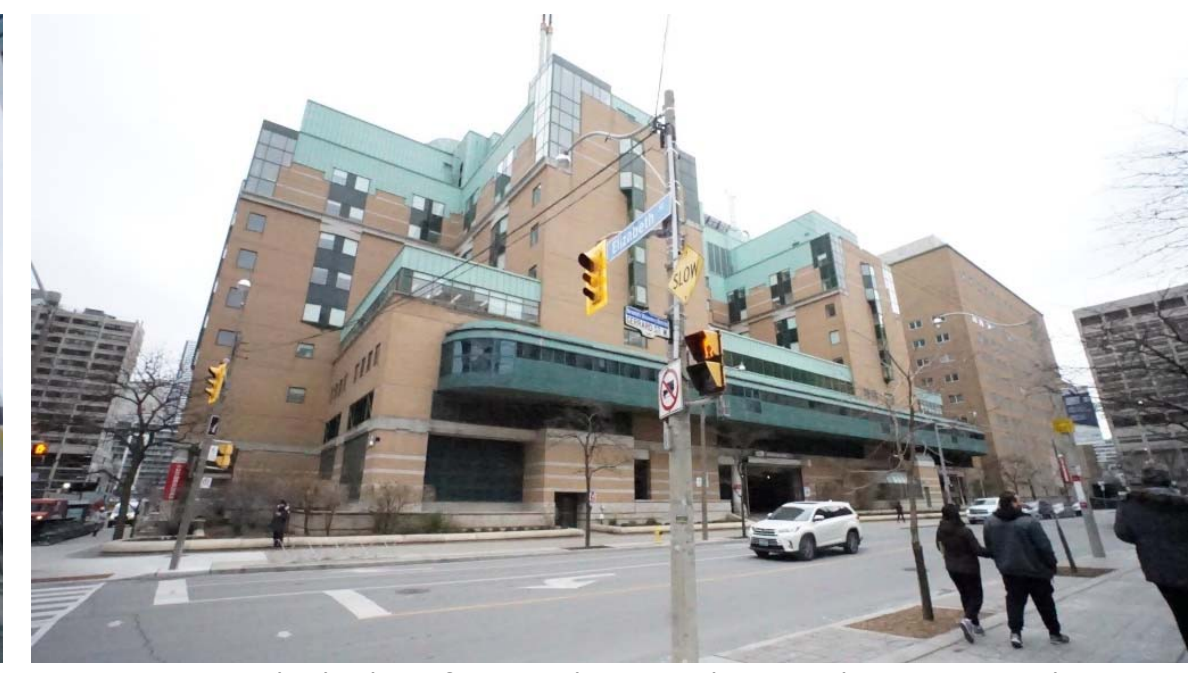

Figure 28. Elizabeth St. \& Gerrard Ave. Looking South-West. By Author. 


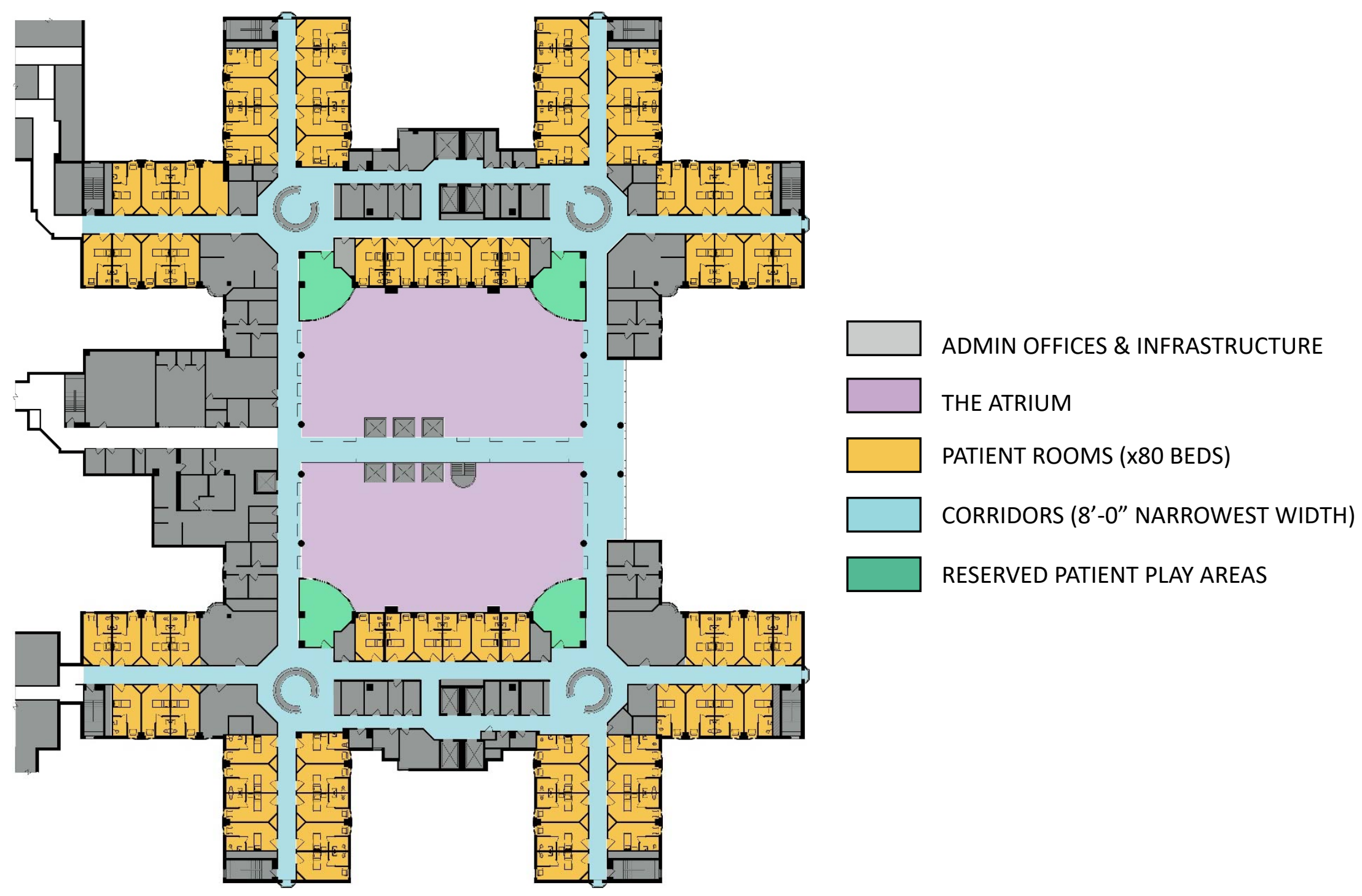

Figure 29. The Atrium Floor Plan ref. from Zeidler Architecture Inc. Floor Plan Recreated by Author 


\section{The Dwelling - Patient Room}

A child convalescent will often spend most of their daily routine within the confines of their private rooms. It is their place to eat, sleep, recharge and find habitual solitude. The lack of outdoor activities or areas of room for play within SickKids Hospital forces the patients to remain incarcerated in their room for the duration of their stay. There are allotted family areas with unique play-based activities distributed throughout the hospital, however, these are not conveniently situated for all patients. The universal provision of the postwar era for individualized patients' experience is also reflected within the Atrium design.

The separation of patients was important in preventing and controlling healthcare associated infections. ${ }^{83}$ Naturally, the single room occupancy increases the patients' privacy, dignity, and their ability to control their immediate environment, however, many young patients crave company, a provision to cure loneliness, and have a longing for companionship.

The typical patient room is approximately 20 square meters ( 215 square feet). They are furnished with a hospital bed, movable overbed table, medical equipment, television, a

\footnotetext{
${ }^{83}$ Hugh Pennington, Chris Isles. 2013. "Should hospitals provide all patients with single rooms?" The BMJ
} September 24. Accessed March 16, 2021. 
reclining chair, a personal washroom, and a modest sized inoperable window. In November

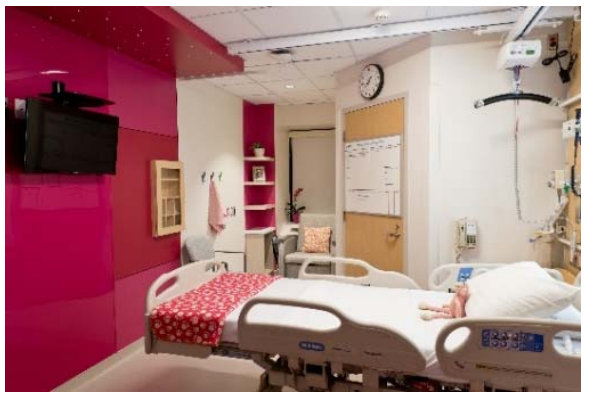

Figure 30. Patient Pink Room Ward 7C. c2017. @ Parkin Architect

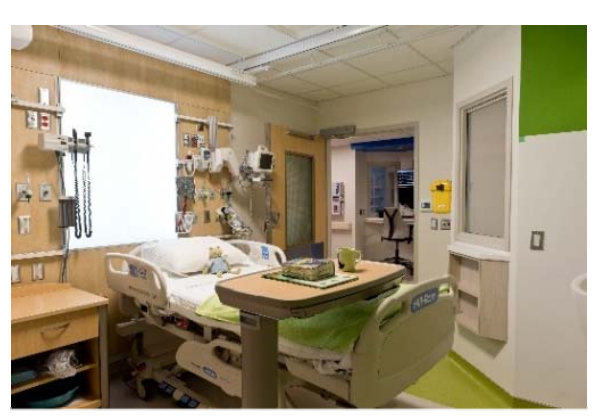

Figure 31. Patient Green Room Ward 7C. c2017. () Parkin Architect of 2017, the redesign of the Intermediate Care for Ward 7C was completed by Parkin

Architects Limited. Their overall design was governed by the existing conditions of the built environment. Vibrant and fun accent colours were used to promote calm and lower stress for both patients and medical staff. Implementing colorology (light therapy - a holistic or alternative treatment) within the patient rooms was a deliberate effort to improve the therapeutic qualities of the given space (Figures $30 \& 31$ ).

This thesis design proposal takes on a dynamic methodology for the development of the proposal for the patient dwelling. It is worth noting that the number of patient beds and the private amenities remain unchanged on every patient room floor. Kisacky acknowledges that in 1984 healthcare expert Roger Ulrich stated, "patients in hospital rooms with windows improved at a faster rate and in greater percentage than patients in windowless rooms." 84

Relocating the washroom from the exterior wall to the interior wall creates a larger surface area for fenestration and much needed natural daylight. Natural daylight in patient rooms

\footnotetext{
${ }^{84}$ Kisacky, Jeanne. 2017. "When Fresh Air Went Out of Fashion at Hospitals." Smithsonian Magazine. June 14. Accessed March 15, 2021.
} 
help maintain the circadian rhythm and provides "photochemical ingredients" necessary for our lives. ${ }^{85}$ The new window design proposed for the patient room is equipped with an operable door to a private balcony with an affixed planter. This personal planter box will encourage young convalescence to garden, which increases their environmental and social responsibilities. In an article, Klemmer, Waliczek, and Zajicek mention that, "students who participate in school gardening score significantly higher on standardized science achievement tests." ${ }^{86}$ In the same manner Montessori states, "Children have an anxious concern for living beings, and therefore the satisfaction of this instinct fills them with delight. It is therefore easy to interest them in taking care of plants and especially of animals." ${ }^{87}$ The simple activity of planting and cultivating boosts kids' cognitive development and teaches children about the connection between nature and their actions, in addition to being accountable for care and nurture a living organism.

\footnotetext{
85 Boubekri, Mohamed. 2008. Daylighting, Architecture and Health. Oxford, UK.: Elsevier Ltd. P.87.

${ }^{86}$ C.D. Klemmer, T.M. Waliczek, and J.M. Zajicek. 2005. "Growing Minds: The Effect of a School Gardening Program on the Science Achievement of Elementary Students." HortTechnology. P.448.

${ }^{87}$ Montessori, Maria. 1948. The Discovery of the Child. Chennai, India: Kalakshetra Publications.
} 


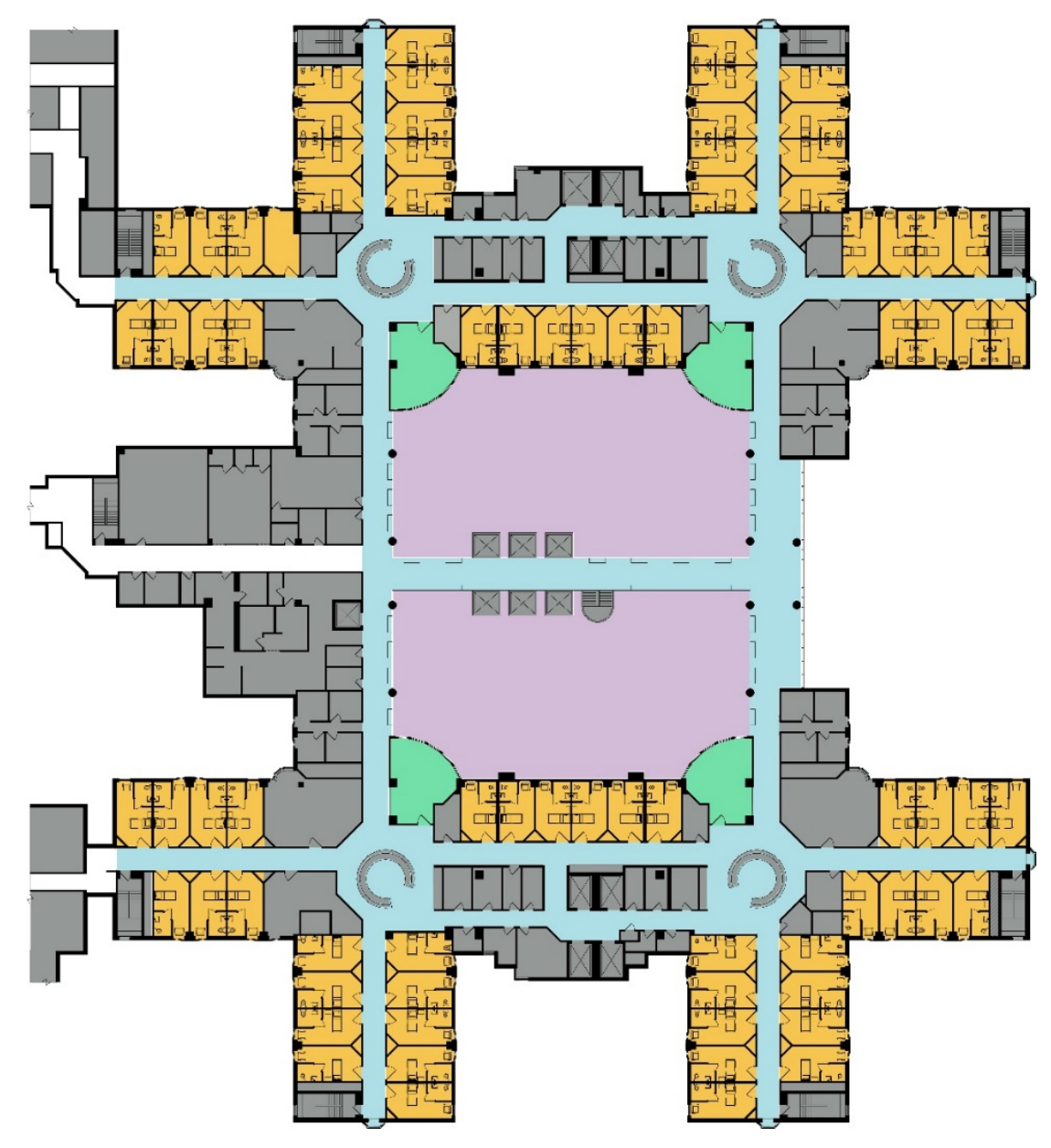

Figure 32. Existing Patient Floor Plan. By Author

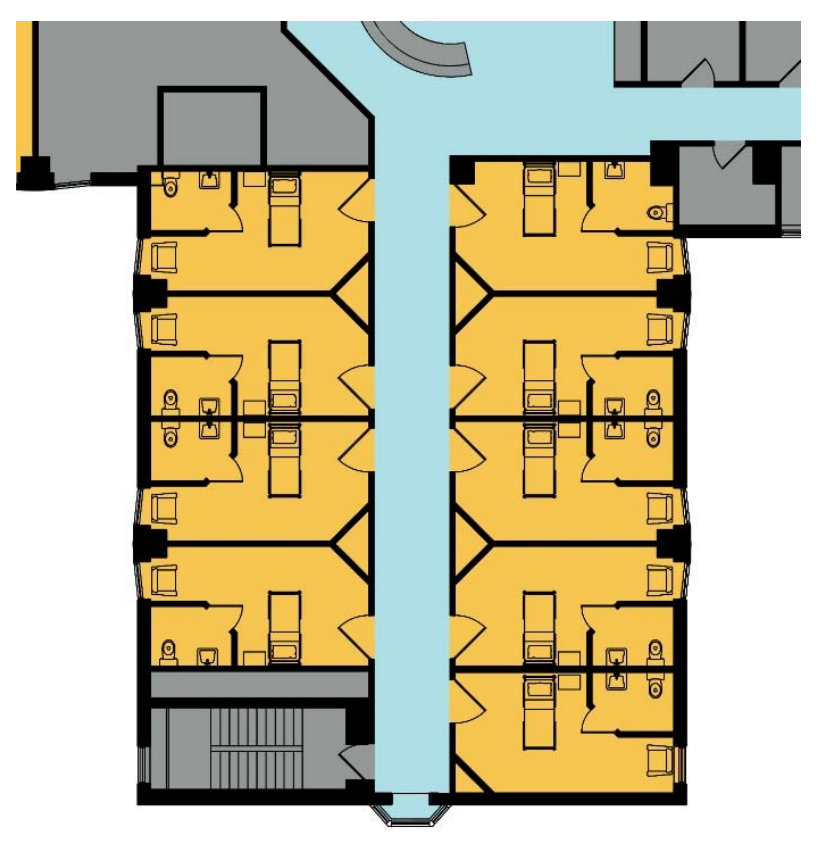

Figure 33. Existing Enlarged Floor Plan. By Author 


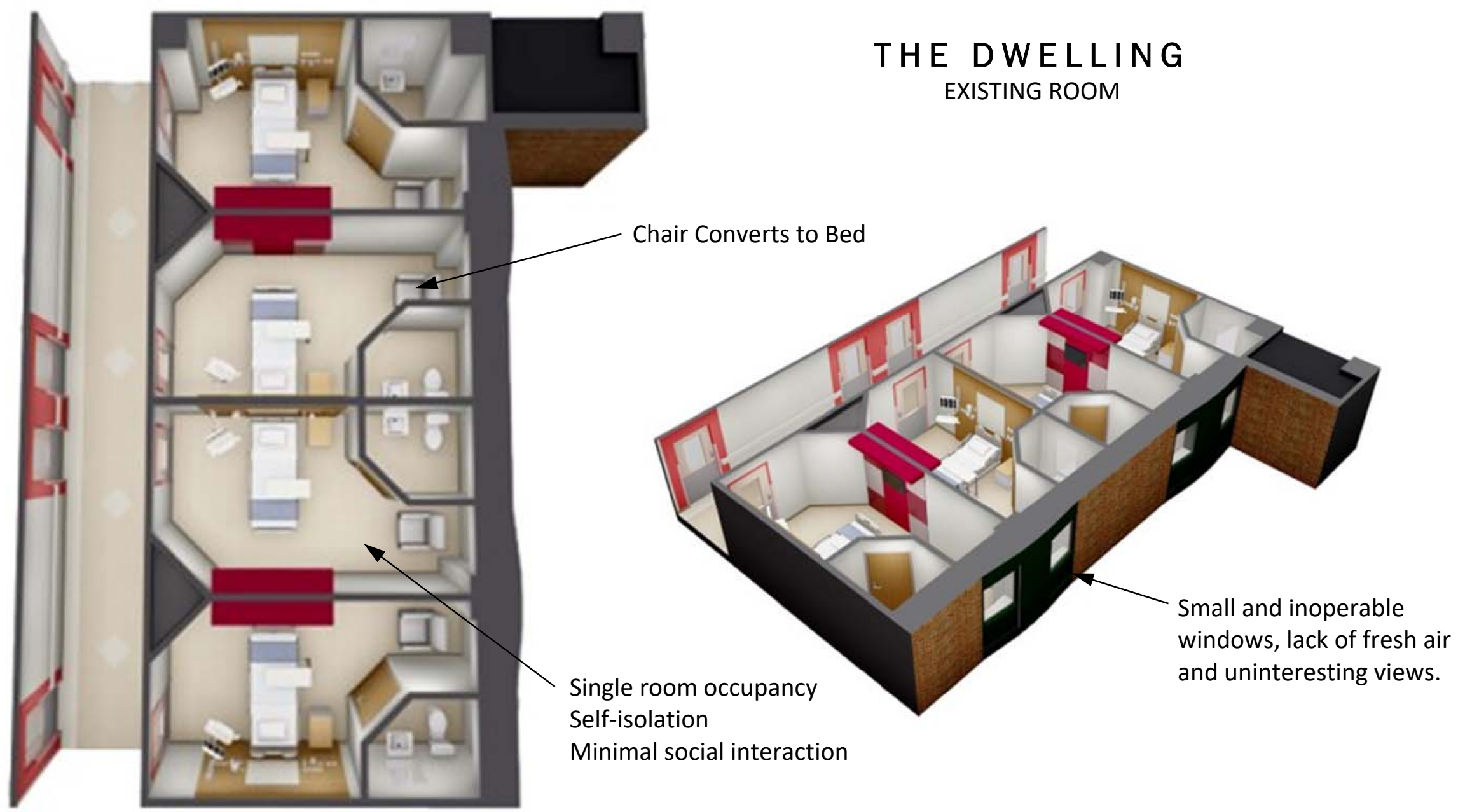

Figure 34. Existing Patient Rooms. 3D Floor Plan Rendering. By Author

Figure 35. Existing Patient Rooms. 3D Isometric Rendering. By Author 
Despite the fear of viral transmission children are naturally drawn to other children. By

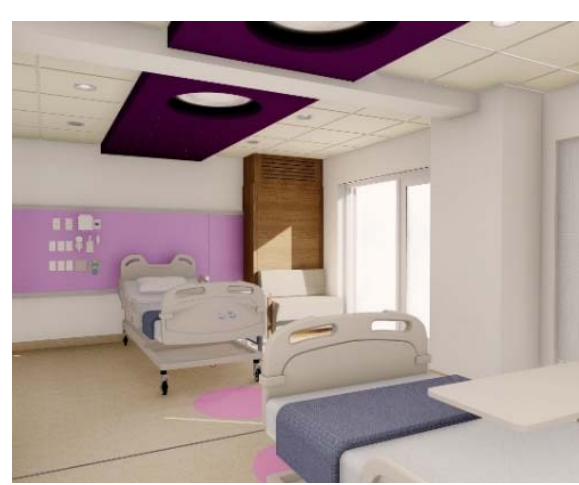

Figure 36. Proposed dwelling room, Daytime Rendering. By Author

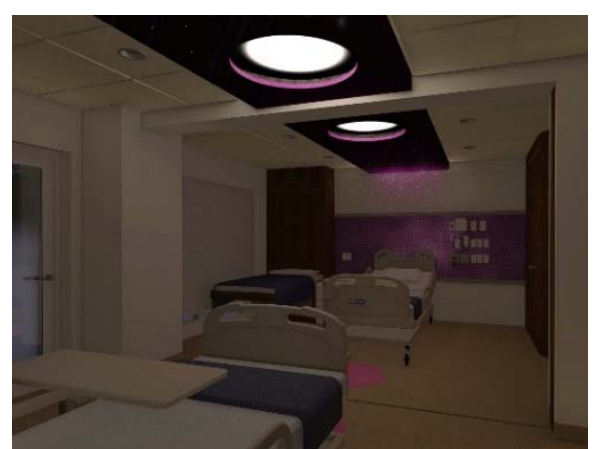

Figure 37. Proposed dwelling room, Evening Rendering. By Author conjoining two dwellings the design provides opportunities to foster associative play that

encourages social interaction. As privacy and dignity are desired by many, a collapsible wall can be unfolded in place to separate the two adjoining rooms. This wall serves a dual function; firstly, rooms can be adaptive for future viral outbreaks where the wall separating the rooms can isolate each patient from one another. The children can continue to socialize with each other by a glass barrier maintaining social distance; secondly (a far-reaching proposal) would be the integration of smart glass with organic light-emitting diode (OLED) technologies built-in. Cumbersome curtains and bulky TVs will be replaced with smart glass or switchable glass that adjusts from transparent to translucent. Since the CES 2017 convention, $\mathrm{LG}^{\mathrm{TM}}$ presented a working prototype of the thinnest TV at $2.5 \mathrm{~mm}$ thick (LG OLED Al ThinQ). ${ }^{88}$ Adapting and applying the latest innovative cloud technologies and social media platforms, patients can interact with the smart glass through various activities such as messaging applications, multiplayer gaming, conference calling, and virtual classrooms

${ }^{88}$ LG. 2021. LG OLED Al ThinQ. March 5. Accessed March 5, 2021. 
(Figure 38). By connecting them in real-time with the hospital community as well as reconnecting them with the outside world offers recognition, and self-identity.

Family presence at the hospital is vital for healing children. Currently, the Ronald McDonald house provides accommodation to families living outside a defined radius or a patient who is in critical condition and cannot return home quite yet after being dismissed from the hospital. Another alternative is the replacement of the conversion/sleeper chair equipped in every room of the hospital with a dual functioning sofa and murphy bed that would minimize the needed space in comparison with a sleeper chair. This would allow the parent/caregiver the convenience to always be by the bedside when the child convalescence is at their most vulnerable.

To juxtapose the grided tiled ceiling, a dropdown ceiling with built in light features that resemble sleeping under the stars referencing to the outside world while confined within the hospital. The walls will be a combination of wood and painted drywall. According to the study completed by Ikei et al, rooms with a moderate ratio of wood exhibited a comfortable feeling, a "significant decrease in diastolic blood pressure and significant 
increases in pulse rate. ${ }^{89}$ The dwelling room is a place of comfort and should resemble qualities of a home. By providing the patient and their family the freedom to interact with the space i.e., open a window/door, allows them complete autonomy and a sense of belonging within the healthcare institution.

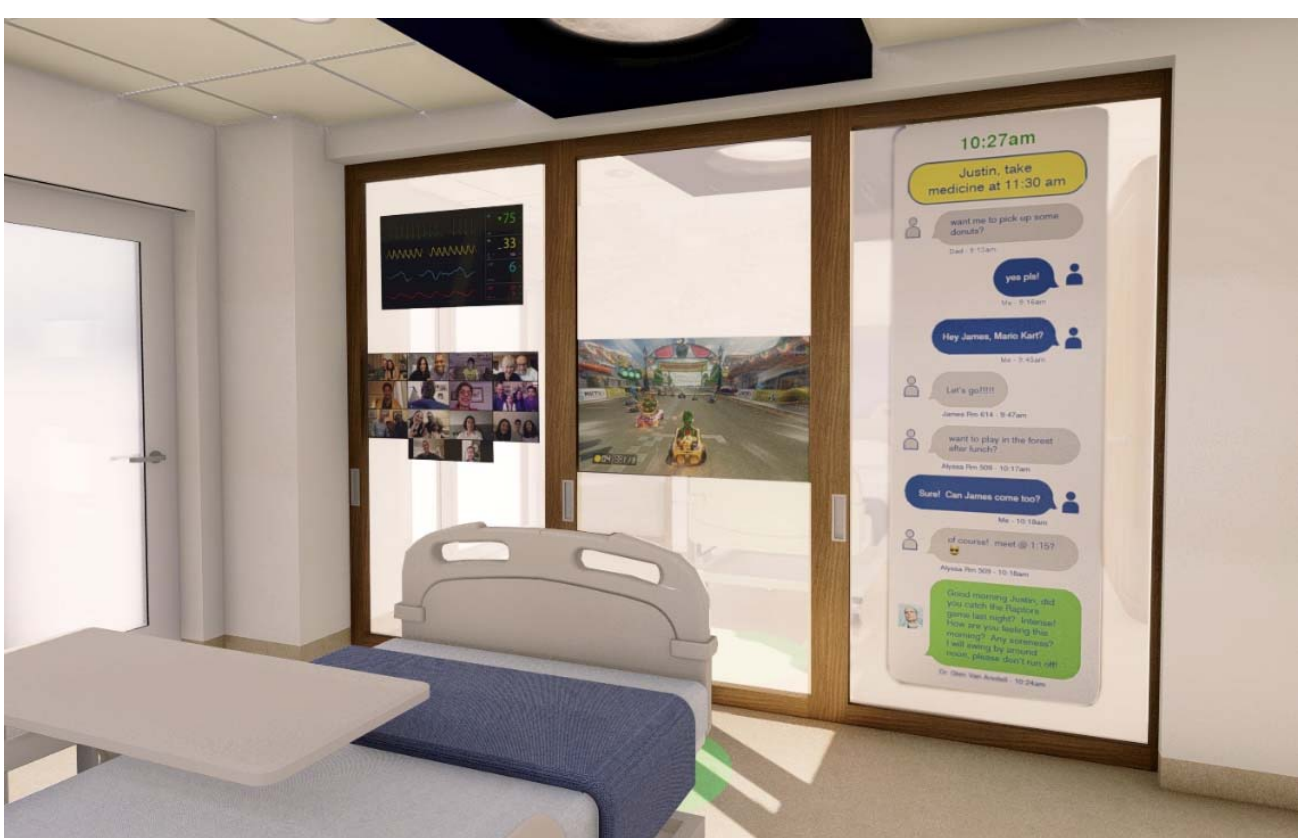

Figure 38. Proposed dwelling room. Interactive digital wall. By Author

\footnotetext{
${ }^{89}$ Ikei, Harumi, Chorong Song, and Yoshifumi Miuazaki. 2017. "Physiological Effects of Touching Wood."
} International Journal of Environmental Research and Public Health. P.19. 


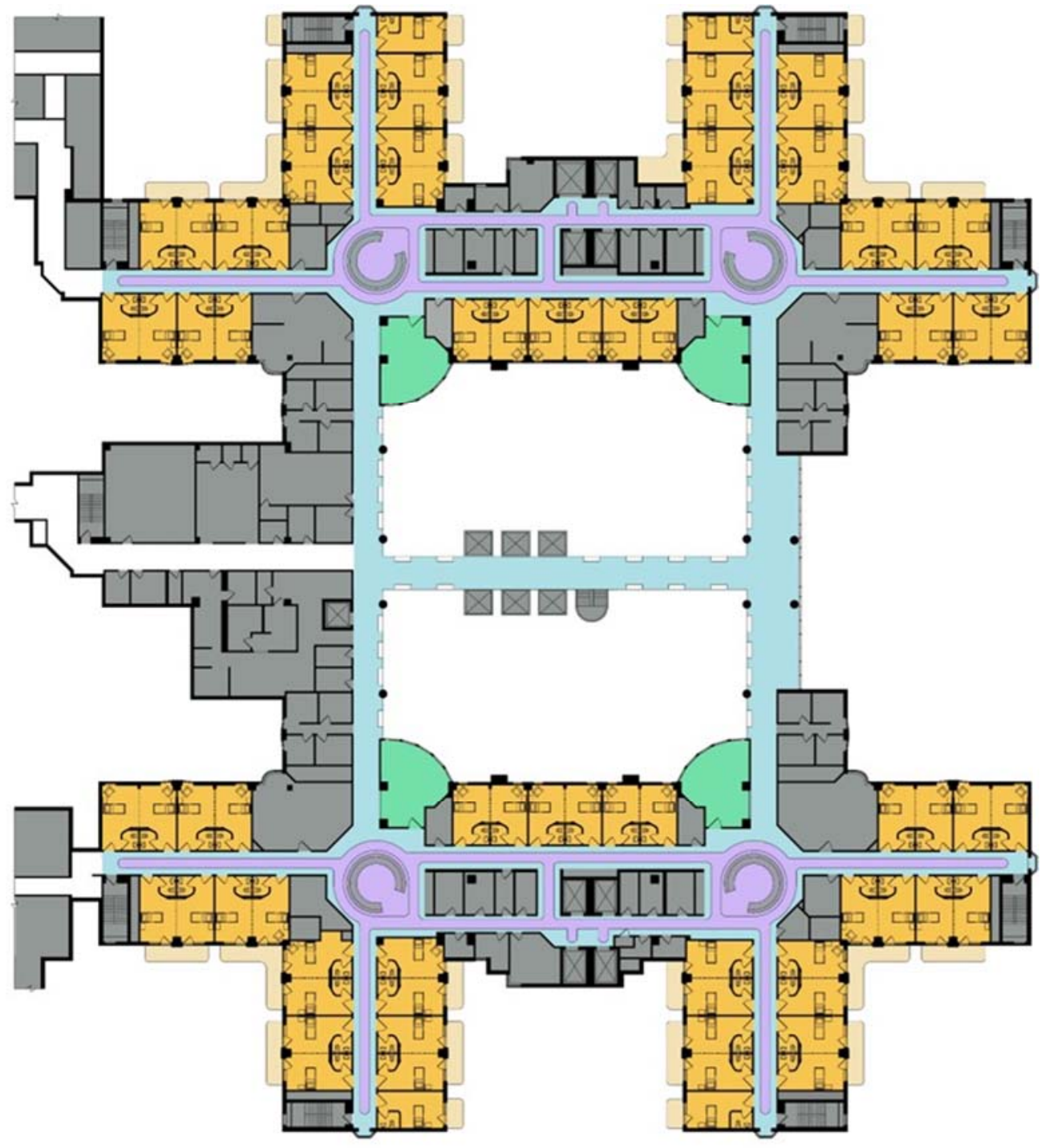

Figure 39. Concept I, Floor Plan. By Author

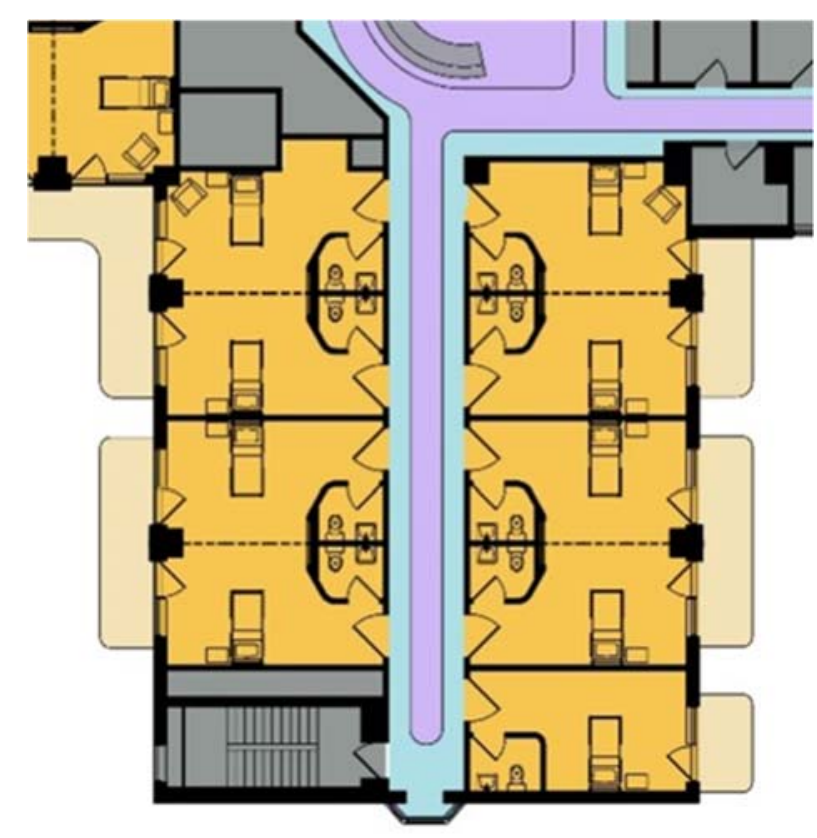

Figure 40. Concept I, Enlarged Floor Plan. By Author 


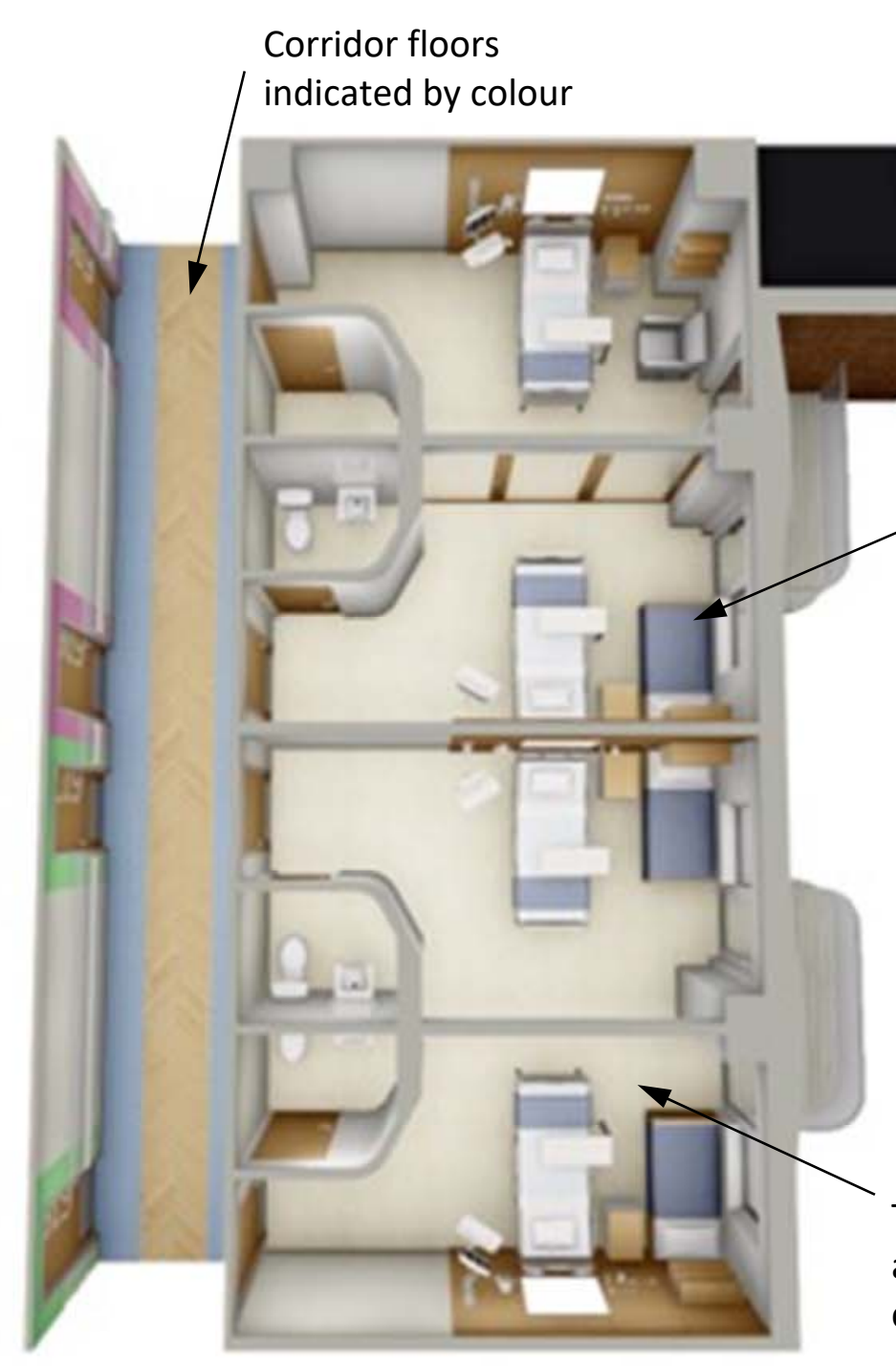

Figure 41. Concept I, Dwelling Rooms. 3D Floor Plan Rendering. By Author

\section{THE DWELLING CONCEPT I}

ndividual room marque colour and signage

Wayfinding corridors floor specific texturized walls

Fixed beds for caregivers

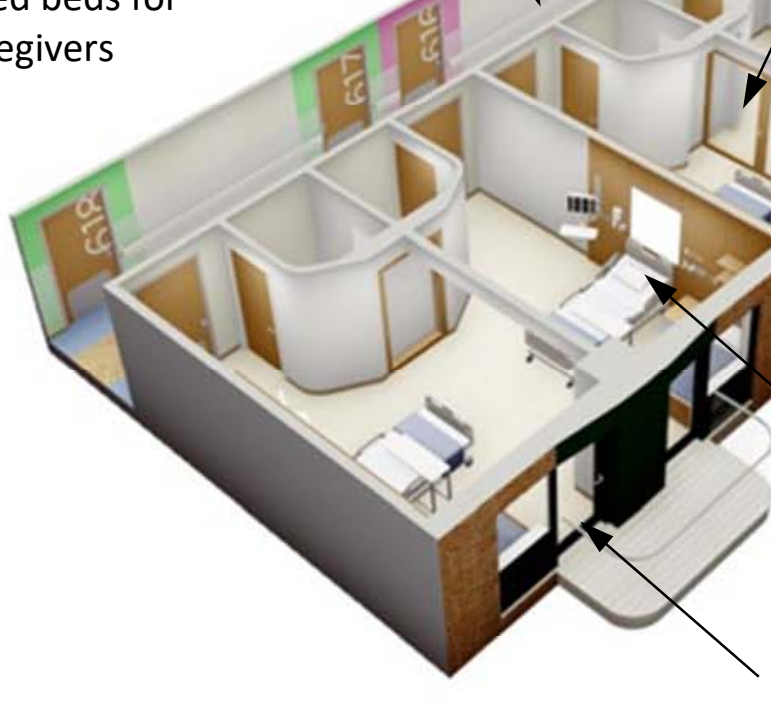

Tandem room occupancy for associative play between child patients
Sliding glass partition to separate rooms for privacy and controlling infectious spread

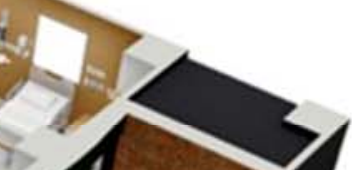
pressurized in case of pandemics

Larger fenestration and operable door with access to a shared balcony
Figure 42. Concept I, Dwelling Room. 3D Isometric Rendering. By Author 


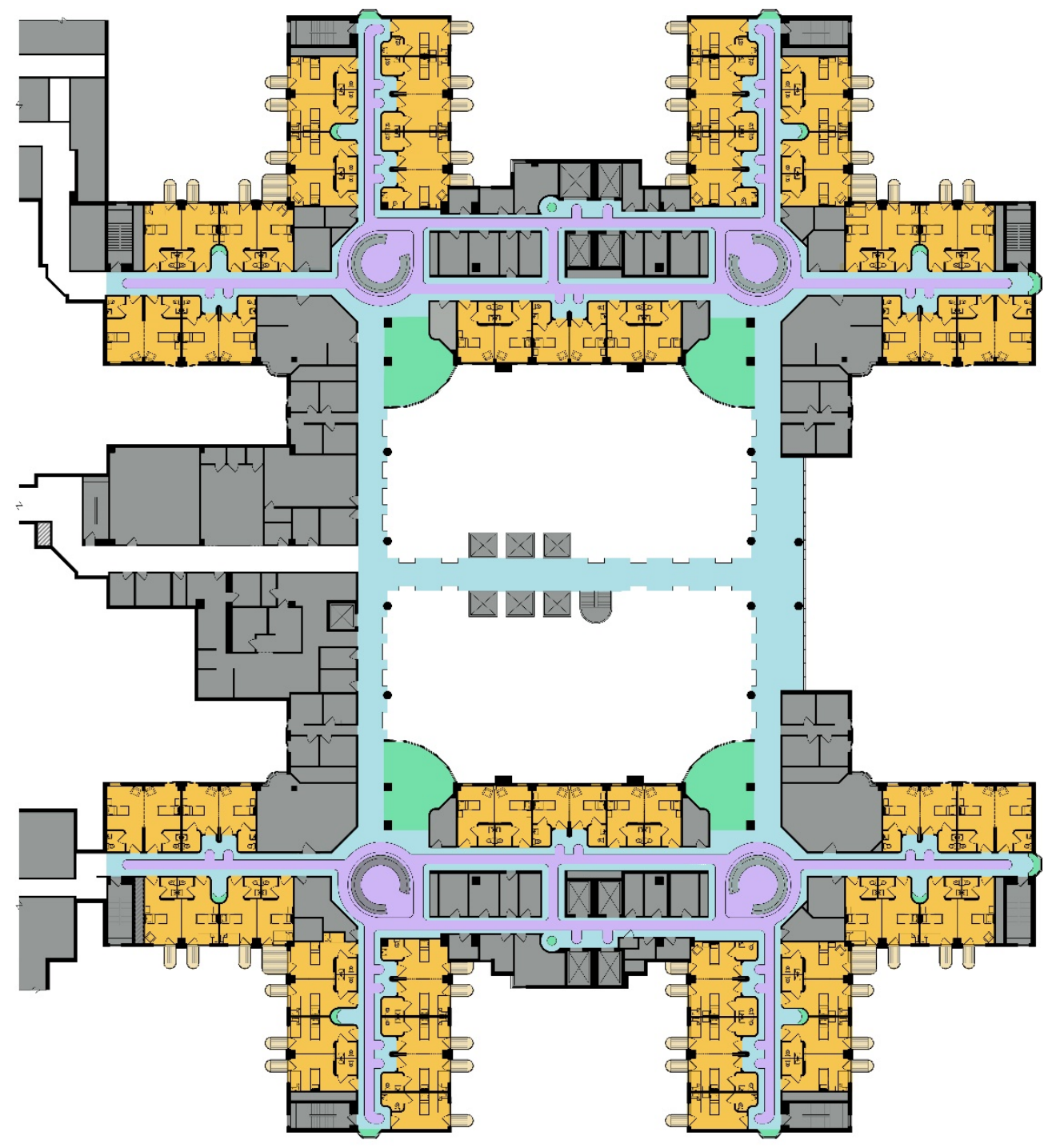

Figure 43. Final Concept Floor Plan. By Author

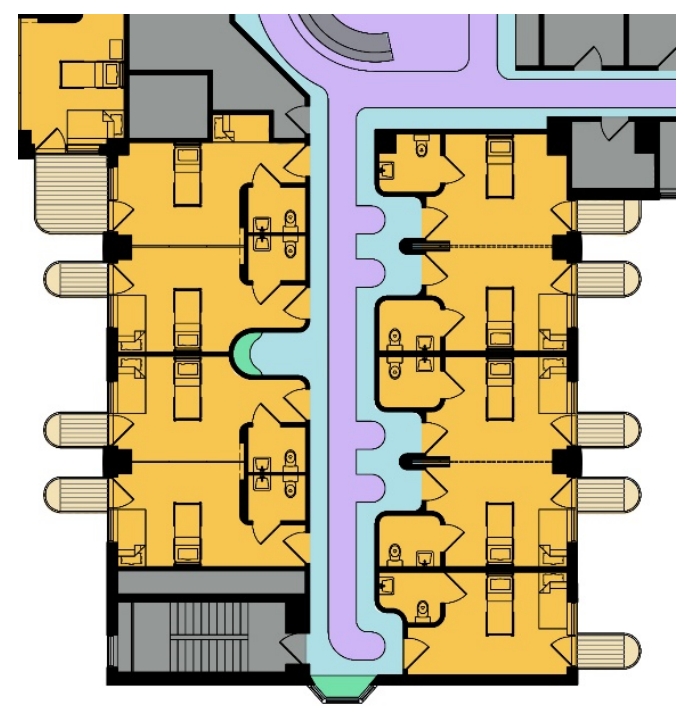

Figure 44. Final Concept Enlarged Floor Plan. By Author 


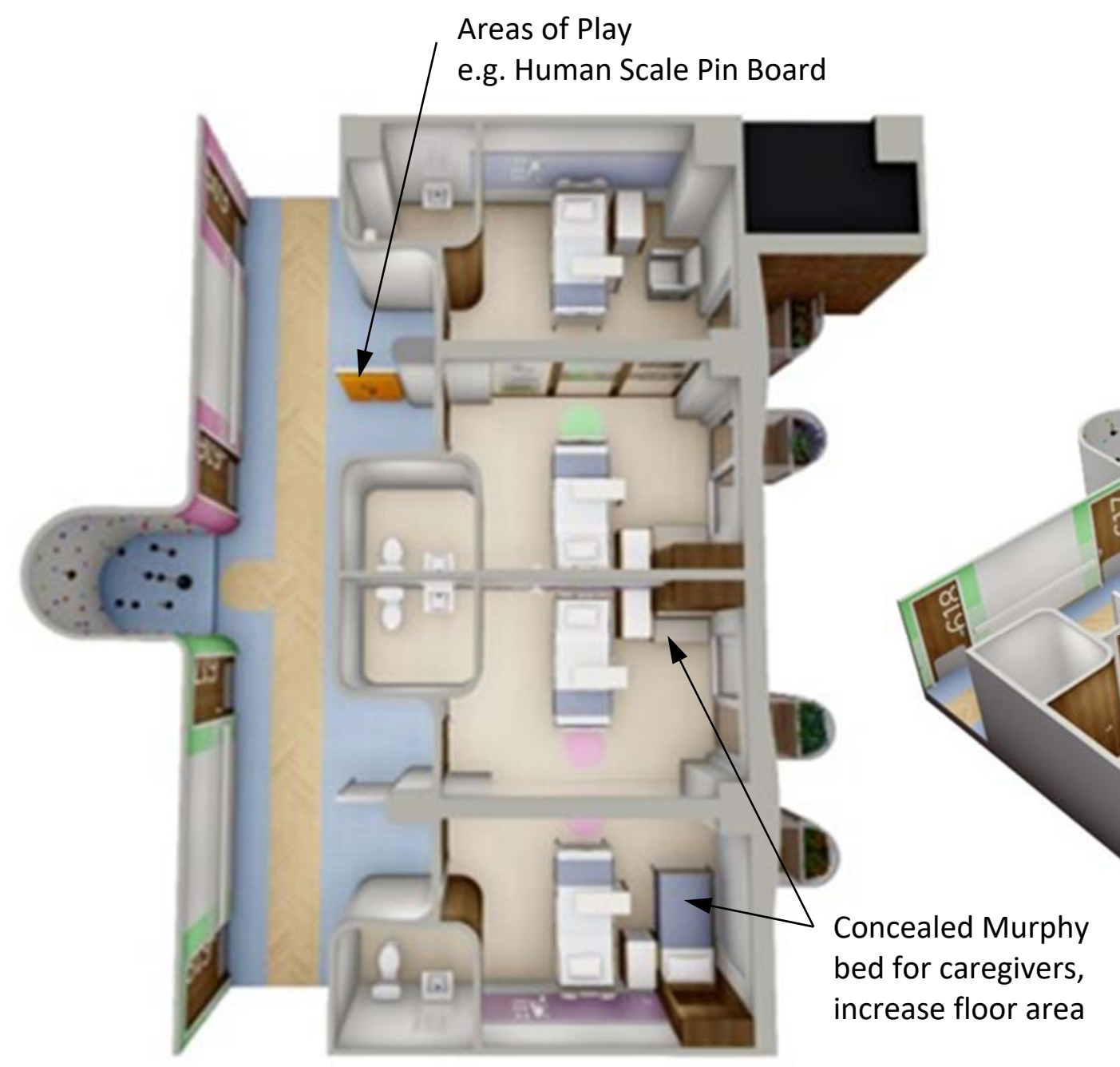

Figure 45. Final Concept, Dwelling Rooms 3D Floor Plan Rendering. By Author

\section{THE DWELLING FINAL DESIGN}

Areas of Play (Examples)

- Rock Climbing

- V.R.

- Painting

/ Smartglass ESG Switchable 


\section{The Streets - Corridors}

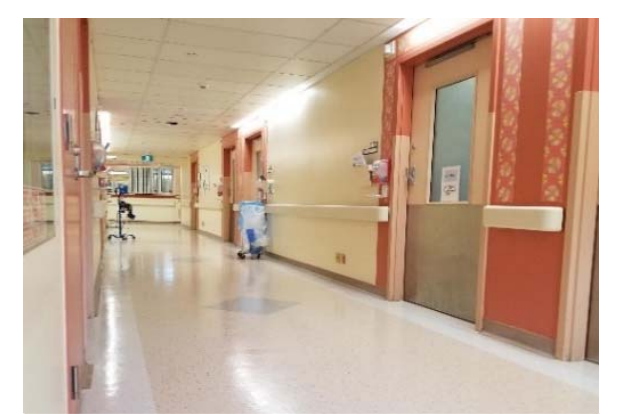

Figure 47. Existing 8-foot-wide corridor. Coloured walls relate to different wards. Image by Author

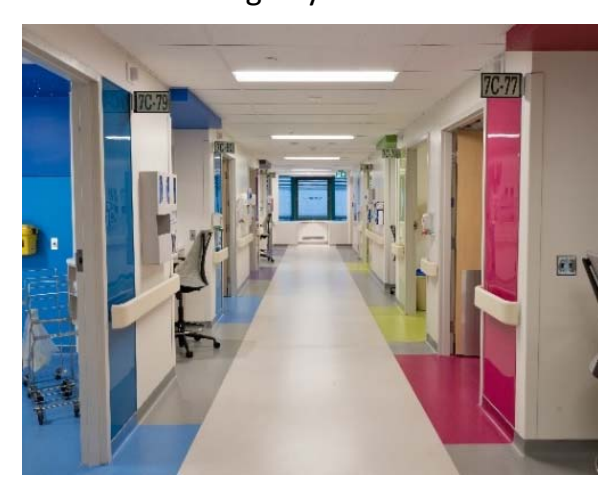

Figure 48. Intermediate care ward 7C corridor. c2017. (C) Parkin Architect
The hospital corridor is treated in this design as the equivalent of the street that connects multiple dwellings forming a community. The street-corridor serves two functions: a place devoted for movement and a place for social interaction. This methodology is relevant to the spatial configuration of modern hospital corridors. The existing corridor has a clear width of $8^{\prime}-0^{\prime \prime}(2450 \mathrm{~m} .-\mathrm{m})$ and a height of $8^{\prime}-0^{\prime \prime}(2450 \mathrm{~mm})$. A continuous handrail at 3'-0" $(914 \mathrm{~mm})$ high borders both walls. The wards are differentiated by wall colour but are otherwise standardized spaces (Figure 47). The design proposal aims to transform the long corridor into an eventful area, persuading patients to leave their rooms and experience a unique journey through a monotonous space.

To supplement the experience of the corridors and facilitate user orientation, wayfinding sensory cues will define patient wards. Wayfinding decisions not only help to remember places but also embody the cognitive and corporeal experience of locating, 


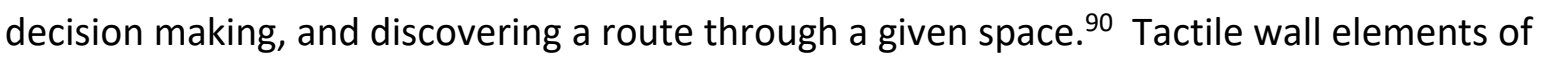
distinctive patterns will be mounted $40^{\prime \prime}(1015 \mathrm{~mm})$ from the floor, a provision that would aid patients with special-needs and the pre-school children. Graphic communication coupled with colour distinctions on both the floors and walls provides visual cues within the built environment (Figure 49). A designated 4'-0" (1220mm) wide "cautionary traffic area" marked on the floors shall be maintained for patient transportation in the event of emergencies, while the remaining width borders act as the sidewalk areas that contribute to increasing the room for play.

The design strategy proposed here defines areas of play along the sidewalk path where one is encouraged to stop and play, meet with others and to socialize. Although small in scale, these event areas are enough for solitude and associative play. Studies show that children use play as a vehicle to work through everyday stresses and anxieties. There is research that suggests that children use solitary play to foster emotional control. ${ }^{91}$ These

${ }^{90}$ Paul A. Symonds, Valeria Lo Lacono, David H.K. Brown. 2017. "Exploring an Absent Presence: Wayfinding as an Embodied Sociocultural Experience." Sociological Research Online. P.9.

91 Hewes, Jane. 2014. "Seeking Balance in Motion: The Role of Spontaneous Free Play in Promoting Social and Emotional Health in Early Childhood Care and Education." Children. P.288. 
functional spaces allow for the occurrence of random events but also a space for self-

reflection and independent play. While the dwelling space is limited to certain activities, these sidewalk spaces offer another option for free play. The proposal does not change the current structure of the corridor, but rather introduces areas where social functions unfold.

In this way, both the functionality and the circulation of the corridor are improved.
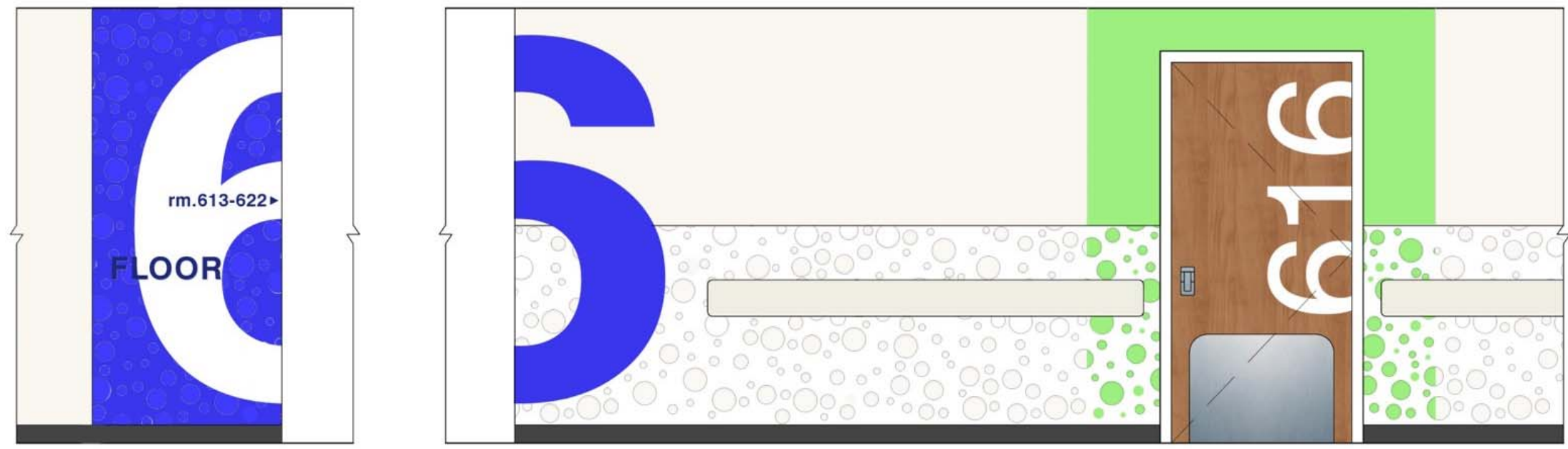

Figure 49. Corridor Elevation, wayfinding Concept. By Author 
Every patient floor has a designated enclosed family playroom (Figure 50). The room overlooks the expanse of the Atrium. However, based on personal experience, I am aware of the fact that the patient room is not accessible throughout the entire day (24 hours). As the hospital is currently following COVID-19 protocols, the designated Family Spaces are available by appointment only. Since these spaces for therapeutic programming, and child and adolescent development remain inaccessible, one can only speculate that the child convalescent remain in their rooms during the length of the pandemic - being a prisoner within an institution for healing which turns out to work as a space of isolation not unlike to places of criminal rehabilitation. The design strategy is to remove the boundaries that inhibit play. These spaces of healthcare should invite unstructured freedom to play throughout the day. Jane Hewes mentions that "young children routinely challenge the rules of play, for example climbing up the slide rather than sliding down it is a playful approach which breaks the rules of how young children are expected to use slides." ${ }^{92}$ Children are often discovering

\footnotetext{
92 Ibid, p.284
} 
environments at their own pace, this interactive space should be free of externally imposed

rules where they can explore their imaginations and push their limits for risk taking.
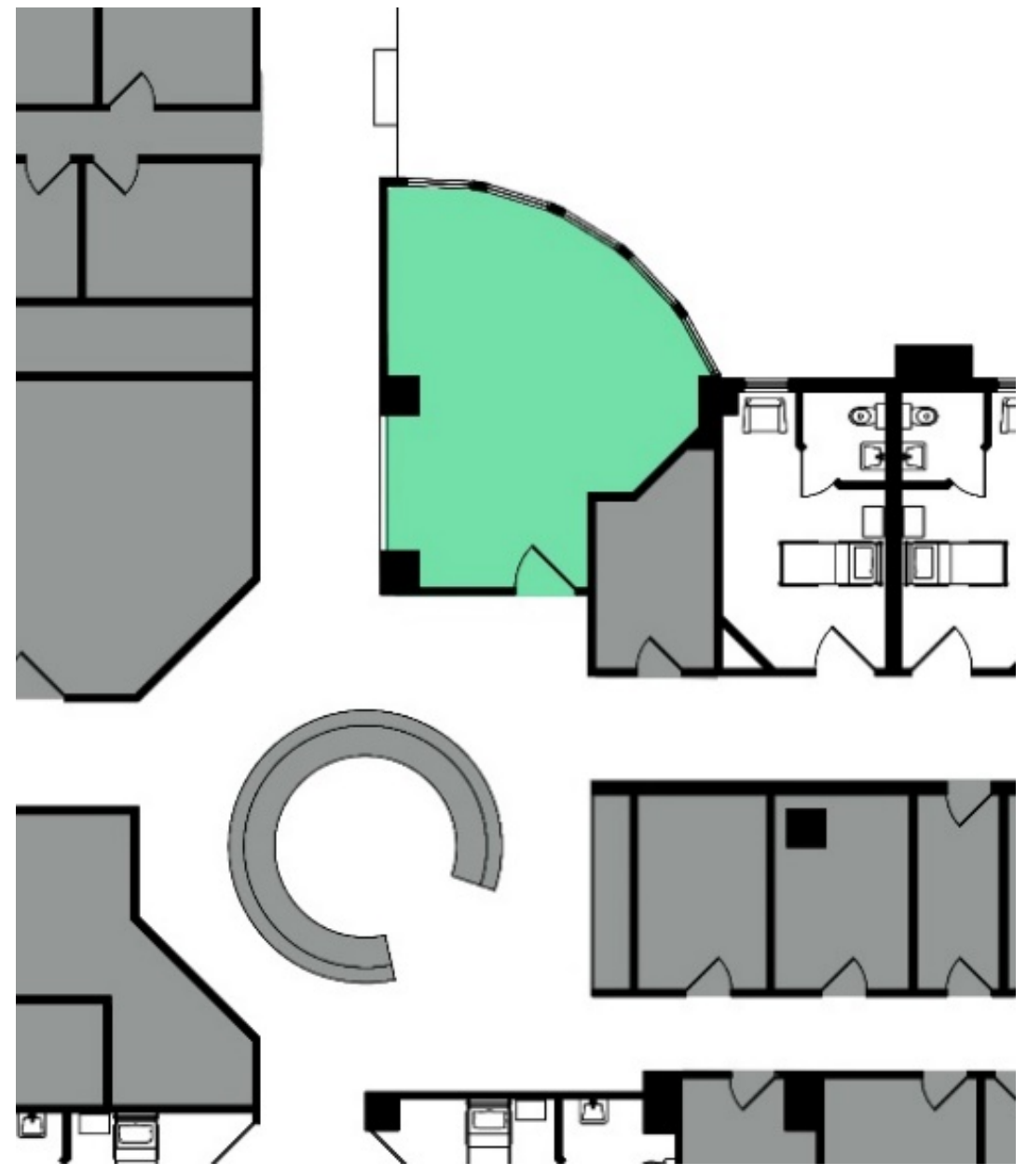

Figure 50. Existing reserved enclosed play area. By Author 


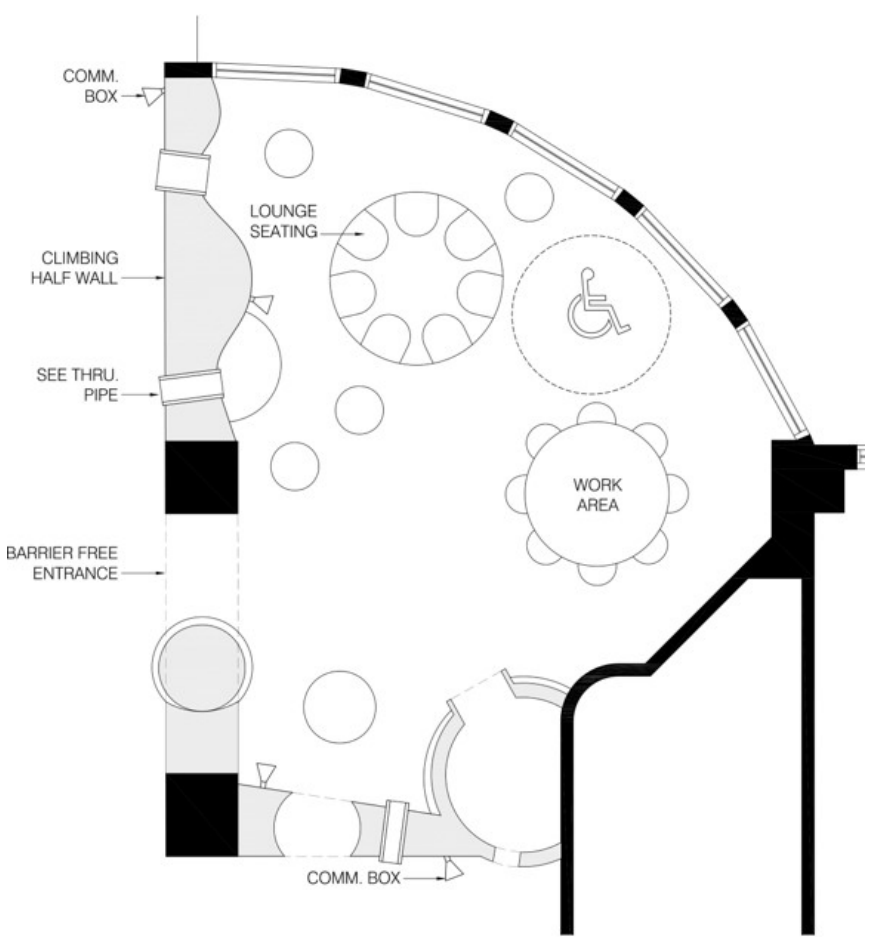

Figure 51. Climbscapes Floor Plan. Exploration and Risk Taking By Author

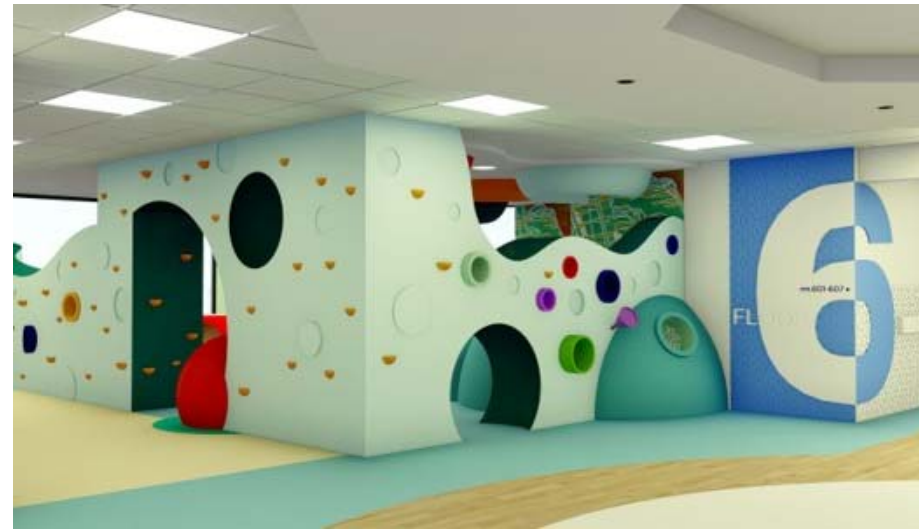

Figure 52. Image 1, Climbscapes. Exploration and Risk Taking By Author

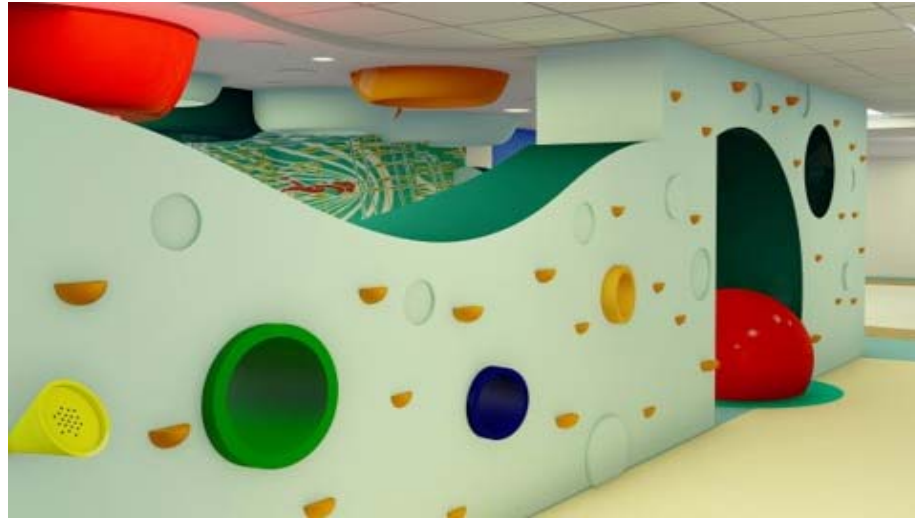

Figure 53. Image 2, Climbscapes. Exploration and Risk Taking By Author

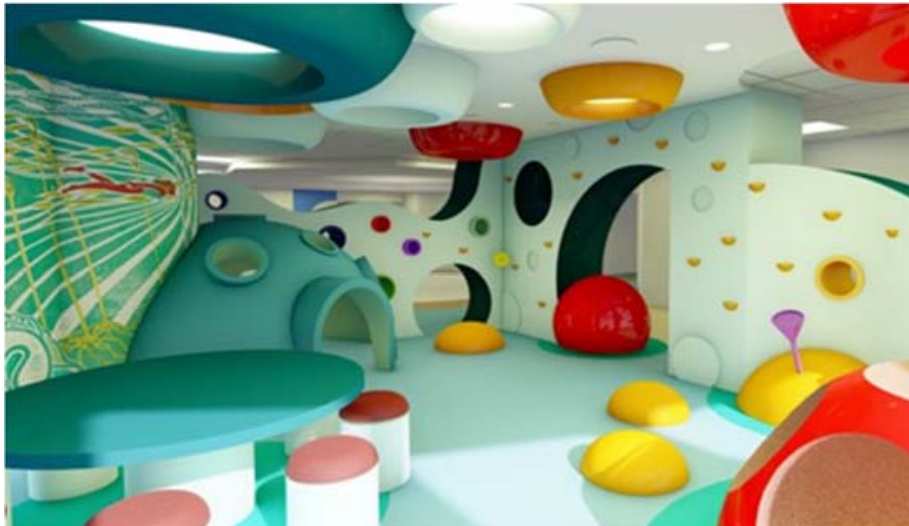

Figure 54. Image 3

Climbscapes. Exploration and Risk Taking

By Author 


\section{The Courtyard}

While the hospital is located centrally in downtown Toronto, the proximity to an

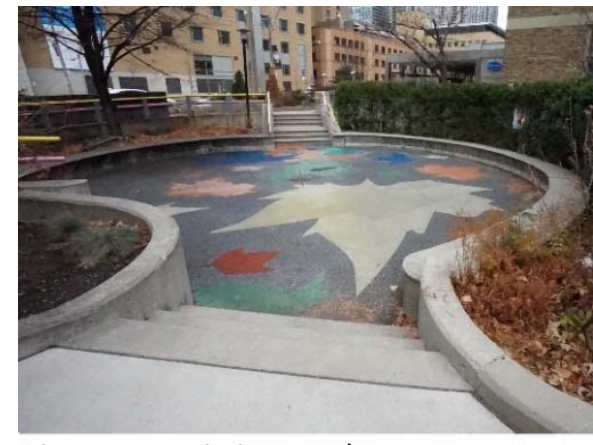

Figure 55. Existing outdoor green space. Nov 24, 2020. By Author.

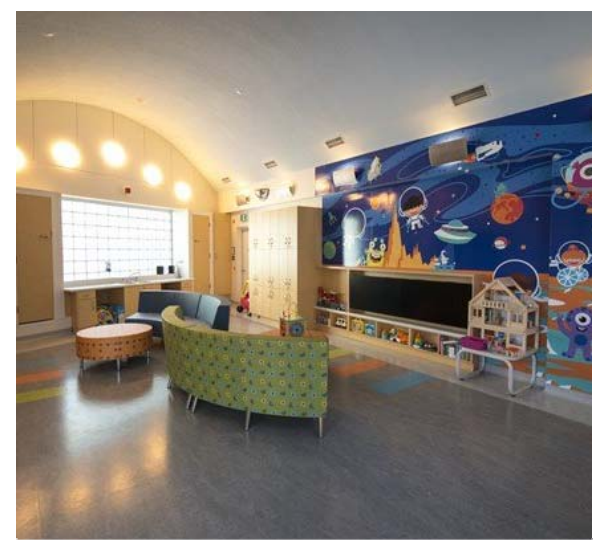

Figure 56. Existing Samsung Space. (C) The Hospital for Sick Children (SickKids) outdoor green space for patient use is inadequate and distant. Currently, city authorities

have not sanctioned minimum standards or guidelines for green spaces in healthcare institutions. Nonetheless, there is an outdoor space at the corner of University Avenue and Gerrard Street, which is underutilized and disconnected from the institution (Figure 55). This concrete park is located next to University Avenue, a busy main road that connects the landmark buildings along the Discovery District. This area is neglected as there are no distinguishable entrance points to the hospital. A secondary area called the Samsung ${ }^{\mathrm{TM}}$ Space

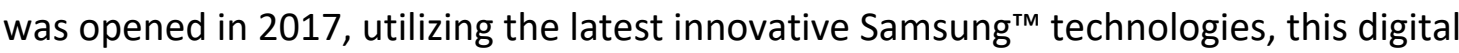
environment provides patients and their families a therapeutic recreation room as well as an outdoor patio space. The seasonally operated and weather permitting patio is furnished with seating arrangements, potted plants, a small provisional slide, and accompanying rooftop units - inconducive for a place for healing. This is the only environment that serves as an outdoor area within the hospital. Instructions provided by the SickKids website is lamentable, "only one elevator goes all the way to the Samsung ${ }^{\mathrm{TM}}$ Space. To find us, take any 
of the Atrium elevators up to the 8th floor, and then take the middle elevator to the 9th

floor!"93 While these instructions seem enthusiastic, it does not factor in how inconvenient

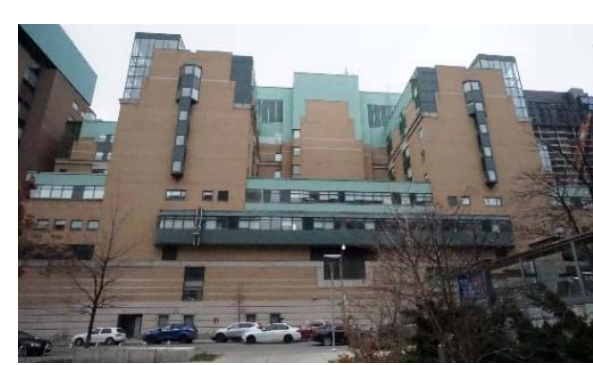

Figure 57. Elm Street. South Elevation. Nov 24, 2020. By Author.

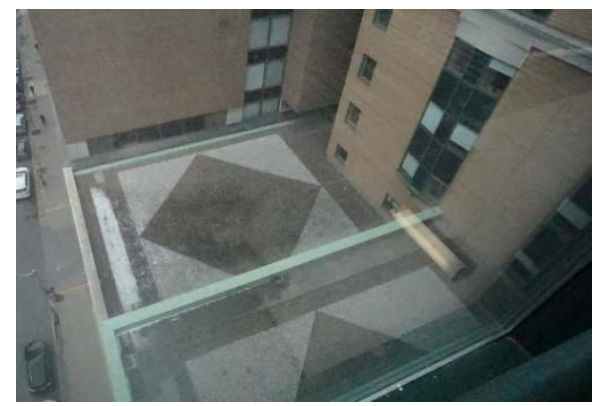

Figure 58. Existing rooftop condition. Nov 24, 2020. By Author. it is for patients to venture to this space. They must take it upon themselves to leave the

privacy of their room and ward to use the public elevator to the eighth floor and transition to

another elevator to get to the ninth floor, occasionally with an IV pole in tow. To some,

crossing the threshold from the private to the public realm is not an issue, whereas other

children may see it as a barrier depending on their physical and psychological conditions.

The final design strategy unifies all the patient usage areas and creates an optimized

private environment for the hospital community. The octothorp floor plan creates unfamiliar

spaces or 'voids' which have the potential to supplement the designated function of a place

for healing of which they are holistically a part of. The Atrium and the main entrance are

positioned in the central and east voids. The current spaces are neglected rooftops areas:

three facing north and three facing south. The initial design of the Atrium provides

unobstructed views from the patient rooms to the outside environment, however the visual

93 The Hospital for Sick Children. 2021. Family Spaces. March. Accessed February 18, 2021. 
aesthetic remained undeveloped and views towards the city remained obscured. This proposed design will focus on the southern-facing centre courtyard. The other complementary courtyards will have the same systematic design approach.

The courtyard is an environment that will develop an emotional bond between the hospital and the community. The intention is to provide a comfortable space for physical and mental therapeutic and restorative healing and to foster a sense of normalcy to patients and their families going through difficult times. It is a two-storey open garden and play area secluded from the main entrance Atrium and can be utilized by working staff, patients, and their caregivers. The Atrium is an acclaimed distinction of Toronto architecture and is also internationally recognized. Keeping the architecture light and airy would not detract from the historic sensibility of the existing architecture that surround three sides of the courtyard space. As seen from Elm Street, the curved translucent façade partially overhangs past the existing brick face of existing architecture. This subtle shift entices curiosity and intrigue from the streetscape (Figure 65, 66). 
The proposal of the courtyard will incorporate different activities that inspire the unstructured and imaginative encounters of outdoor play, within an indoor environment. The open space encourages imaginative play activities as well as areas of solitude for any age group. Various areas for climbing, exploring, reading, meditating, observing, and live performances - to name a few - are significant for a patient's regenerative healing and cognitive development. Moreover, it offers the individual the security and safety that they and their families require to participate in shared playful activities. The courtyard has the unique opportunity to attract patients from all wards on all floor levels to participate in unified associative play. This is essential to the individual as this reestablishes autonomy, personal identity, and sense of belonging within the healthcare institution.

Only accessible from the $5^{\text {th }}$ and $6^{\text {th }}$ floors, the $7^{\text {th }}$ and $8^{\text {th }}$ floors will have balcony views into the courtyard space. Every patient has a direct connection from their rooms without any restrictions. The courtyard utilizes different surfaces, textures and natural raw materials offers the individuals an opportunity to discover and build up their own play world by employing the different elements within the space. The hard surfaces of the concrete structure are balanced by the soft surfaces of wood and vegetation - real and artificial. The 
walking pathways are fragmented with embedded hexagon tiles of differing colours and textures allowing for spontaneous games of jumping and spatial discovery. Three light and sound well towers penetrate through the roof and funnel natural daylight at different moments throughout the day. Each tower will be cladded on the interior and exterior with natural non-hypoallergenic wood species. The essence of the natural wood off-gassing immerses the courtyard with a forest-like aroma. Within the wells, one can experience the interplay between light and shadow and the cavernous echo within the space. Selective niches are pierced throughout allowing external observers an alternative experiential perspective (Figure 84, 85, 86).

As previously mentioned, the courtyard is an enclosed space mitigating any abundant noise pollution from the street and the city. The ventilation system will be a balance between natural fresh air and mechanical air circulation. Climate control, temperature, relative humidity, and fresh air circulation will be monitored and automated to minimize the carbon footprint of these courtyard spaces. A four-storey curtain wall system maximizes the southerly sun exposure, while an outdoor courtyard permits views towards the city. This courtyard floats away from the main building a symbolic sense of detachment from the 
hospital, offering the patient a glimmer of hope that recovery is attainable. An inspirational living wall of various vegetation will blanket the existing brick façade. Rainwater from the roof will be collected and drained down through the living wall into storage cisterns and then recirculated for irrigation to the trees and vegetation distributed throughout. In the event for pruning and care, grass shall be kept artificial to reduce noise pollution from concurring lawn maintenance.

The courtyard proposal is an innate connection with nature that the hospital desires within the downtown core of Toronto. The physiological relaxation from touching wood or grass beneath the feet, to the natural aromas from plants and wood materials to the sounds emanating from the social activities and live performances are indicative of restorative healing. Observing or partaking in these activities releases happiness chemicals in the brain all of which reduces stress, improves cognitive function and creativity, and improves our well-being. 


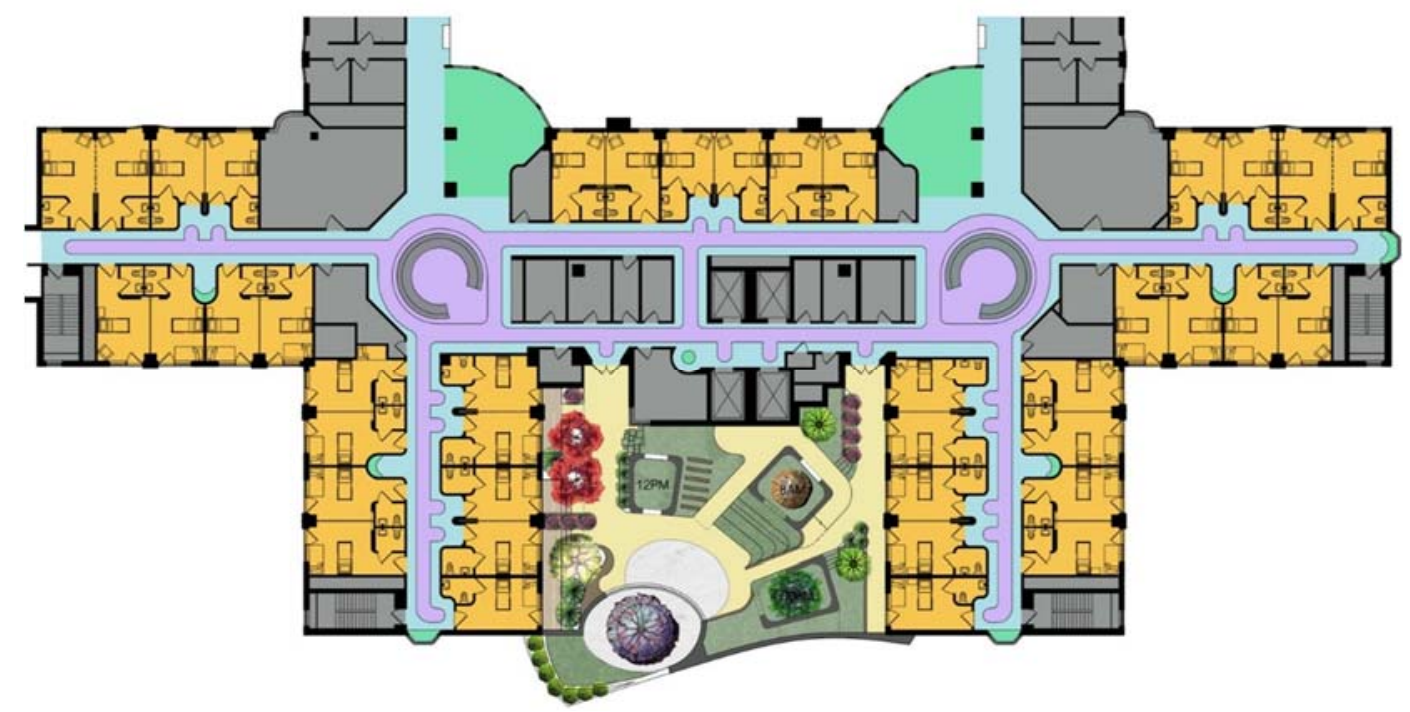

Figure 59. Private Courtyard, accessible from fifth floor. By Author

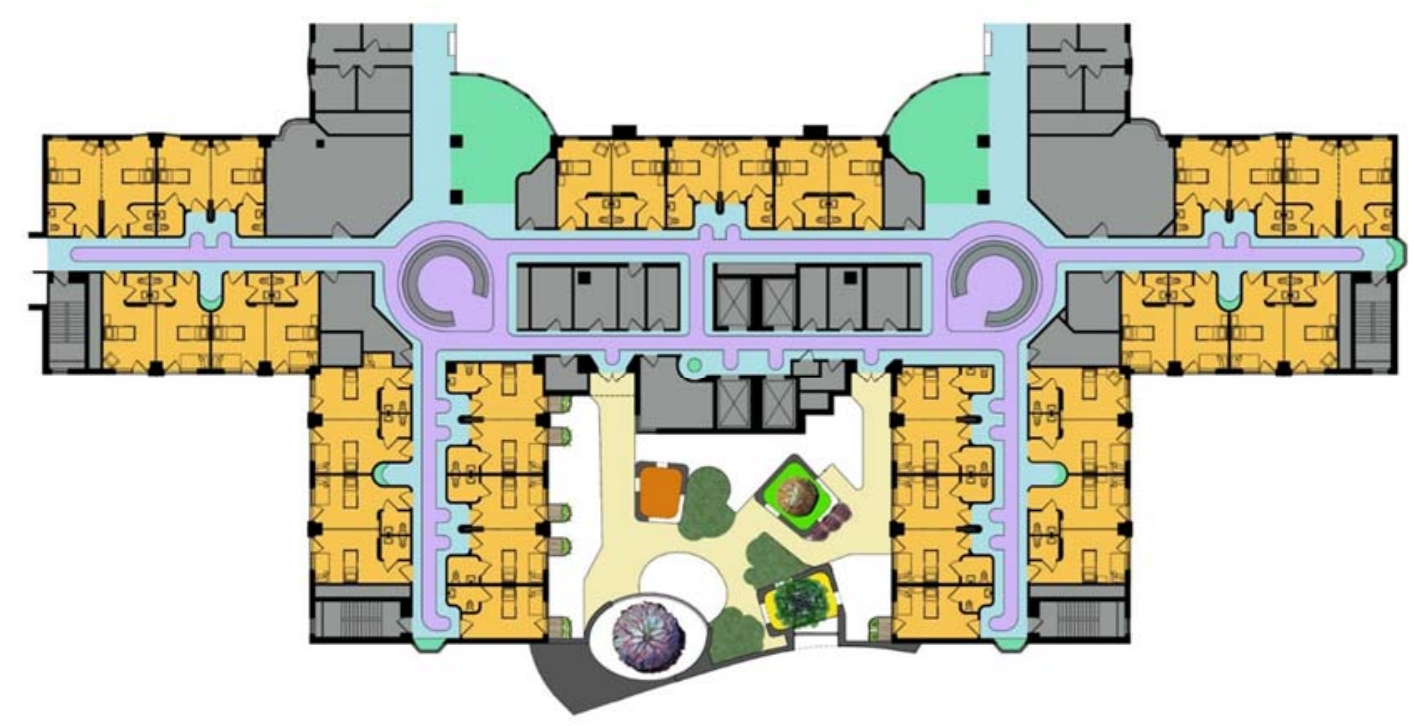

Figure 60. Private Courtyard, accessible from sixth floor. By Author 


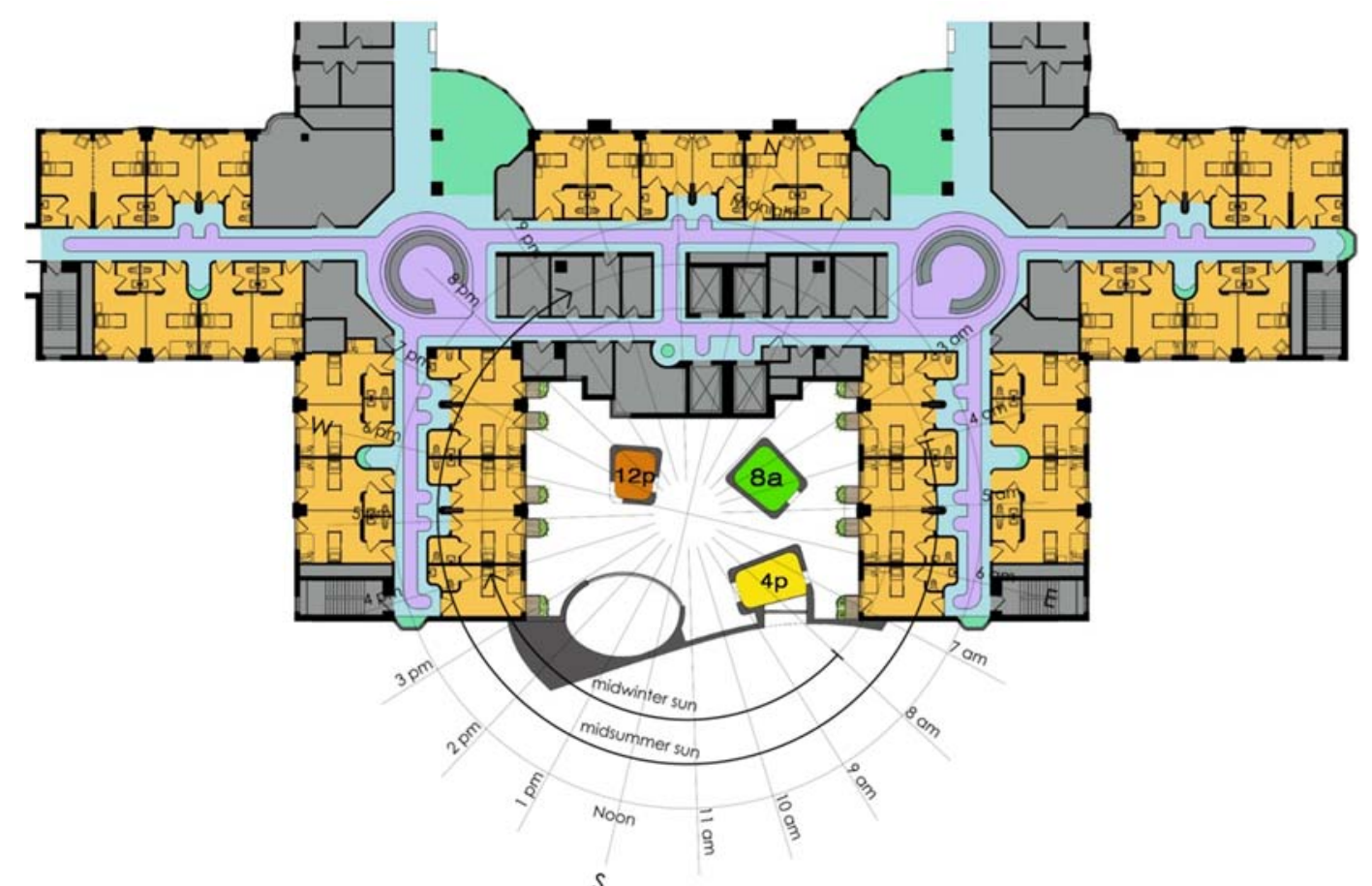

Figure 61. Private Courtyard, upper floors. Superimposed sun-path diagram. By Author

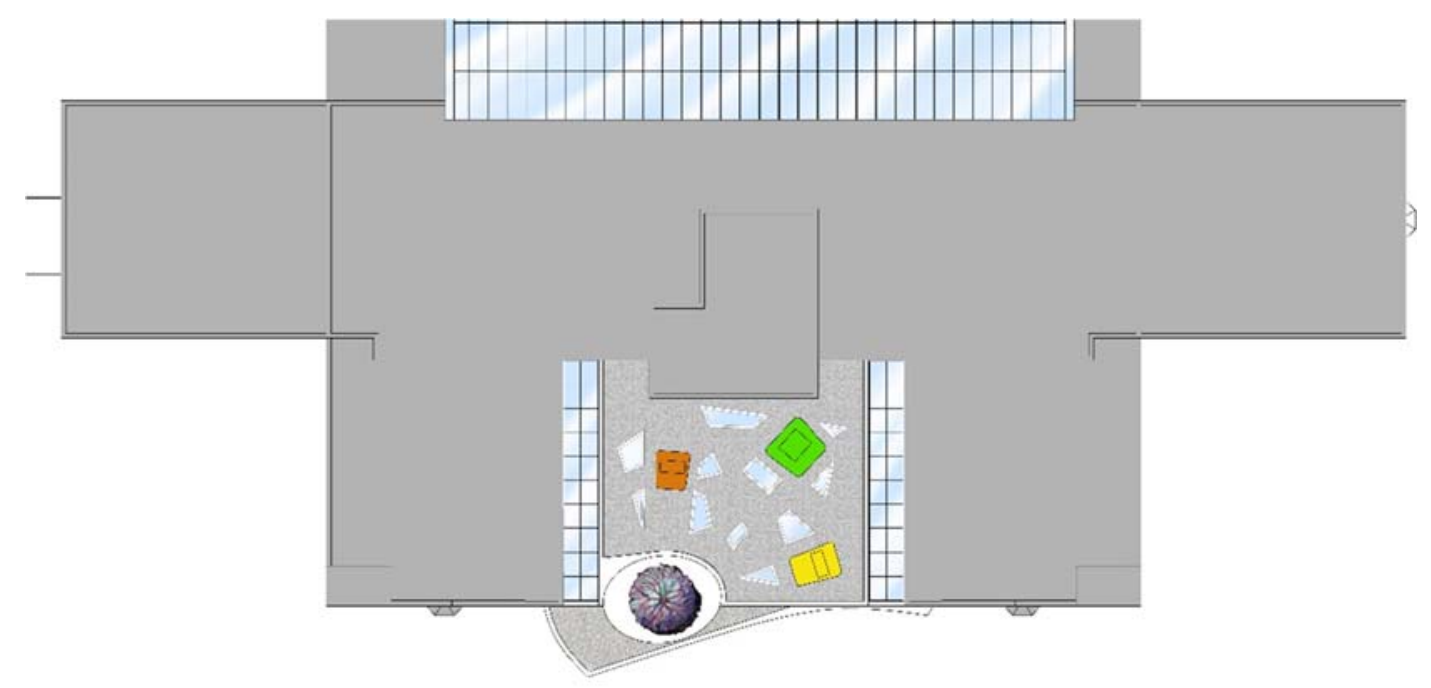

Figure 62. Proposed Rooftop. By Author 


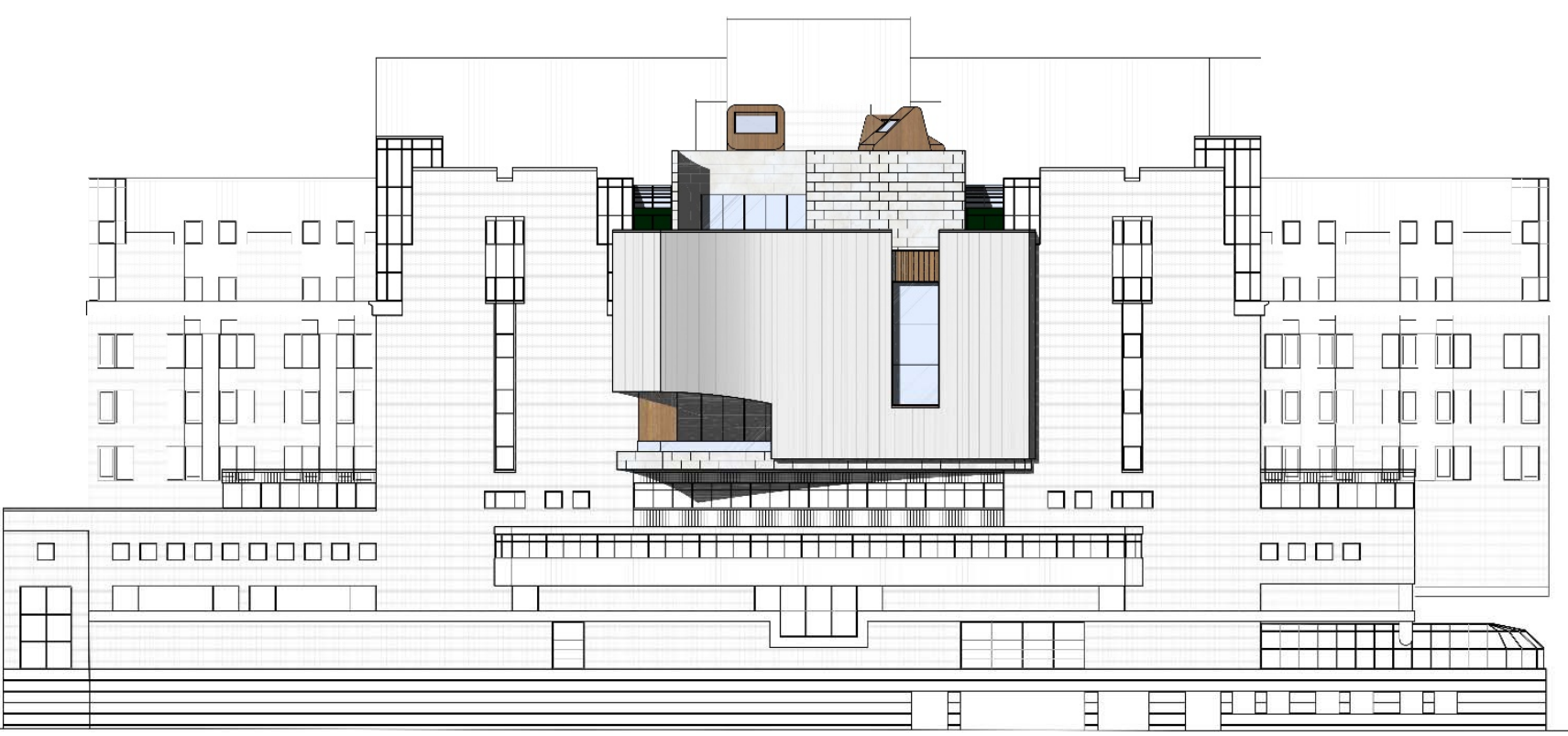

Figure 63. Proposed South Elevation. By Author

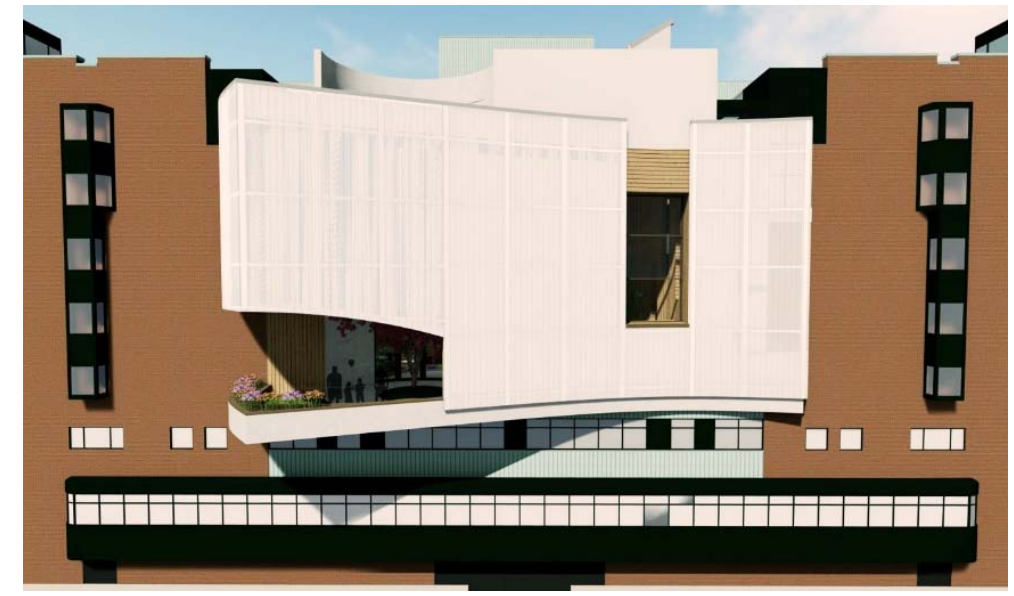

Figure 64. Proposed South Elevation, coloured rendering. By Author 


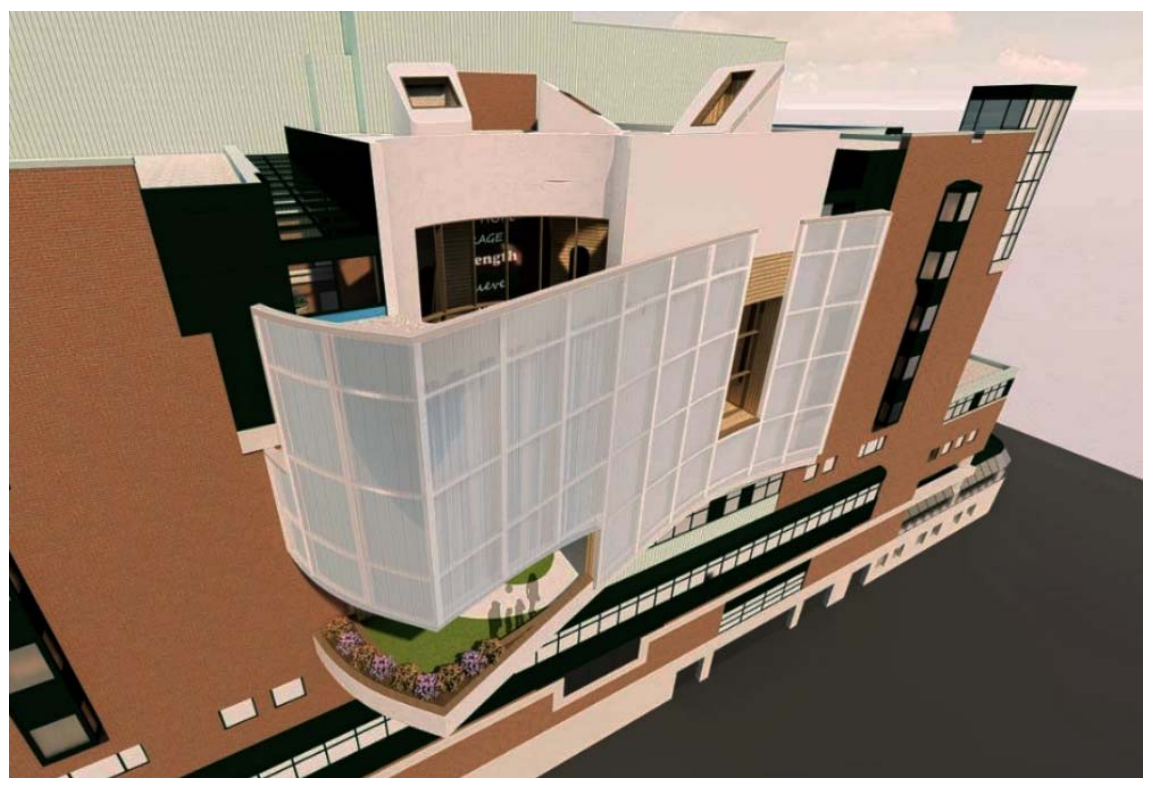

Figure 65. Exterior Isometric Rendering By Author

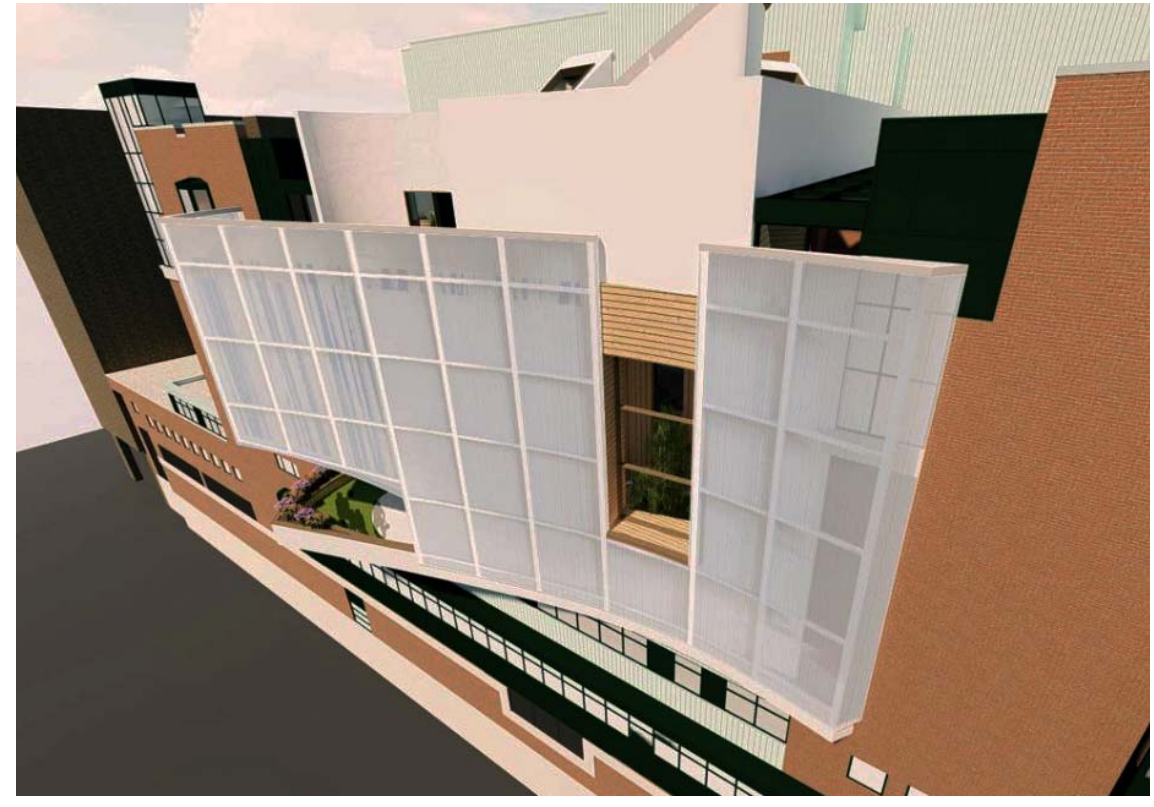

Figure 66. Exterior Isometric Rendering By Author 


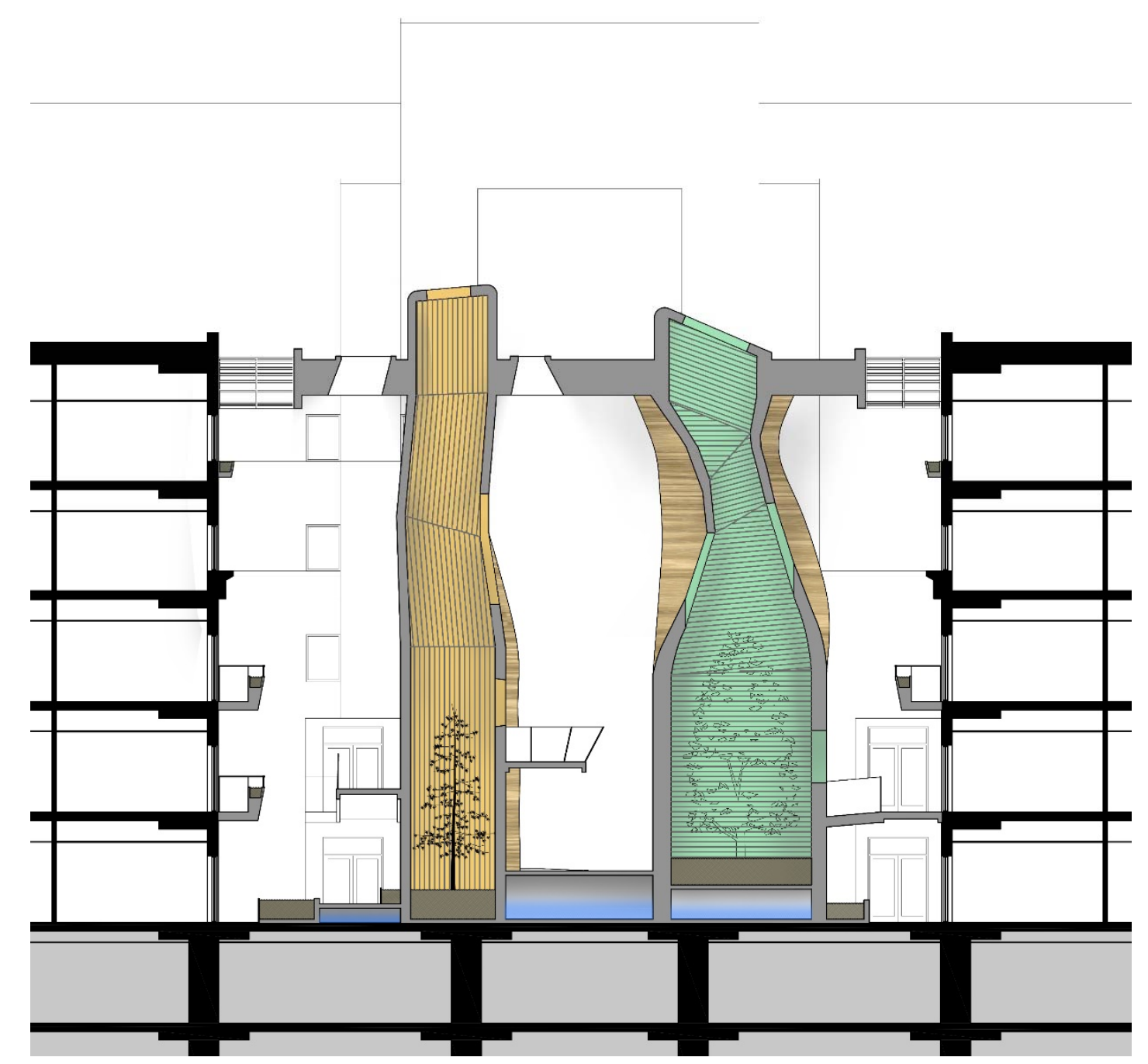

Figure 67. Courtyard, West to East Building Section. By Author 


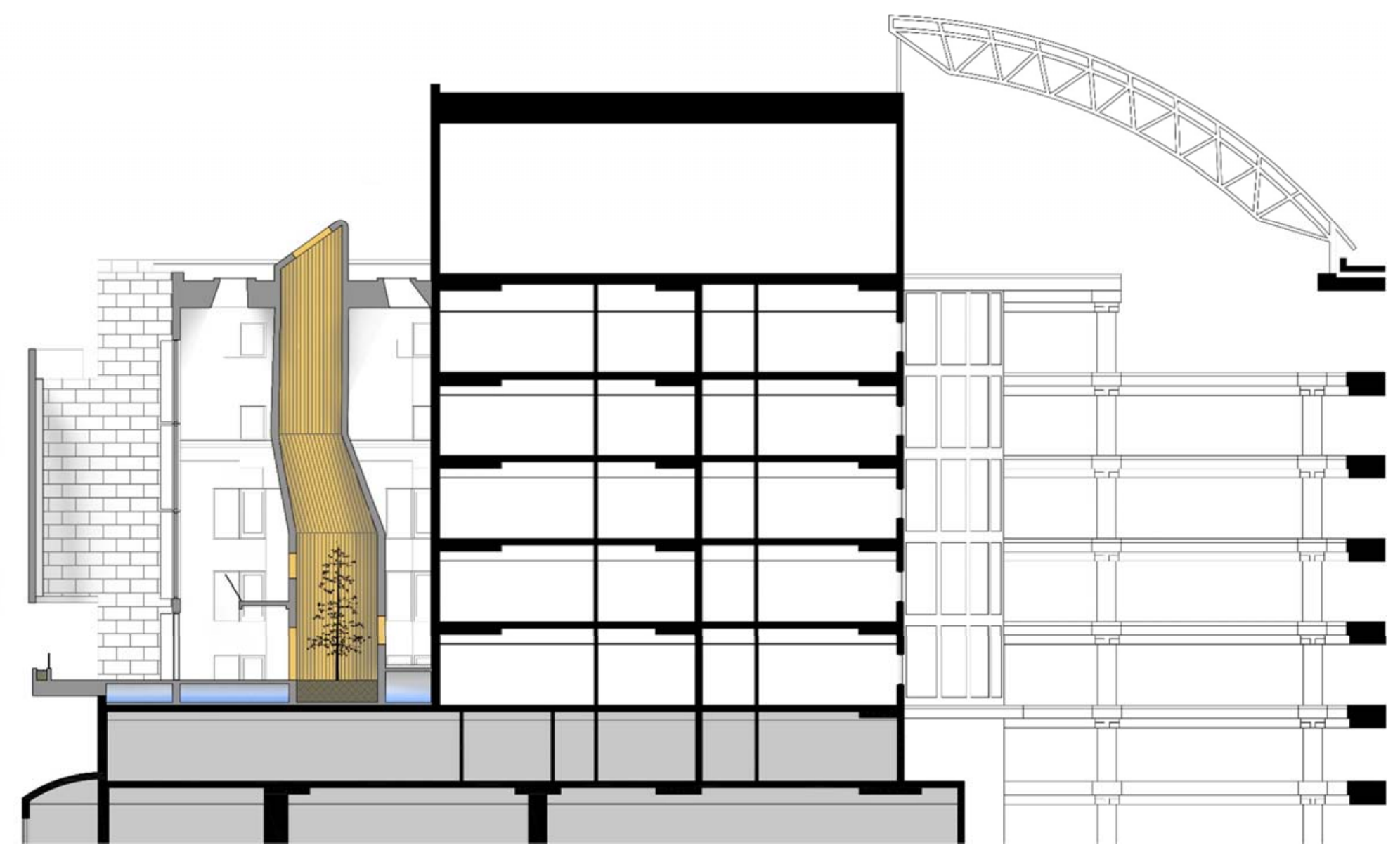

Figure 68. Courtyard, South to North Building Section. By Author 


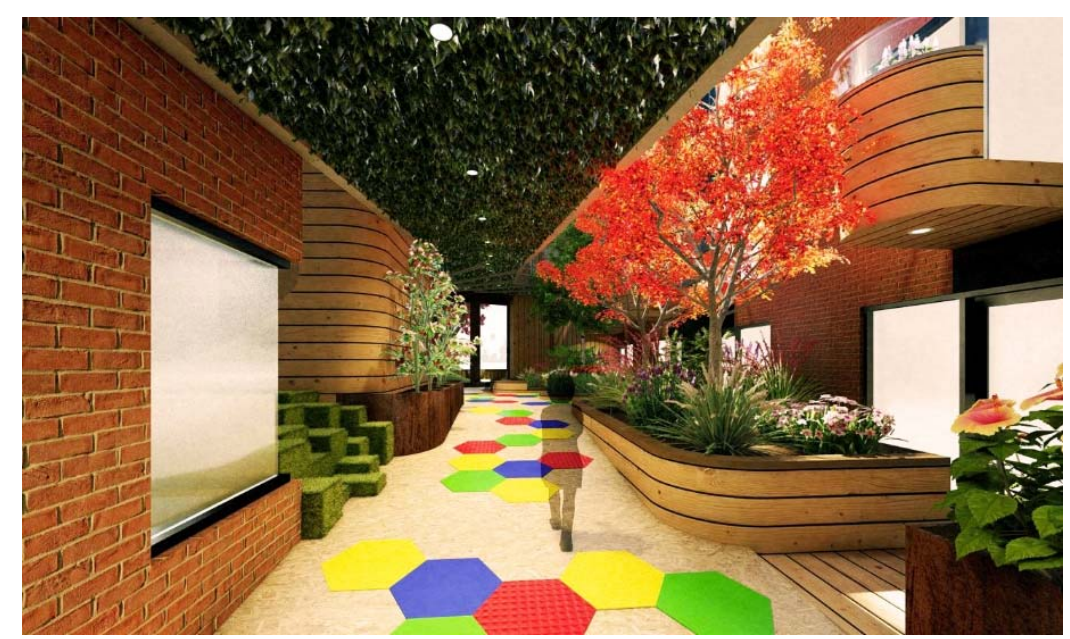

Figure 69. Entering Interior Courtyard, $5^{\text {th }}$ Floor By Author

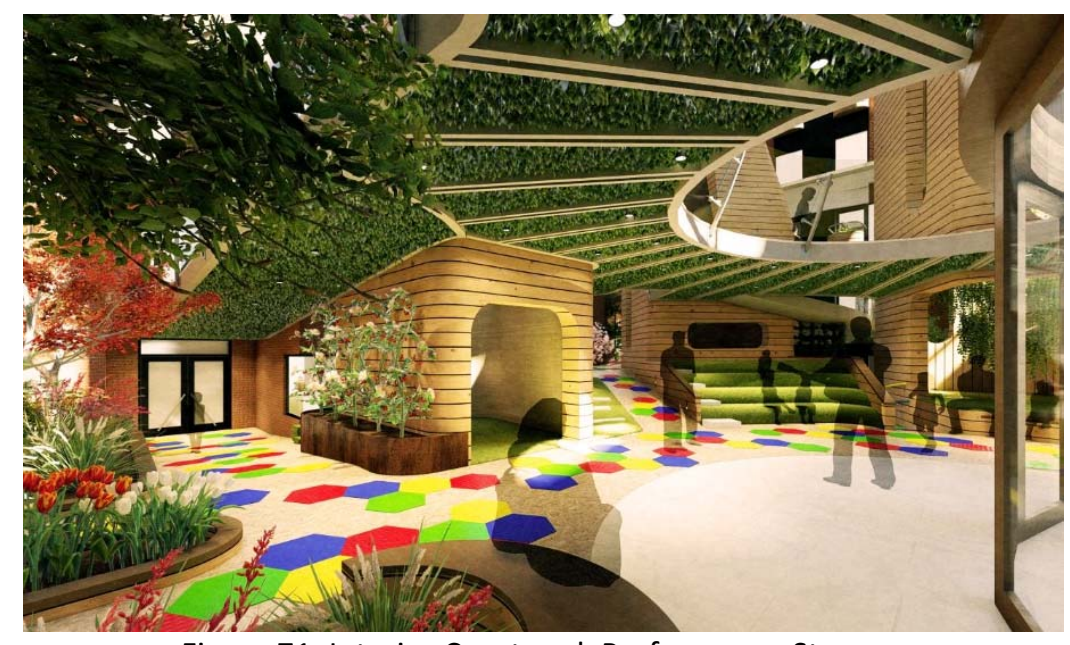

Figure 71. Interior Courtyard, Performance Stage.

By Author

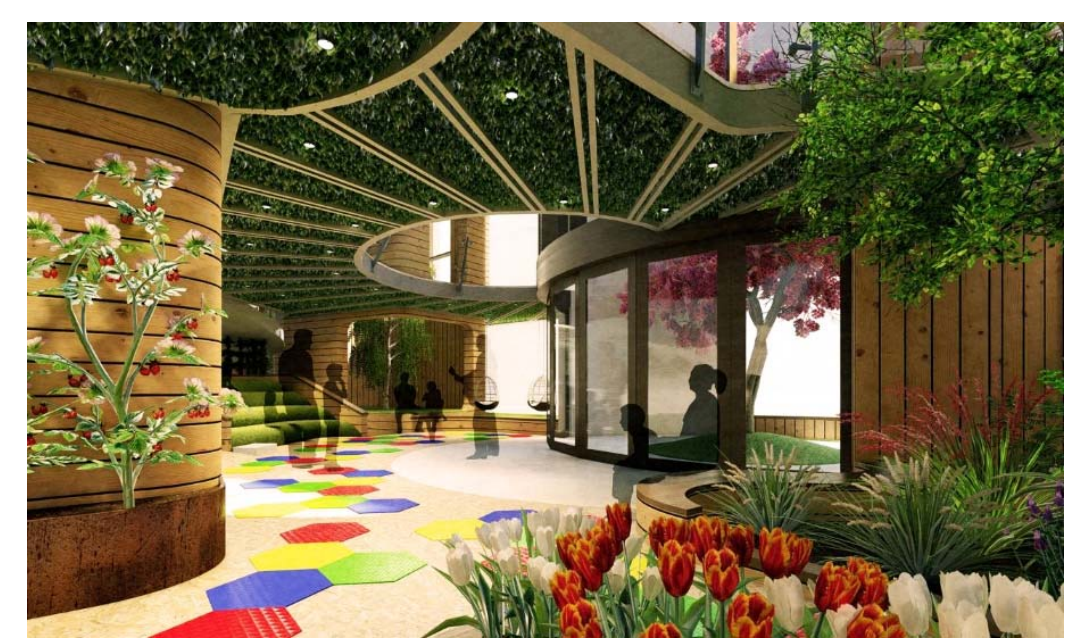

Figure 70. Interior Courtyard, Performance Stage. By Author

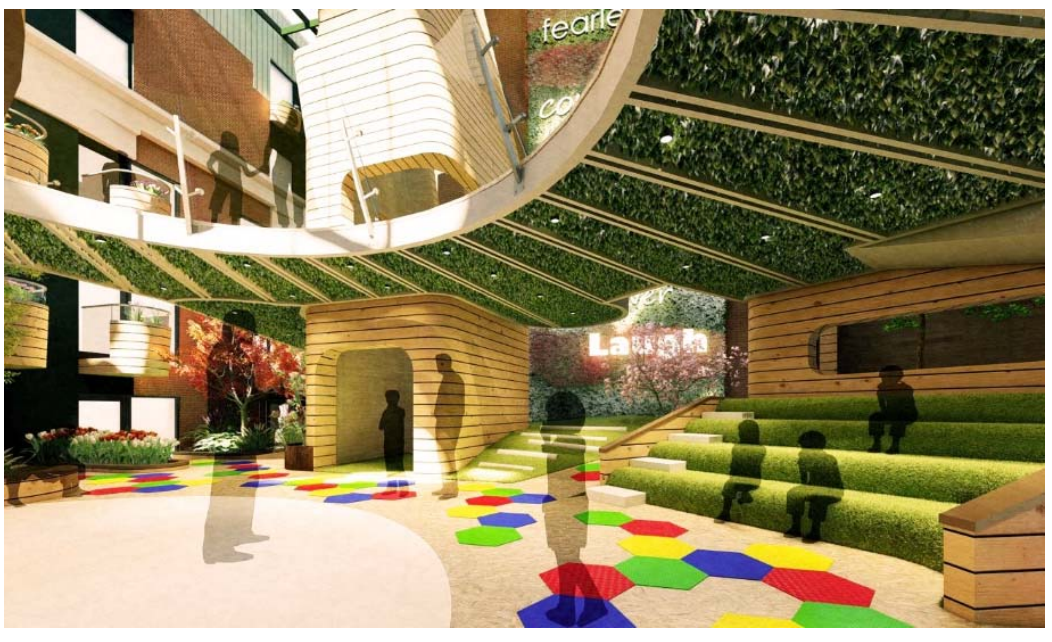

Figure 72. Interior Courtyard, Performance Stage. By Author 


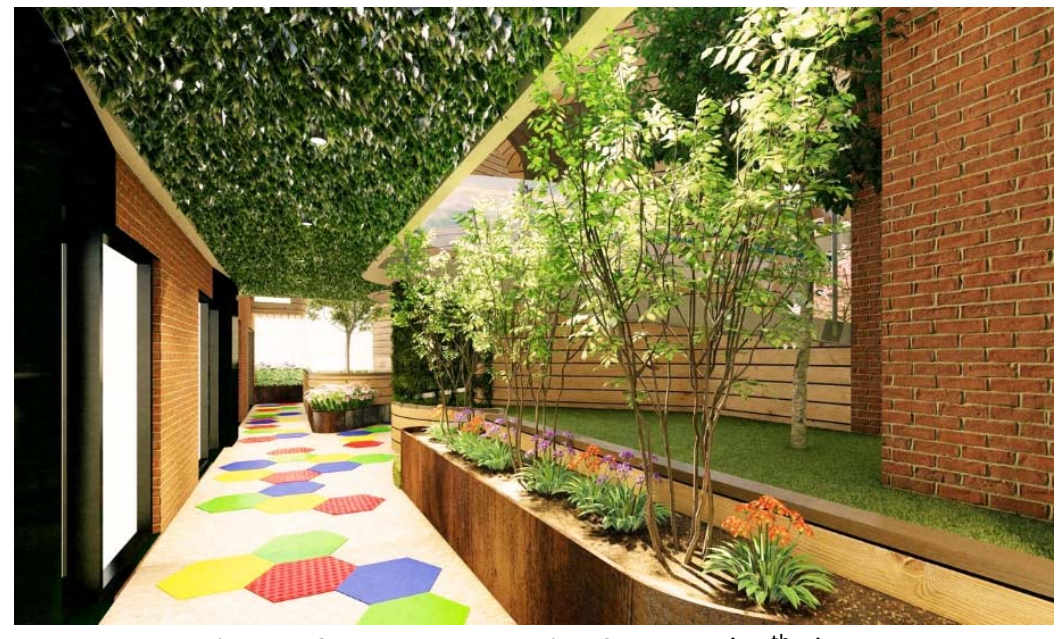

Figure 73. Entrance Interior Courtyard, $5^{\text {th }}$ Floor. By Author

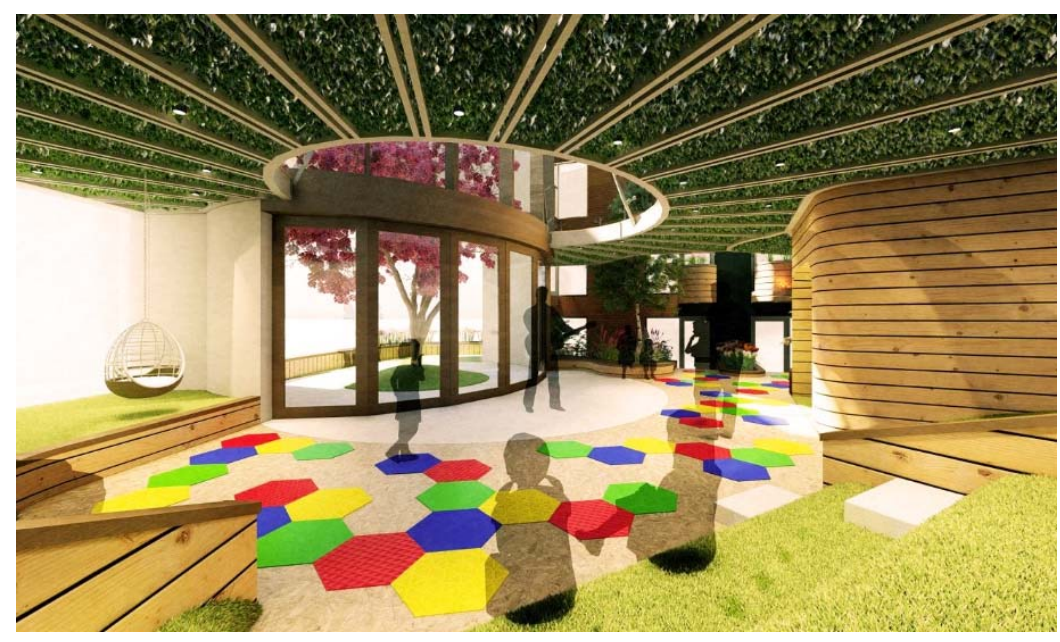

Figure 75. Interior Courtyard, Performance Stage. By Author

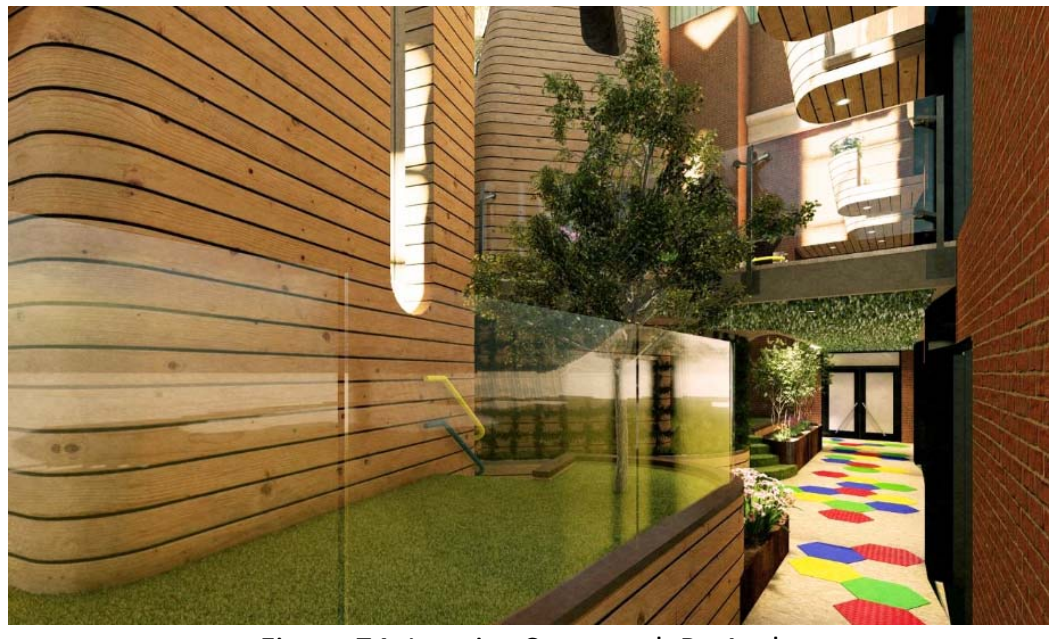

Figure 74. Interior Courtyard. By Author

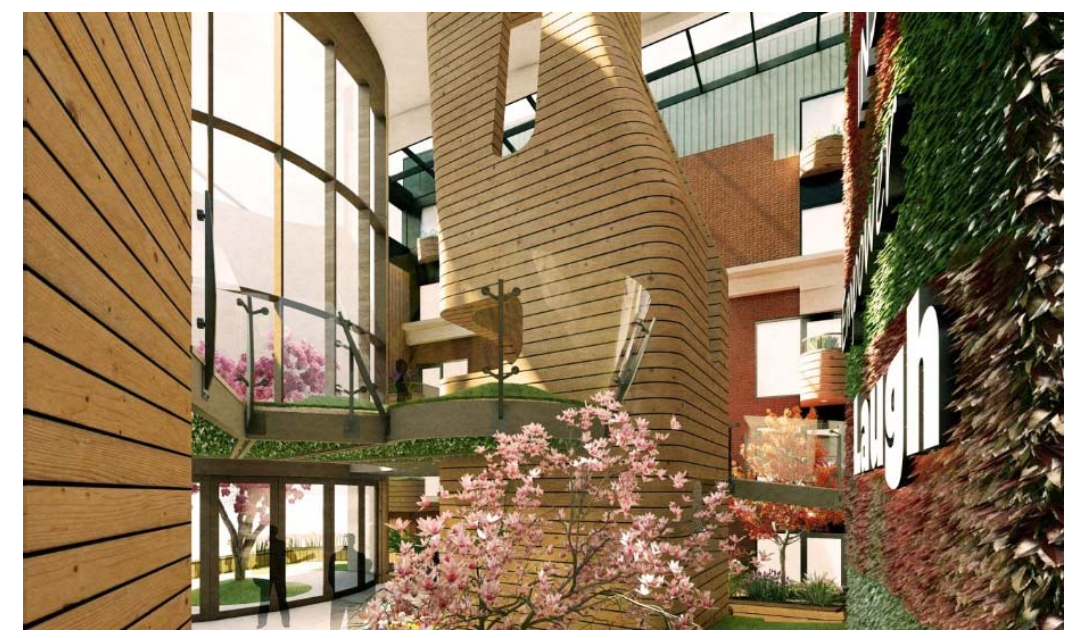

Figure 76. Interior Courtyard. By Author 


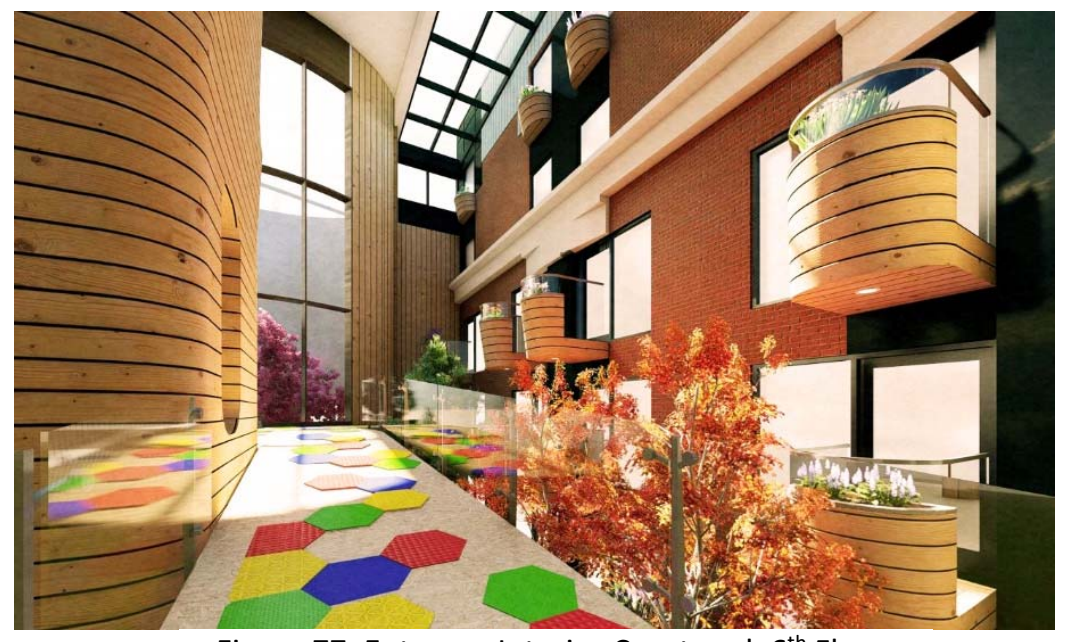

Figure 77. Entrance Interior Courtyard, $6^{\text {th }}$ Floor.

By Author

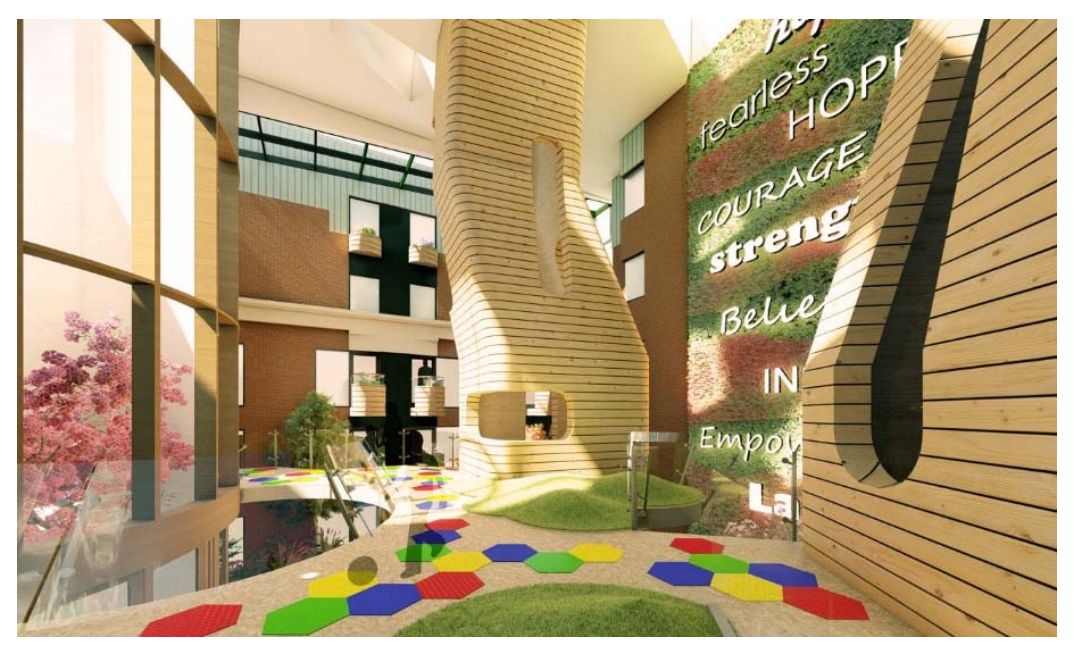

Figure 79. Interior Courtyard, upper terrace. By Author

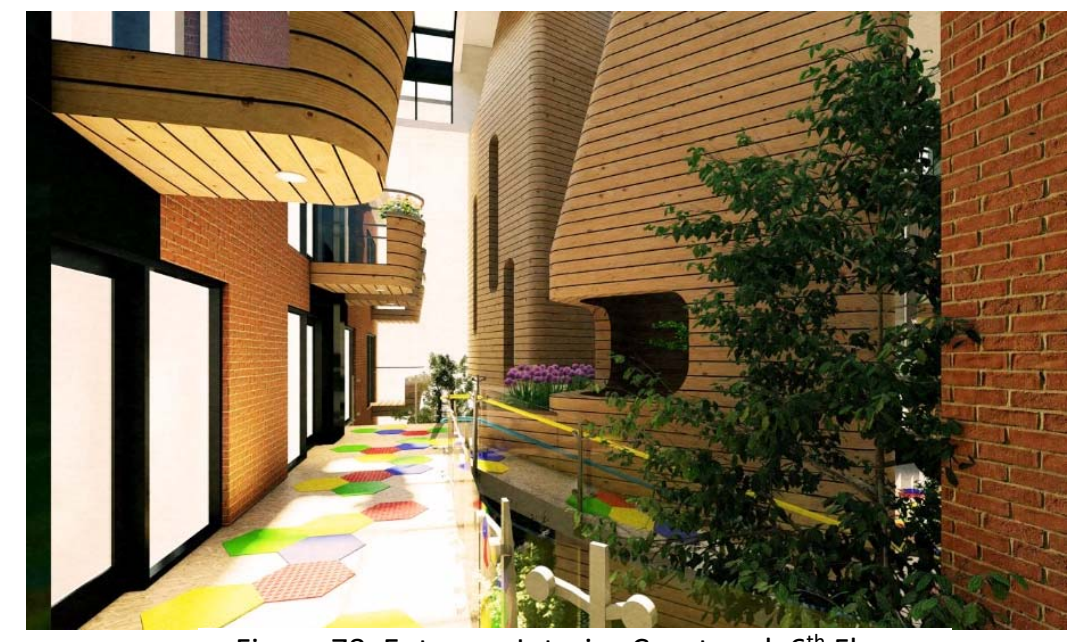

Figure 78. Entrance Interior Courtyard, $6^{\text {th }}$ Floor. By Author

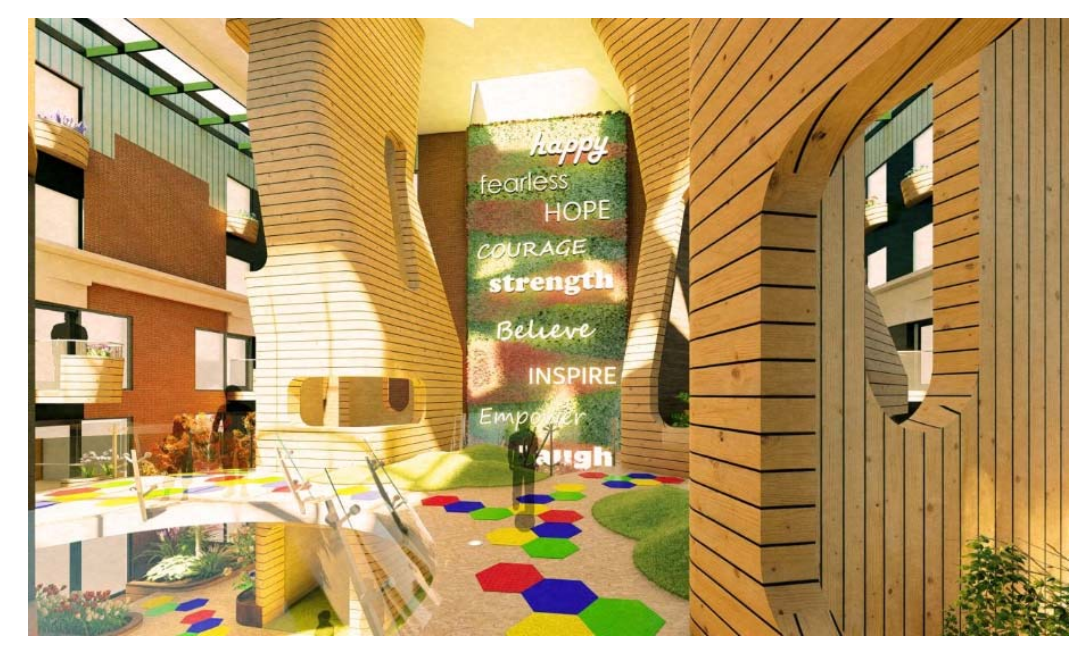

Figure 80. Interior Courtyard, upper terrace. By Author 


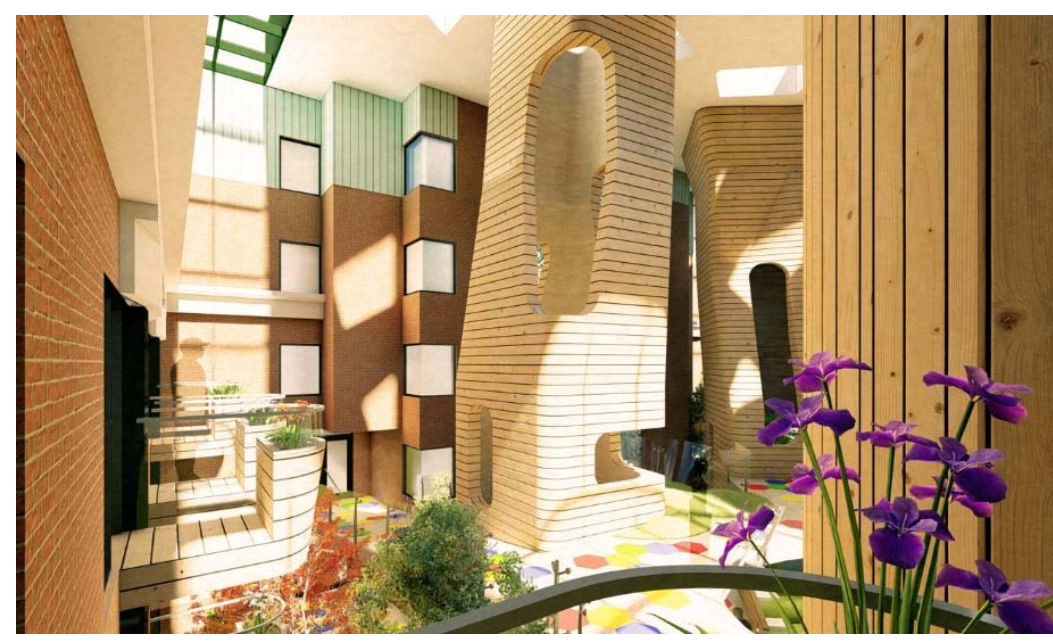

Figure 81. Interior Courtyard, view from patient room balcony. By Author

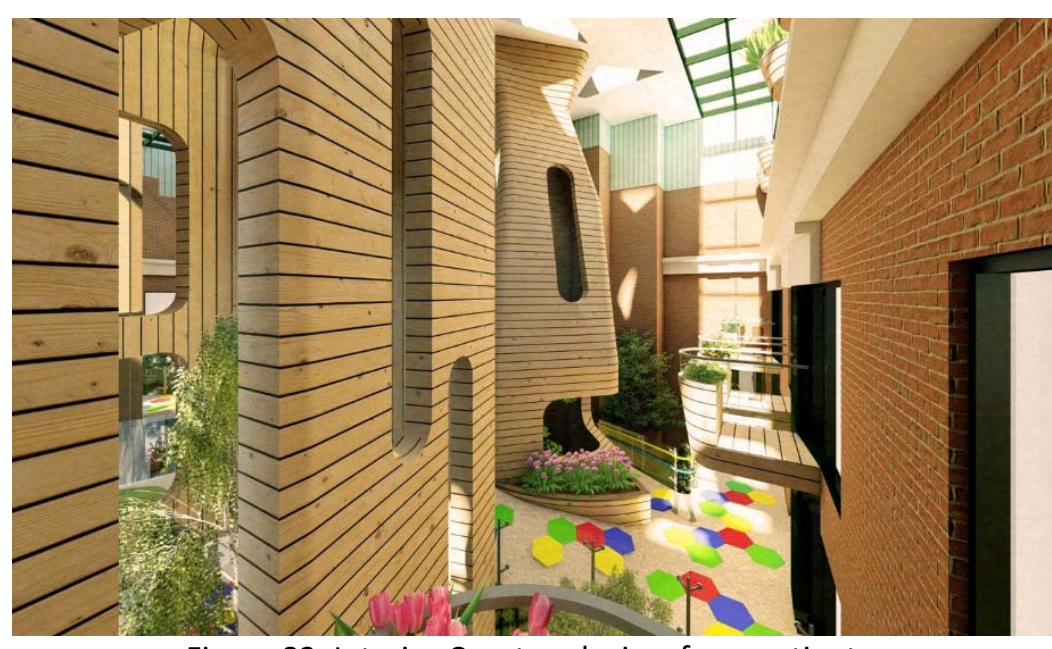

Figure 83. Interior Courtyard, view from patient room balcony. By Author

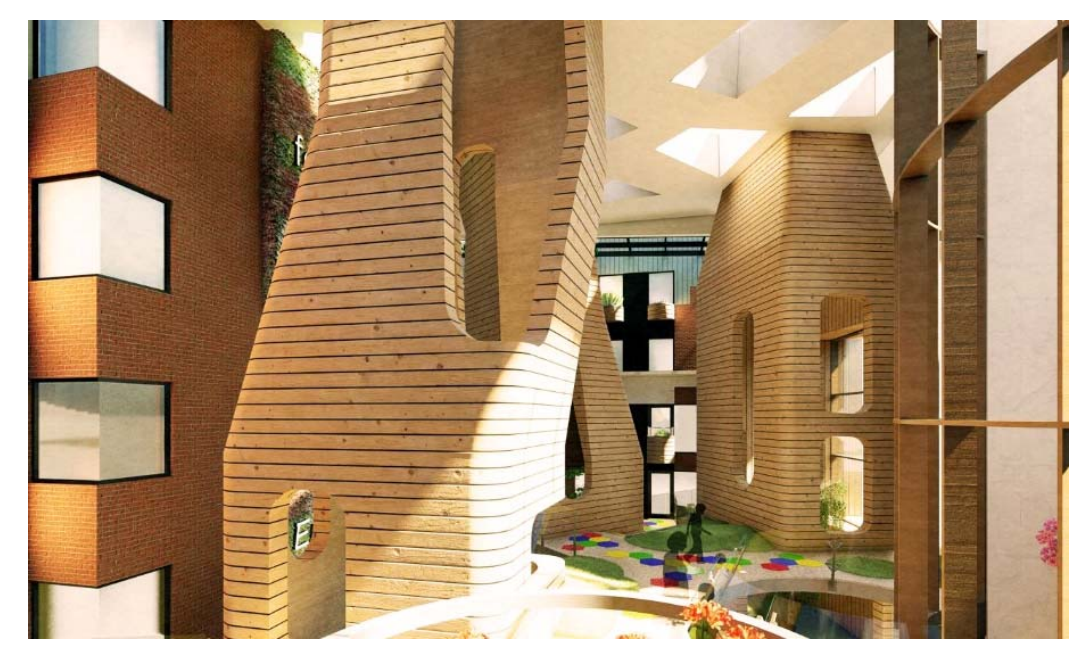

Figure 82. Interior Courtyard, view from patient room balcony. By Author

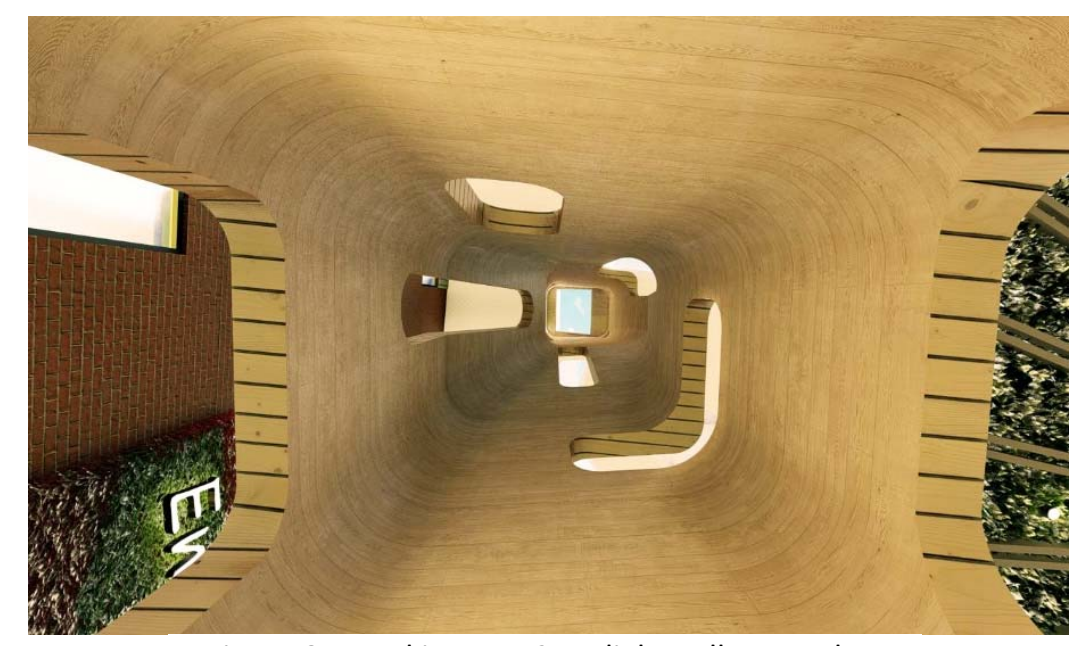

Figure 84. Looking up $12 \mathrm{pm}$ lightwell. By Author 


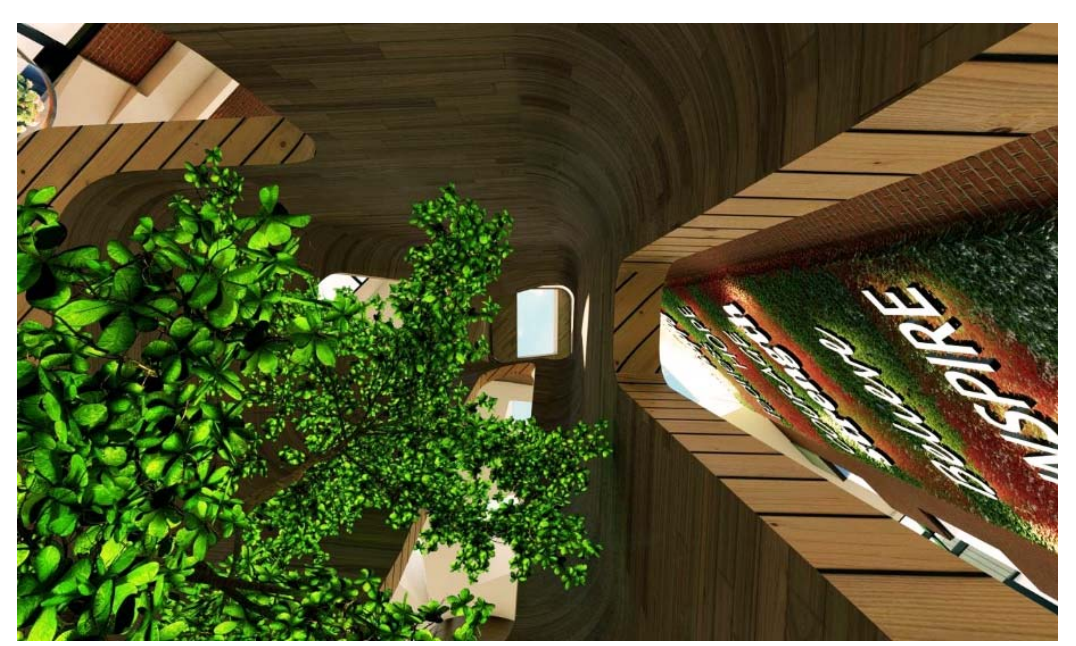

Figure 85. Looking up 8am lightwell. By Author

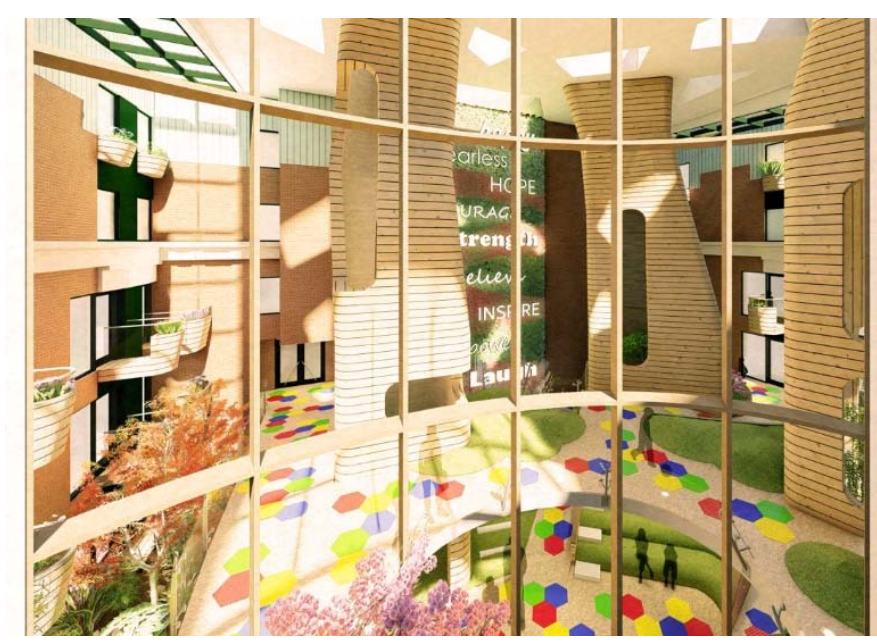

Figure 87. Exterior Terrace, curtain wall. By Author

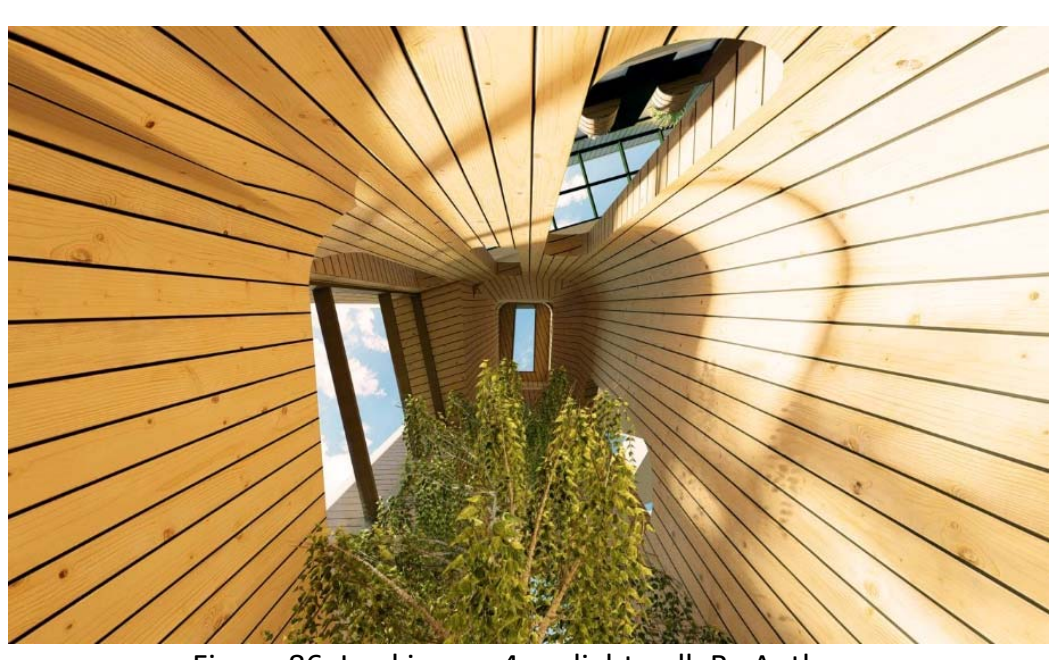

Figure 86. Looking up 4pm lightwell. By Author

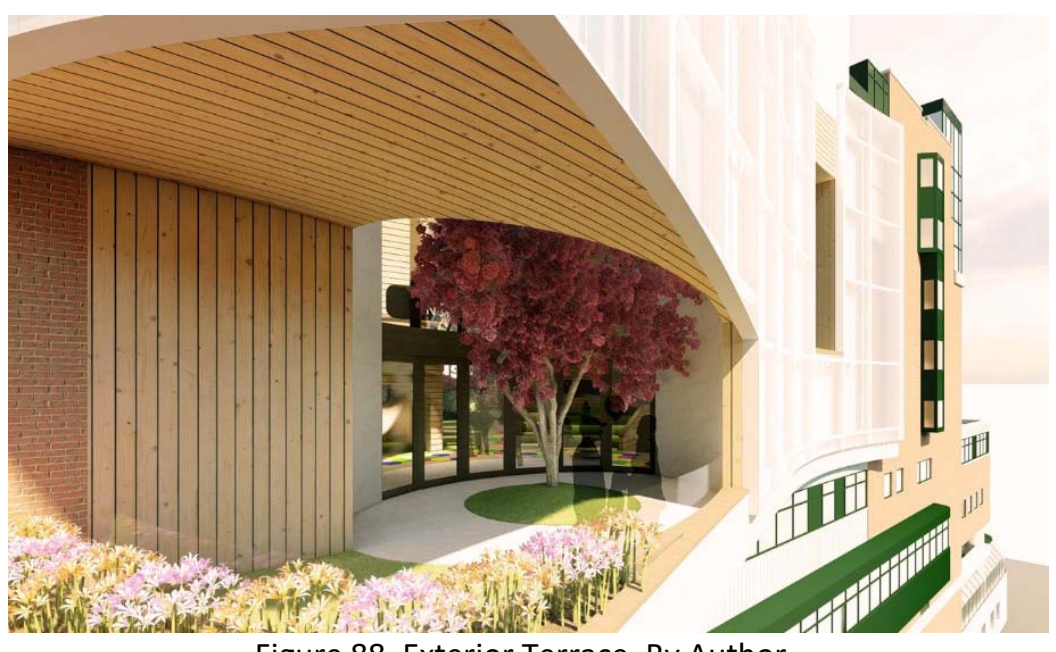

Figure 88. Exterior Terrace. By Author 


\section{GUIDING PRINCIPLES FOR PLAY}

The purpose of this chapter is to propose a standardized typology for pediatric establishments. It proposes a set of design elements that encourages the rethinking of healing spaces within the built environment. The principles of rooms for play can be interpreted as a methodical approach to the design of future healthcare facilities and the retrofitting of existing. Room for play spaces are based on the following considerations:

- Shared Rooms: Re-establish the concept of associative play within patient rooms while maintaining safety measures to prevent the spread of infectious diseases. Allow for social interaction and not isolation. Children have a strong desire to connect with each other through activities and play;

- No Place Like Home: Parents and caregivers provide compassion and reassurance; their comfort is equally as important to the patient. Provide patients and their families with the comforts of a home and a place to rest and recharge near each other;

- Natural Daylight: Maximizing fenestration areas for positive health regeneration and well-being. As well as provide significant energy savings; 
- Fresh Air Circulation: Operable windows or doors for patient rooms to allow outdoor air circulation, changes to air temperature and relative humidity;

- Online Community Connection: Technological advancements have made it easier and quicker to connect with friends and family. The presence to socially interact with the hospital community and the outside world acknowledges self-identity and belonging;

- Rethinking Corridors: Intermittent areas for play and social events, enticing children to move out of their rooms when possible. Typically, one- or two-person engagements;

- Easy Wayfinding: Graphic communication is distinct and concise for any age groups as well as children with special needs. Colour, large script, and tactile patterns are unique to each patient ward;

- Evoking Discovery: Running fingers along smooth curving surfaces slowly reveal a discovery which is much more effective than sharp corners when drawing individuals through a space; 
- Open Areas of Play: A devoted area of play located within the patient wards. These open rooms for play invite children of any age to engage with the built environment. Rules are discouraged and risk taking is encouraged;

- Connection with Nature: Visual and non-visual (auditory, haptic, olfactory) ephemeral connections with natural environments.

- Awareness of ecological conditions: i.e., seasonal changes and sun path orientation create conditions of dynamic light and shadows throughout the day.

- Low maintenance gardens change over time. Plant cultivation, will enhance the mystery and discovery, followed by the surprise of plant growth.

These concepts support the improvement of a positive experience within a healthcare environment. As a result, children not only heal both physically and mentally, but are cognitively stimulated through social interaction, exploration, discovery, risk taking, and problem solving. The introduction of such play functions, increasing children's well-being while in the hospital and would also contribute to a reduction in burnout and stress related issues among hospital staff, nurses, and doctors. The prospect of these design strategies has potential long term economic benefits. Creating an environment indicative of rooms for play 
encourages convalescent recovery at a faster rate. Ultimately, it is possible that patient room turnover would be quickened from the increase of patient discharge. Such affirmation could only be tested by literally implementing such design changes in a portion of the hospital testing the hypothesis with evidence-based research studies that exceeds the scope off this thesis. Such room for play design strategy has the potential to persuade parents into being future donors. In a similar manner, additional philanthropic installations can be donated and located within corridors, the open play area, or within the courtyard. There is a sense of pride when a donor sees their name inscribed next to an installation. 


\section{CONCLUSION}

Pediatric hospitals have focused on healing the body for a long time, but growing evidence has shown the need to focus on healing and promoting the overall well-being of the patient is established through multisensory conditions, natural outdoor environments, and the act of play within the built environment. Architecture is perceived as an extension of nature, which is incorporated into a man-made environment and therefore creating an opportunity for comprehending and inhabiting the world around us. The natural ecosystem helps to enhance human stimuli and provide a visual and non-visual connection. Humans utilize their senses to make decisions, and therefore biophilic design is critical and should be embraced in modern spaces. An individual's sense of reality is reinforced and articulated through consistent interaction between the senses. ${ }^{94}$ Perceiving architecture as connected to our senses is not a self-sufficient and isolated phenomenon since it connects a human being's existential experience and attention to expanded horizons. ${ }^{95}$ Equally important is the

\footnotetext{
${ }^{94}$ Pallasmaa, Juhani. 2012. In The Eyes of the Skin: Architecture and the Senses. P.44

${ }_{95}$ Montagu, Ashley. 1986. Touching: The Human Significance of the Skin. New York: Harper \& Row. P.3.
} 
fact that architecture provides the material and conceptual structure to hospital institutions

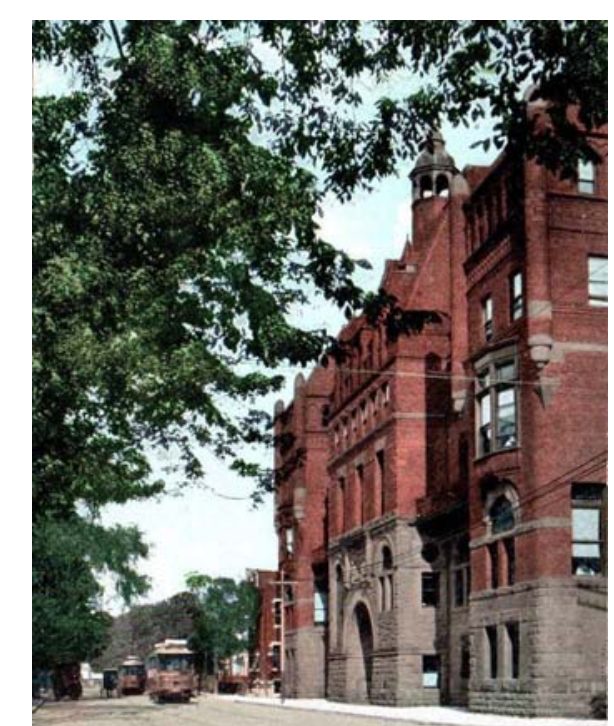

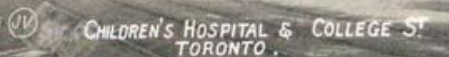

Figure 89. Children's Hospital and College Street, c1910. Observe how the word "Sick" has been removed. (C) John Chuckman as well as the conditions of a person's daily life. Rather than relying predominantly on vision,

architectural design incorporates different realms of positive healing environments,

establishing rooms for play in pediatric hospitals, contributing to the holistic healing of

children.

The SickKids Hospital in Toronto is renowned as one of the top pediatric hospitals in

the world. Why should a place for healing and therapy be aptly named - SickKids -

associating place with a negative connotation, and identifying patients with the condition

illness? Why create a moniker that suggests illness and inspires depression? Is the ambiguity

of the hospital name synonymous with the current built environment of the hospital

community and the everyday experience of these spaces? This thesis introduced a collection

of proposals to find rooms for play. Perhaps the new framework should have a positive

implication that encourages hope and empowerment in a future remodeled and renamed

hospital. 


\section{B I BLIOGRA PHY}

Aalto, Alvar. 1995. Alvar Aalto Volume / 1922-1962. Basel, Switzerland: Birkhauser Verlag GmbH.

Aalto, Alvar. 1932. "Sanatorium Paimio, Finland." The Master Builder 80-82.

Abbas, Mohamed Yusoff, and Roslinda Ghazali. 2010. "Healing environment of pediatric wards." Procedia Social and Behavioral Sciences 948-957.

Adams, Annmarie. 2008. Medicine by Design The Architect and the Modern Hospital, 1893-1943. Minneapolis : University of Minnesota Press.

Adams, Annmarie, and David Theodore. 2020. "Designing for "Little Convalescents": Children's Hospitals in Toronto and Montreal, 1875-2006." CBMH/BCHM Volume 9 201-243.

Adams, Annmarie, and David Theodore. 2006. "The Architecture of Children's Hospitals in Toronto and Montreal, 1875-2010." In Children's Health Issues in Historical Perspective, by Cheryl Krasnick Warsh and Veronica Strong-Boag, 439-478. Waterloo: Wilfred Laurier University Press.

Adams, Annmarie, David Theodore, Ellie Goldenberg, Coralea McLaren, and Patricia McKeever. 2010. "Kids in the atrium: Comparing architectural intentions and children's experiences in a pediatric hospital lobby." Social Science \& Medicine 658-667.

Archeyes. 2020. Paimio Sanatorium / Alvar Aalto. May 15. Accessed May 16, 2021.

https://archeyes.com/paimio-sanatorium-alvar-aalto/.

Bachelard, Gaston. 1958. The Poetics of Space. France: Presses Universitaires de France.

Berk, Dr. Lee S., interview by Janelle Ringer. 2019. Laughter: A fool-proof prescription (April 1).

Bolten, Bettina, and Giuseppe Barbiero. 2020. "Biophilic Design: How to Enhance Physical and Psychological Health and Wellbeing in our Built Environments." Visions for Sustainability, November. 
Boubekri, Mohamed. 2008. Daylighting, Architecture and Health. Oxford, UK.: Elsevier Ltd.

Burns, lan, Helen Cox, and Helen Plant. 2000. "Leisure or therapeutics? Snoezelen andthe care of older persons with dementia." International Journal of Nursing Practice 118-126.

C.D. Klemmer, T.M. Waliczek, and J.M. Zajicek. 2005. "Growing Minds: The Effect of a School Gardening Program on the Science Achievement of Elementary Students." HortTechnology 448-452.

Carrington, Damian. 2020. Greener play areas boost children's immune systems, research finds. October 14. Accessed December 6, 2020.

https://www.theguardian.com/environment/2020/oct/14/greener-play-areas-boostchildrens-immune-systems-research-finds.

Cushing, Debra Flanders, and Evonne Miller. 2020. Creating Great Places: Evidence-Based Urban Design for Health and Wellbeing. New York, NY: Routledge.

Dalke, Hilary, Paul J. Littlefair, and David L. Loe. 2004. Lighting And Colour For Hospital Design. Norwich, UK: The Stationery Office.

DuBose, Jennifer, Lorissa MacAllister, Khatereh Hadi, and Bonnie Sakallaris. 2018. "Exploring the Concept of Healing Spaces." The Center for Health Design 43-56.

Eberle, Scott G. Winter 2014. "The Elements of Play, Toward a Philosophy and a Definition of Play." American Journal of Play 214-233.

Edge, Steve, and Carolyn Hayles. 2017. "Examining the economic, psychological and physiological benefits of retrofitting holistic sustainable and biophilic design strategies, for the indoor environment." Living and Sustainability: An Environmental Critique of Design and Building Practices, Locally and Globally, February 10: 515-525.

Ehrenzweig, Anton. 1975. The Psycho-Analysis Of Artistic Vision And Hearing: An Introduction to a Theory of Unconscious Perception. London: Sheldon Press. 
Frascari, Marco. 2012. "De Beata Architectura, Places for Thinking." In The Cultural Role of Architecture, by Paul Emmons, John Hendrix and Jane Lomholt, 143-155. Milton Park,Abingdon: Routledge.

Garce, Melinda La. 2004. "Daylight Interventions and Alzheimer's Behaviors - A Twelve-Month Study." Journal of Architectural and Planning Research 257-269.

Ghazali, Roslinda, and Mohamed Yusoff Abbas. 2010. "Paediatric Community: Healing Environment Conducive Enough?" ASEAN Conference on Environment-Behaviour Studies 42-54.

Healthline. 2020. Can a Loss of Taste and Smell Be a Symptom of COVID-19? October 12. Accessed March 5, 2021. https://www.healthline.com/health/coronavirus-loss-of-taste-loss-ofsmell\#bottom-line.

-. 2021. Hyperosmia. Accessed March 20, 2021. https://www.healthline.com/human-bodymaps/depressor-septi-nasi.

Hewes, Jane. 2014. "Seeking Balance in Motion: The Role of Spontaneous Free Play in Promoting Social and Emotional Health in Early Childhood Care and Education." Children 280-301.

Huelat, Barbara J. 2003. Healing Environments: Design for the Body, Mind and Spirit. Alexandira, Virginia: Medezyn.

Hugh Pennington, Chris Isles. 2013. "Should hospitals provide all patients with single rooms?" The BMJ . September 24. Accessed March 16, 2021. https://www.bmj.com/content/347/bmj.f5695.

Huizinga, Johan. 1938. Homo Ludens. Netherlands: Random House.

Ikei, Harumi, Chorong Song, and Yoshifumi Miuazaki. 2017. "Physiological Effects of Touching Wood." International Journal of Environmental Research and Public Health 1-23.

Johnson, Andrew P. 2014. "Cognitive Development: Piaget and Vygotsky." In Education Psychology: Theories of Learning and Human Development, by Andrew P. Johnson, 1-7. National Science Press. 
Joseph, Anjali, and Roger Ulrich. 2007. "Sound Control for Imporved Outcomes in Healthcare Settings." The Center for Health Design 1-17.

Joshi, Sumedha M. 2008. "The sick building syndrome." The National Center for Biotechnology Information 61-64.

Kisacky, Jeanne. 2017. Rise of the Modern Hospital: An Architectural History of Health and Healing, 1870-1940. Pittsburgh, PA.: University of Pittsburgh Press.

-. 2017. When Fresh Air Went Out of Fashion at Hospitals. June 14. Accessed March 15, 2021. https://www.smithsonianmag.com/history/when-fresh-air-went-out-fashion-hospitals$180963710 /$.

Klepeis, Neil E., William C. Nelson, Wayne R. Ott, John P. Robinson, Andy M. Tsang, and Paul Switzer. 2001. "The National Human Activity Pattern Survey (NHAPS)." J Expo Anal Environ Epidemiol (J Expo Anal Environ Epidemiol) 231-252.

Levin, David Micheal. 1993. Modernity and the Hegemony of Vision. Los Angeles: University of California Press.

Lueder, Rani. 2003. "Are Just Little Children Adults? ." ErgoSolutions Magazine 32-34.

Montagu, Ashley. 1986. Touching: The Human Significance of the Skin. New York: Harper \& Row.

Montessori, Maria. 1948. The Discovery of the Child. Chennai, India: Kalakshetra Publications.

Ozgen, Elif. 2018. "An evaluation on the change of healing perception at healthcarefacilities: The Royal Children's Hospital." International Journal of Emering Trends in Health Sciences 7-13.

Pallasmaa, Juhani. 2012. In The Eyes of the Skin: Architecture and the Senses. West Sussex, UK: John Wiley \& Sons Ltd.

Park, Sung Jun, and Hyo Chang Lee. 2019. "Spatial Design of Childcare Facilities Based on Biophilic Design Patterns." Sustainability 1-15.

Parten Newhall, Midred B. 1933. "Social Play Amoung Preschool Children." Journal of Abnormal Psychology 136-147. 
Paul A. Symonds, Valeria Lo Lacono, David H.K. Brown. 2017. "Exploring an Absent Presence:

Wayfinding as an Embodied Sociocultural Experience." Sociological Research Online 1-21.

Pfefferbaum, Betty. 2020. "Mental Health and the Covid-19 Pandemic." The New England Journal of Medicine. August 6. Accessed February 12, 2021.

https://www.nejm.org/doi/full/10.1056/NEJMp2008017.

Raypole, Crystal. 2019. "How to Hack Your Hormones for a Better Mood." Healthline. September 30. Accessed December 7, 2020. https://www.healthline.com/health/happy-hormone.

Sawyers, Janet K. 1994. "The Preschool Playground: Development Skills Through Outdoor Play." Journal of Physical Education, Recreation \& Dance 31-33.

Schwab, Katharine. 2019. Kids surrounded by greenery may grow up to be happier adults. March 01. Accessed March 13, 2021. https://www.fastcompany.com/90313598/kids-surrounded-bygreenery-may-grow-up-to-be-happier-adults.

-. 2019. What is biophilic design, and can it really make you happier and healthier? April 11. Accessed March 13, 2021. https://www.fastcompany.com/90333072/what-is-biophilicdesign-and-can-it-really-make-you-happier-and-healthier.

Song, Chorong, Harumi Ikei, Bum-Jin Park, Juyoung Lee, Takahide Kagawa, and Yoshifumi Miyazaki. 2018. "Psychological Benefits of Walking through Forest Areas." International Journal of Environmental Research and Public Health 1-10.

Spence, Charles. 2020. "Senses of place: architectural design for the." Cognitive Research: Principles and Implications 1-26.

Sternberg, Esther, interview by Krista Tippett. 2013. The Science of Healing Places (October 24).

The Hospital for Sick Children. 2021. Family Spaces. March. Accessed March 18, 2021. https://www.sickkids.ca/en/patients-visitors/family-spaces/.

Upham, Becky. 2020. Everydayhealth.com. June 8. Accessed November 22, 2020. https://www.everydayhealth.com/alzheimers-disease/how-to-make-your-own-busy-boardfor-someone-with-alzheimers-disease/. 
US National Organization. 2015. November. Accessed December 4, 2020. https://www.ncbi.nlm.nih.gov/pmc/articles/PMC4653605/.

Vijayalakshmi, J, S Kamala, and Chandrakala Maran. 2018. "Laugh Your Way to a Quality Life with Laughter Yoga." International Education and Research Journal 1-2.

Wencer, David. 2011. Historicist: Your New Hospital for Sick Children. January 22. Accessed March 13, 2021. https://torontoist.com/2011/01/historicist_your_new_hospital_for_sick_children/.

World Health Organization. 2021. Constitution. Accessed March 15, 2021. https://www.who.int/about/who-we-are/constitution.

Wright, Gwendolyn. 1983. Building the Dream, A Social History of Housing in America. Cambridge, MA.: MIT Press.

Yin, Jie, Jing Yuan, Nastaran Arfaei, Paul J. Catalano, Joseph G. Allen, and John D. Spengler. 2020. "Effects of biophilic indoor environment on stress and anxiety recovery: A between-subjects experiment in virtual reality." Environment International 136, December: 1-10.

Zeidler Architects Inc. 2021. SickKids Slaight Family Atrium. January. Accessed March 14, 2021. https://zeidler.com/projects/sickkids-slaight-family-atrium/.

Zumthor, Peter. 2006. Thinking Architecture. Basel, Switzerland: Birkhäuser . 